\title{
AURELINO FERNANDES SCHMIDT JUNIOR
}

\section{Estudo anatômico da distribuição, tamanho e número dos linfonodos mediastinais em brasileiros adultos}

Tese apresentada à Faculdade de Medicina da Universidade de São Paulo para obtenção do título de Doutor em Ciências.

Área de concentração: Cirurgia Torácica e Cardiovascular.

Orientador: Prof. Dr. Fabio Biscegli Jatene

São Paulo

2004 
A Célia, pela compreensão e apoio.

Aos meus pais Aurelino e Silvia, minha profunda gratidão.

Aos meus filhos, Ana Clara, Pedro e Gabriel, estímulo da alegria em minha vida. 


\section{AGRADECIMENTOS}

Ao Dr. Olavo Ribeiro Rodrigues, Professor Adjunto Doutor da Disciplina de Cirurgia Torácica da Universidade de Mogi das Cruzes, responsável pelo grande estímulo de minhas carreiras profissional e docente, nobilíssimo ser humano e autor da idéia deste estudo.

Ao Dr. Fabio Biscegli Jatene, professor livre-docente da cadeira de Cirurgia Torácica da Faculdade de Medicina da Universidade de São Paulo, pelo acolhimento junto ao programa de residência médica em Cirurgia Torácica e no programa de doutorado como meu orientador.

Aos biólogos Aristides Tadeu Correia e Rosângela Monteiro, do laboratório Anatomo-Cirúrgico do Instituto do Coração do HCFMUSP, pela amizade e colaboração nas fases de laboratório e redação desta pesquisa.

Ao Prof. Prof. Dr. Carlos Augusto Gonçalves Pasqualucci, do Serviço de Verificação de Óbitos da Capital, pela oportunidade de realização deste estudo, cedendo as instalações e a permissão para as dissecções dos cadáveres deste estudo.

Ao Dr. Luis Felipe Pinho Moreira, docente da pós-graduação do Curso de Cirurgia Torácica e Cardiovascular da FMUSP, e à Sra. Creusa Maria Rovieri Dal Bó, pelo auxílio na análise estatística.

Ao Dr. Marco Antonio Soufen, professor assistente da Disciplina de Patologia da Faculdade de Medicina da Universidade de Mogi das Cruzes, pela análise das lâminas histológicas. 
Ao Dr. Roberto Storte Matheus, professor assistente da Disciplina de Cirurgia Torácica do curso de Medicina da Universidade de Mogi das Cruzes, pela amizade e pelas sugestões no decorrer desta tese.

À Sra. Dalva Midori Suzuki Saito, biomédica do laboratório de Anatomia Patológica e pós-graduanda do curso de mestrado em Engenharia Biomédica da Universidade de Mogi das Cruzes, pelo preparo das lâminas histológicas.

Ao Sr. Sérgio Spezzia, video-maker da Videoteca do Instituto do Coração do HCFMUSP, pelo auxílio na elaboração da documentação fotográfica.

Aos acadêmicos Jorge Du Ub Kim e Daniela Vieira da Costa, do curso de Medicina da Universidade de São Paulo, pelo auxílio nas dissecções e na aquisição dos dados no programa de computador.

Ao Dr. Aurelino Fernandes Schmidt, ex-professor da disciplina de Urologia do curso de Medicina da Universidade de Mogi das Cruzes e meu pai, pela minha formação ética e humanística, sendo uma referência de cultura e honestidade. 


\section{SUMÁRIO}

Resumo

Summary

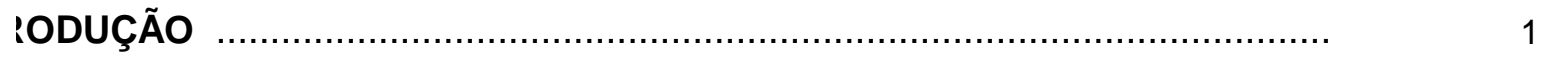

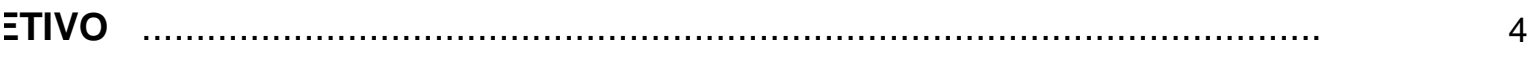

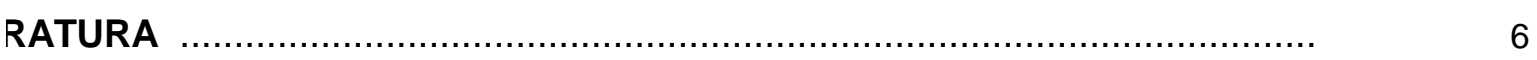

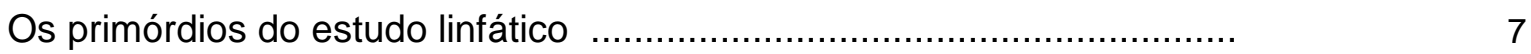

Localização dos linfonodos no mediastino ……...................................

Os estudos anatômicos .................................................................... 10

3.4 Os estudos por meio de tomografia computadorizada do tórax ............ 12

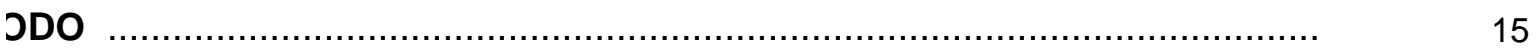

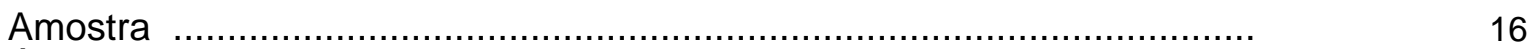

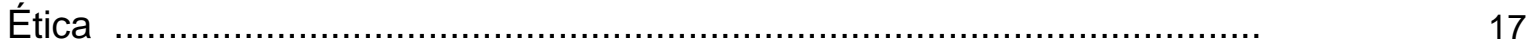

Técnica de dissecção .....................................................................

4.4 Individualização dos linfonodos ....................................................... 35

4.5 Registro digital das imagens ......................................................... 36

4.6 Estudo histológico ........................................................................ 37

4.7 Mensuração dos linfonodos no computador ....................................... 38

4.8 Parâmetros avaliados .................................................................. 39

4.9 Análise estatística ........................................................................... 41

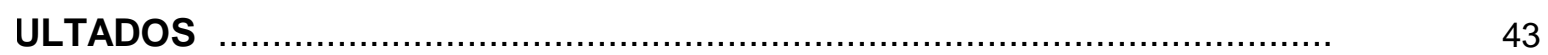

5.1 Cadeias e número de linfonodos .................................................. 44

5.2 Formato linfonodal .................................................................... 46

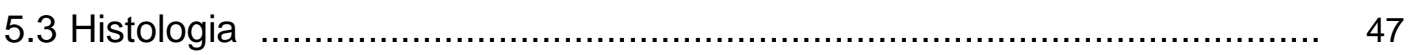

5.4 Tamanhos linfonodais .................................................................. 49

5.5 As diversas variáveis e o número linfonodal ......................................... 51

5.6 As diversas variáveis e os tamanhos dos linfonodos ............................ 52

5.7 Comparações entre os parâmetros analisados ....................................... 52

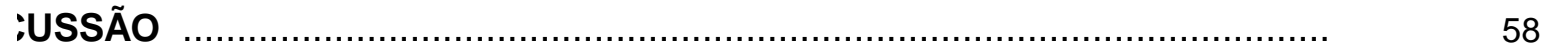

6.1 Considerações sobre o número de linfonodos ..................................... 59

6.2 Considerações sobre o tamanho linfonodal ............................................ 61

6.3 Considerações sobre o método de medida ............................................ 64

6.4 Considerações sobre a localização dos linfonodos no mediastino .......... 65

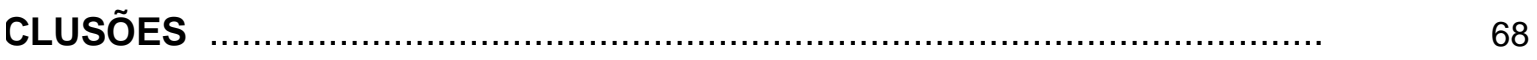

KOS …...................................................................................

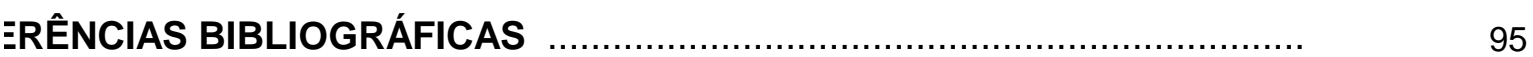




\section{RESUMO}

SCHMIDT Jr., A.F. Estudo anatômico da distribuição, tamanho e número dos linfonodos mediastinais em brasileiros adultos. São Paulo, 2004. 100p. Tese (Doutorado) - Faculdade de Medicina, Universidade de São Paulo.

As alterações de tamanho e número dos linfonodos mediastinais resultante de seu envolvimento em processos neoplásicos e infecciosos são conhecidas. No entanto, estes parâmetros ainda não foram claramente definidos. O objetivo deste estudo é o de analisar os linfonodos das diversas cadeias mediastinais quanto ao tamanho e número em brasileiros adultos e correlacionar os achados com a idade, sexo, raça, altura, peso, causa mortis e fatores histológicos próprios dos linfonodos. Cinqüenta cadáveres de brasileiros adultos foram estudados, 38 do sexo masculino, 39 brancos, com média de idade de 59,9 $\pm 14,1$ anos, altura de $173,1 \pm 7,6 \mathrm{~cm}$ e peso de $71,0 \pm 12,0 \mathrm{~kg}$. A dissecção do mediastino foi realizada bilateralmente, sendo todos os linfonodos ressecados e isolados. A área e os diâmetros transversos maior e menor de cada linfonodo foram determinados por análise de imagem.

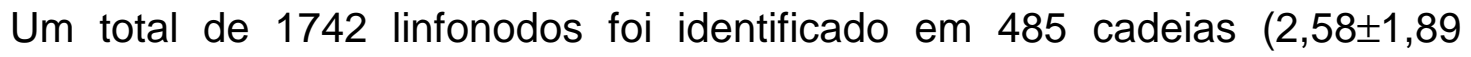
linfonodos/cadeia). De acordo com o lado, observou-se uma média de $21,2 \pm 8,5$ linfonodos à direita e 13,6 $\pm 6,3$ à esquerda. A coalescência linfonodal determinou um achado de mais 158 linfonodos quando recontados à lâmina corada por HE. O tamanho médio da área, eixo maior e menor foi maior na cadeia $7\left(195 \mathrm{~mm}^{2}, 18,75 \mathrm{~mm}\right.$ e $\left.10,92 \mathrm{~mm}\right)$ e $4 \mathrm{R}\left(115 \mathrm{~mm}^{2}, 13,72 \mathrm{~mm}\right.$ e $8,30 \mathrm{~mm}$ ), apresentando média de $49,41 \mathrm{~mm}^{2}, 9,40 \mathrm{~mm}$ e $5,76 \mathrm{~mm}$ para as demais regiões. O tamanho padrão máximo demonstrou valores do eixo menor de até $20 \mathrm{~mm}$ na cadeia $7,16 \mathrm{~mm}$ na cadeia $4 \mathrm{R}$ e $12 \mathrm{~mm}$ nas demais cadeias. A distribuição, número e tamanho dos linfonodos não se alteraram de acordo com o intervalo de idades estudado e não sofreram influência do sexo, raça, peso ou altura. O tamanho linfonodal aumentou em função da coalescência por lesões granulomatosas prévias, causando uma diminuição do número total de linfonodos. 


\section{SUMMARY}

SCHMIDT Jr., A.F. Anatomical study of distribution, size and number of the mediastinal lymph nodes in Brazilian adults. São Paulo, 2004. 100p. Tese (Doutorado) - Faculdade de Medicina, Universidade de São Paulo.

The changes of size and number of the lymph nodes resulted from the involvement in neoplastic and infectious diseases is known. However, these parameters are not yet clearly defined. The aim of this study is to analyze the lymph nodes in the many mediastinal regions according to the size and number in Brazilian adults and correlate the findings with age, sex, race, height, weight, cause of death and histological factors inherent the lymph nodes. Fifth cadavers of Brazilian adults were studied, 38 male, 39 white, with mean age of $59.9 \pm 14.1$ years, $173.1 \pm 7.6 \mathrm{~cm}$ height and $71.0 \pm 12.0 \mathrm{~kg}$. The dissection of the mediastinum was performed bilaterally and all the lymph nodes were resected and isolated. The area and the major and minor transverse axis of each lymph node set by image analysis. A total of 1742 lymph nodes was dissected in 485 chains (2.58 \pm 1.89 lymph node/chain). According to the side, a mean of $21.2 \pm 8.5$ lymph nodes was observed at the right side and $13.6 \pm 6.3$ at the left side. The nodal coalescence determinated the finding of more 158 lymph nodes when recounted at the lamina stained by $\mathrm{HE}$. The mean area, major and minor axis were larger in regions $7\left(195 \mathrm{~mm}^{2}\right.$, $18.75 \mathrm{~mm}$ and $10.92 \mathrm{~mm})$ and $4 \mathrm{R}\left(115 \mathrm{~mm}^{2}, 13.72 \mathrm{~mm}\right.$ and $\left.8.30 \mathrm{~mm}\right)$, with a mean of $49.41 \mathrm{~mm}^{2}, 9.40 \mathrm{~mm}$ and $5.76 \mathrm{~mm}$ in the other regions. The maximum pattern size demonstrated values of the minor axis until $20 \mathrm{~mm}$ in station \#7, $16 \mathrm{~mm}$ in \#4R and $12 \mathrm{~mm}$ in the remaining stations. The distribution, number and size of the lymph nodes were stable for the interval of ages studied, did not suffering influence from the sex, race, weight or height. The lymph node size increased as function of coalescence due to previous granulomatous lesions, causing a decrease in the total number of lymph nodes. 
1. INTRODUÇÃO 


\section{Introdução}

A importância de um estudo dos grupos linfonodais do mediastino deriva do seu envolvimento ativo em diversos processos neoplásicos e infecciosos. É conhecida a característica de aumento dos linfonodos mediastinais nestas situações.

O tamanho e o número dos linfonodos mediastinais, contudo, ainda não foram claramente definidos. Isto decorreu da existência de uma grande variabilidade na presença dos linfonodos em certas regiões mediastinais. Também não houve a adoção de uma sistematização na dissecção linfonodal em estudos prévios, com uso de denominações diferentes para cada região. Isto, associado ao emprego de diferentes técnicas de abordagem das cadeias linfonodais, que variou entre a técnica necroscópica e operatória, dificultou as comparações entre resultados.

O conceito de adenomegalia ainda é fundamental no entendimento de diversas afecções. Certos fatores intrínsecos aos linfonodos poderiam afetar a expressão numérica e o tamanho dos linfonodos no mediastino. Estes aspectos ainda não foram bem esclarecidos e podem gerar controvérsias na análise de amostras não-equiparadas.

As casuísticas brasileiras de doenças com envolvimento mediastinal linfonodal não são compatíveis com as de trabalhos americanos, ingleses e japoneses. Sugere-se existir algum fator que interfira no tamanho dos linfonodos de brasileiros. A definição de tamanho e número dos linfonodos do 
mediastino, encontrados por meio de dissecção anatômica, não está estabelecida, mormente para a população brasileira.

Através do exame anatômico do mediastino é possível, baseado na localização de cada linfonodo, definir seu tamanho e número nas diversas cadeias mediastinais, possibilitando estabelecer um padrão de normalidade para a população estudada. Este trabalho servirá de base para os estudos de doenças que acometem os linfonodos mediastinais com alterações de sua visibilidade numérica e tamanho. 
2. OBJETIVOS 


\section{Objetivos}

Analisar os linfonodos das diversas cadeias mediastinais quanto ao tamanho e número em brasileiros adultos e suas correlações com idade, sexo, peso, altura, raça e causa mortis.

Correlacionar o tamanho e número com a coalescência linfonodal e a presença de granulomas cicatriciais, no sentido de evidenciar as possíveis influências decorrentes destes fatores no padrão linfonodal da população estudada. 
3. LITERATURA 


\section{Literatura}

\subsection{Os primórdios do estudo linfático}

Os canais linfáticos foram primeiramente reconhecidos por Herófilo, em aproximadamente 300 a.C. Sua presença, no entanto, permaneceu esquecida por cerca de 2000 anos, quando redescobertos por Aselius, em 1622. Estes vasos foram denominados linfáticos por Bartholin e, no mesmo ano, descritos vagamente no pulmão por Rudbeck. Willis (1627) ilustrou os linfáticos pleurais em animais, próximo à época em que Harvey (1628) descreve seu famoso estudo sobre os vasos sangüíneos. Mascagni, em 1784, foi o primeiro a descrever os canais linfáticos na profundidade do parênquima pulmonar. Sappey (1876) estudou a estrutura do linfonodo e começou a aperfeiçoar os conceitos sobre a rede de origem dos capilares linfáticos e seus coletores (TRAPNELL, 1963).

Barety, em Paris, citado por CAPLAN (1990), já havia publicado uma pesquisa a respeito das adenopatias traqueobrônquicas em 1874. É, entretanto, atribuída a ROUVIÈRE, na França, em 1929, a primeira e extensa descrição anatômica moderna das vias linfáticas do tórax e das cadeias linfonodais do mediastino humano. Este autor descreveu as cadeias linfonodais no tratado Anatomie des Lympathiques de L'homme, em 1932, didaticamente dividindo os linfonodos intratorácicos em quatro grandes grupos: mediastinais anteriores ou pré-vasculares, mediastinais posteriores, peritraqueobrônquicos e intrapulmonares. 
Mais modernamente, diversos autores (TRAPNELL, 1963; RODRIGUES GRANDE et al., 1983; LIEN \& LUND, 1985; RIQUET et al., 1986; RIQUET et al., 1989; MURAKAMI et al.; 1990; RIQUET et al., 1994) interessaram-se pelo estudo dos canais linfáticos pulmonares por meio de injeções de contrastes radiológicos subpleurais para a determinação dos trajetos linfáticos até o mediastino.

\subsection{Localização dos linfonodos no mediastino}

A maioria dos autores que se ocuparam com o estudo da vias linfáticas do tórax, disseminação mediastinal do carcinoma broncogênico e esvaziamento linfonodal do mediastino na cirurgia pulmonar utilizou-se das divisões anatômicas das regiões linfonodais descritas por ROUVIÉRE (1929) ou fez uso da nomenclatura e dos mapas linfonodais propostos por NARUKE, em 1978, e pela AMERICAN THORACIC SOCIETY (ATS), em 1983. Diferenças na classificação das estações linfonodais no mediastino de acordo com dois sistemas resultaram em confusão na interpretação dos resultados finais.

NARUKE e SUEMASU (1976), no Japão, no período de 1962 a 1972, operaram 468 doentes com câncer de pulmão no National Cancer Center de Tóquio. Todos os linfonodos mediastinais e do pulmão ressecado foram removidos e designados em um mapa cuja nomenclatura admitiu 14 cadeias linfonodais intratorácicas, sendo nove as cadeias mediastinais (Fig. 1). 


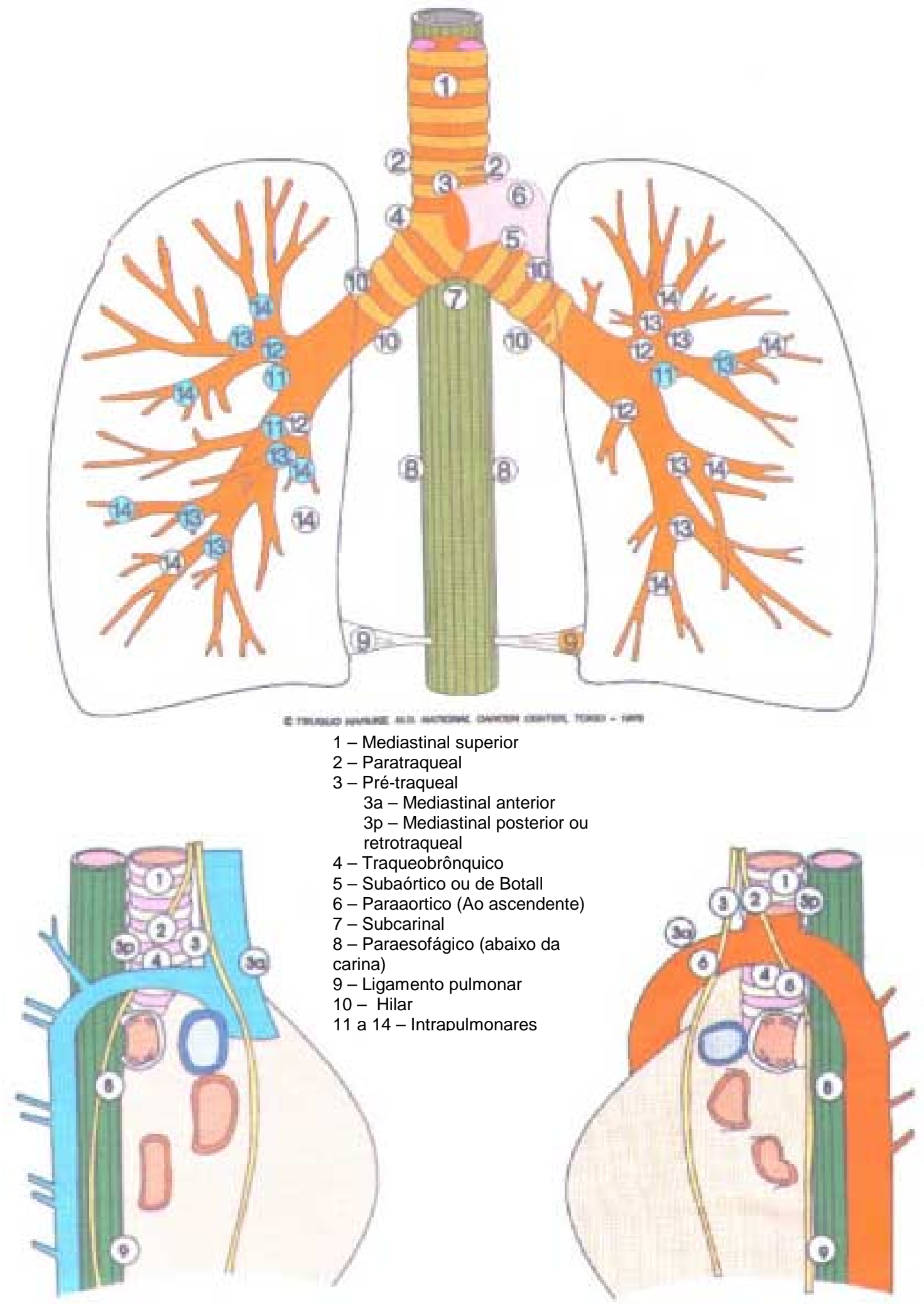

Fig. 1 - Mapa das cadeias linfonodais mediastinais (NARUKE et al., 1978). 
Em 1997, um estudo unificando os dois sistemas de classificação das vias linfáticas do tórax foi relatado por MOUNTAIN e DRESLER, sendo adotado pelo American Joint Committee on Cancer e pela União Internacional Contra o Câncer (AJCC / UICC). Neste novo sistema foram adotadas referências anatômicas para a identificação de todas as cadeias mediastinais. Por este esquema, foram denominados como N2 todos os linfonodos compreendidos pela reflexão pleural mediastinal. Os linfonodos distais a esta, compreendidos pela pleura visceral, foram classificados como N1, não tendo sido objeto de interesse do nosso estudo (ANEXO A).

\subsection{Os estudos anatômicos}

São escassos os estudos linfonodais do mediastino com interesse de elucidação anatômica. Autores americanos (GLAZER et al., 1985), ingleses (NOHL, 1956) e japoneses (NARUKE e SUEMASU, 1976; NARUKE, 1978) ocuparam-se com o estudo anatômico dos linfonodos mediastinais na intenção de elucidar as vias de disseminação do carcinoma broncogênico.

KIYONO et al., em 1988, no Japão, estudaram em 40 cadáveres o tamanho e o número dos linfonodos mediastinais encontrados em cada cadeia linfonodal no povo japonês. Para tanto, basearam-se no mapa das cadeias linfonodais definido pela ATS. Os linfonodos foram medidos em seus diâmetros transversos maior e menor por meio de um paquímetro. Realizaram a mensuração de 20 linfonodos antes e após a fixação por formalina a $10 \%$, observando uma média do grau de encolhimento de $2 \pm 7,8 \%$ 
no diâmetro linfonodal. Observaram que os linfonodos maiores localizavamse na cadeia subcarinal (cadeia nำ7) seguida pela cadeia traqueobrônquica 10R, equivalente à cadeia 4R pelo mapa da ATS. O tamanho dos linfonodos mediastinais foi maior nos habitantes da zona rural que nos da zona urbana. Em 5 cadáveres o tamanho máximo linfonodal excedeu o padrão às custas de linfonodos calcificados (2 casos), fusões linfonodais (2 casos) ou linfonodomegalia.

CAPLAN, em 1990, na Argentina, estudou a distribuição dos grupos linfonodais do mediastino em órgãos intratorácicos de 432 cadáveres por meio da dissecção de peças anatômicas. Esse autor propôs uma nomenclatura para as cadeias linfonodais e não se preocupou com a preservação de sua sintopia porque estudou blocos viscerais. Também não definiu o tamanho e o número exato de linfonodos por cadeia linfonodal esperado na sua amostra. Relatou a presença de linfonodos mediastinais mais constantemente na região ântero-lateral direita da traquéia, tendo sido estes também os maiores linfonodos encontrados.

No Brasil, FERNANDEZ (1992), em tese defendida na Universidade de São Paulo, comparou o papel da tomografia computadorizada e da mediastinoscopia no estadiamento linfático do mediastino no câncer de pulmão. O autor utilizou-se de recomendações internacionais por não existirem publicações nacionais que determinassem um padrão para os

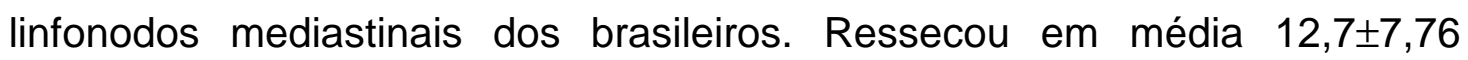
linfonodos por paciente. Observou aumento significante de comprometimento linfonodal por neoplasia quando mediam mais de $20 \mathrm{~mm}$ de diâmetro (23\%), 
enquanto linfonodos de mesmo tamanho nas populações japonesa, norteamericana e européia apresentaram probabilidade de acometimento acima de $80 \%$. Estes dados, sugeriu o autor, foram decorrentes da presença de linfonodos mediastinais de grandes dimensões na população brasileira, fruto da alta incidência de doenças inflamatórias no nosso meio.

\subsection{Os estudos por meio de tomografia computadorizada do tórax}

Não foi objeto deste estudo a definição das cadeias linfonodais por meio da tomografia computadorizada. Entretanto, a maioria dos autores fez uso deste método para a avaliação dos linfonodos mediastinais, alguns deles comparando as observações de imagem com a dissecção linfonodal.

GLAZER et al., em 1985, nos Estados Unidos, investigaram o número e o tamanho dos linfonodos mediastinais nas 11 estações linfonodais do tórax definidas no mapa da American Thoracic Society (ATS), em 100 pacientes adultos selecionados aleatoriamente, por meio de tomografia computadorizada. Verificaram que em mais de $50 \%$ dos casos os maiores linfonodos foram observados nas cadeias linfonodais subcarinal (cadeia nำ) e traqueobrônquica direita (cadeia $\mathrm{n}$-4R). Estes autores definiram os tamanhos dos linfonodos mediastinais para cada cadeia.

GENEREUX e HOWIE (1984), no Canadá, avaliaram as dimensões dos linfonodos mediastinais obtidas por tomografia computadorizada do tórax em 39 pacientes cuja história prévia excluísse doenças granulomatosas ou 
malignas, avaliando a sensibilidade e especificidade do método relativo aos dados obtidos pela dissecção de 12 cadáveres. Restringiram-se a amostrar os maiores linfonodos de 4 áreas: espaço retro-inominada, espaço prétraqueal, subcarinal e janela aortopulmonar. Nenhum linfonodo excedeu $20 \mathrm{~mm}$ em maior diâmetro à tomografia. Verificou, entretanto, um tamanho de até $30 \mathrm{~mm}$ do eixo maior à dissecção. As médias dos diâmetros foram significantemente diferentes para linfonodos do mediastino superior em comparação aos linfonodos contíguos à carina $(p<0,001)$.

MURRAY et al., em 1995, na Inglaterra, compararam o tamanho dos linfonodos mediastinais em uma população de 48 pacientes de origem indiana (asiáticos) por meio de tomografia computadorizada. Observaram que $81,3 \%$ dos pacientes com contato prévio para tuberculose têm linfonodos mediastinais de tamanho em torno de $7 \mathrm{~mm}$ no menor eixo em todas as estações linfáticas do mediastino, 10,4\% têm linfonodos com tamanho de 8$10 \mathrm{~mm}$ e 8,3\% têm linfonodos maiores que $10 \mathrm{~mm}$ no menor eixo do plano transverso. Os linfonodos medindo $7 \mathrm{~mm}$ ou mais no eixo menor foram significantemente mais freqüentes na população com evidência de tuberculose prévia.

PRENZEL et al., 2003, na Alemanha, estudaram os linfonodos mediastinais por meio da análise da tomografia em 80 casos e dos espécimes retirados de 256 pacientes com neoplasia de pulmão de células não-pequenas. Encontraram 847 linfonodos mediastinais sem doença cujo

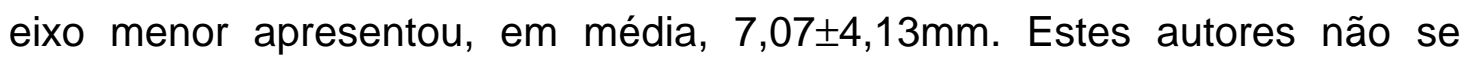
preocuparam com a análise do tamanho linfonodal de acordo com o padrão 
definido para cada cadeia por meio de um mapa. Também realizaram a análise de 36 linfonodos antes da fixação e após a preparação pela hematoxilina-eosina (HE), encontrando uma média do eixo menor de

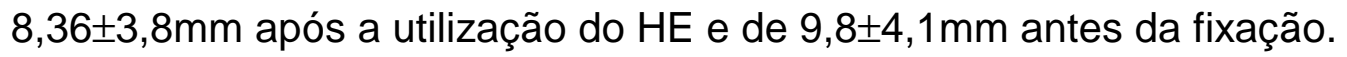


4. MÉTODO 


\section{Método}

\subsection{Amostra}

Foram realizadas 55 dissecções em cadáveres pelo autor no período de março de 2001 a junho de 2003. Foram excluídos deste estudo cinco cadáveres que apresentaram à dissecção presença de empiema pleural em 2 cadáveres, paquipleuris, fibrose mediastinal e carcinomatose pleural. Todos os cinqüenta cadáveres de adultos cuja causa mortis não foi resultante direta de doenças com acometimento linfonodal do mediastino foram estudados.

Compilaram-se os registros de idade, sexo, peso, altura e grupo étnico de todos os cadáveres incluídos no estudo. Da casuística, 38 (76\%) cadáveres eram do sexo masculino e 12 do sexo feminino. A idade variou de 36 a 90 anos, com média de 59,9 914,1 e mediana de 60 anos. Trinta e nove eram brancos, 7 negros e 4 pardos. A altura máxima foi de $185 \mathrm{~cm}$ e a mínima de $150 \mathrm{~cm}$, com média de $173,1 \pm 7,6 \mathrm{~cm}$. O peso variou de 31 a 114 quilos, com média de $71 \pm 12 \mathrm{~kg}$.

Após a conclusão do laudo do patologista, foram revisados todos os diagnósticos de causa mortis, que foram então incluídos nas fichas do protocolo. Em $50 \%$ dos casos a causa mortis final, determinada pelo estudo necroscópico, foi o edema pulmonar. A relação dos dados dos casos estudados está expressa no ANEXO B. 


\section{2 Ética}

Esta pesquisa encontrou-se enquadrada nas Normas de Pesquisa em Seres Humanos (Pesquisa em Saúde) expressas na Resolução n 196/96 do CONSELHO NACIONAL DE SAÚDE e na Lei 8.501, de 30/11/92, que trata sobre a utilização de cadáver. Foi aprovada pela Comissão de Ética para Análise de Projetos de Pesquisa da Diretoria Clínica do Hospital das Clínicas da Faculdade de Medicina da Universidade de São Paulo.

\subsection{Técnica de dissecção}

Foi utilizada técnica similar à da técnica operatória. No Serviço de Verificação de Óbitos da Capital, os cadáveres foram posicionados em decúbito lateral com fixação anterior e posterior do tronco. Após a colocação de campos operatórios, a cavidade torácica foi abordada por toracotomia póstero-lateral, iniciando-se em nível do processo espinhoso da $3^{\underline{a}}$ vértebra dorsal e terminando junto à $5^{\mathrm{a}}$ cartilagem costal no $5^{\circ}$ espaço intercostal, com secção dos côtos posteriores da $4^{\mathrm{a}}$ e $5^{\mathrm{a}}$ costelas. Um afastador de Finochieto auxiliou no afastamento das costelas. A dissecção foi praticada primeiro à direita e depois à esquerda pela mudança do decúbito, com igual via de acesso contralateral.

Foi realizada a abertura da pleura mediastinal, sendo iniciada a dissecção das diversas cadeias mediastinais a partir do ponto mais alto da cavidade pleural, no estreito superior do tórax, junto à alça do nervo laríngico recorrente à artéria subclávia direita. Deste plano, procedeu-se à dissecção 
em sentido caudal, sendo retirados todos os blocos linfoadiposos mediastinais, traqueobrônquicos, subcarinais e paraesofágicos até ser alcançado o ligamento pulmonar, junto ao diafragma.

A dissecção linfonodal foi baseada nas definições de reparos anatômicos sugeridas pelo mapa adotado pela AJCC / UICC (ANEXO A). Seguiu os seguintes procedimentos:

O lobo superior do pulmão foi tracionado caudalmente para exposição da pleura mediastinal que foi inteiramente aberta.

- Cadeia linfonodal no1 (linfonodos mediastinais superiores): foi dissecada junto à abertura torácica superior (limite cranial). Seu limite anatômico caudal foi a borda superior do tronco braquiocefálico venoso esquerdo. Foi removido todo tecido gorduroso perivascular, expondo-se a emergência do nervo laríngico recorrente direito e sua alça em nível da artéria subclávia direita, bem como os linfonodos justapostos ao ângulo venoso compreendido pelo encontro das veias braquiocefálicas (Fig.2 e 3). 

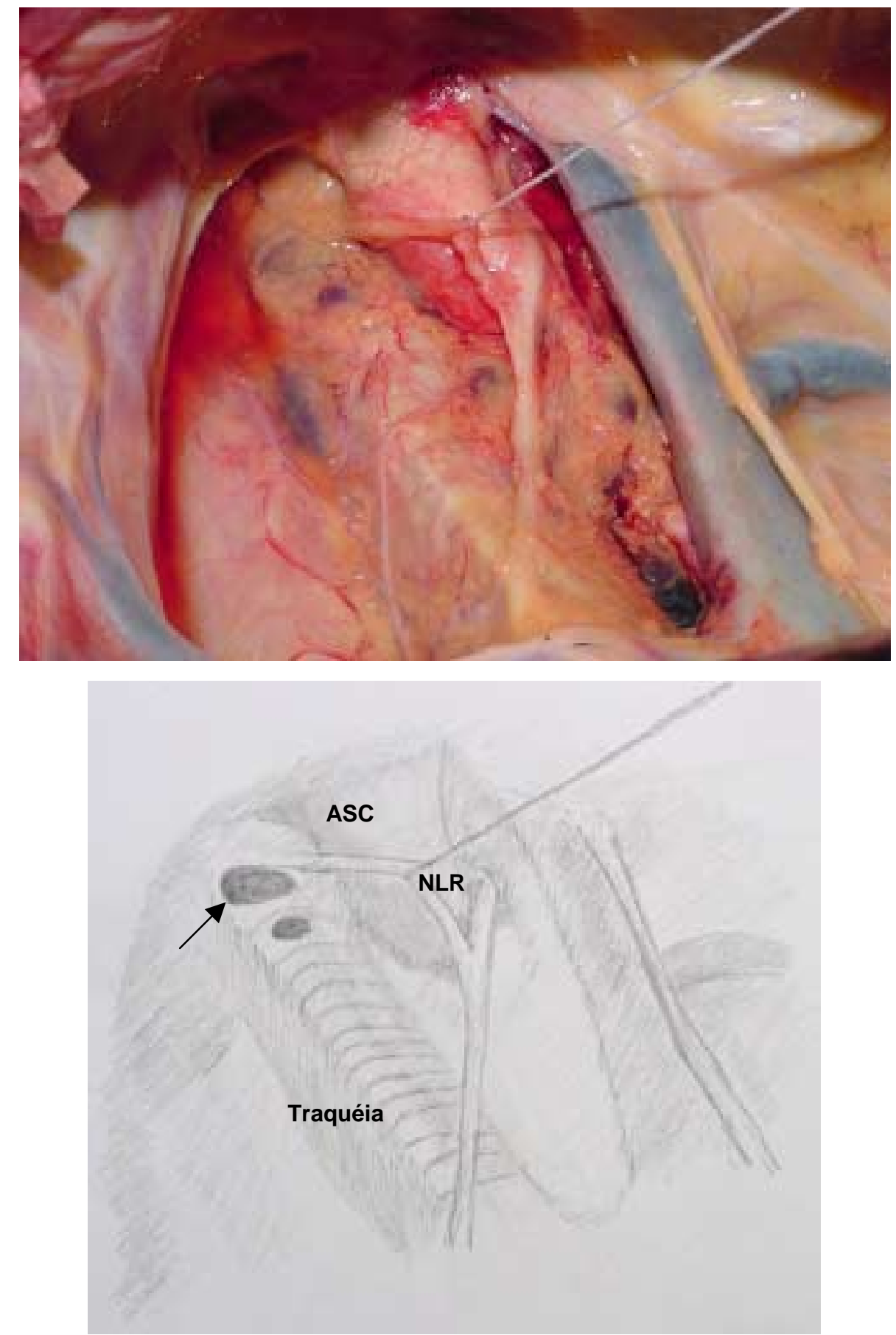

Fig. 2 - Dissecção cranial do mediastino à direita com o reparo no nervo laríngico recorrente (NLR). Nota-se a cadeia 1 (seta), posterior à artéria subclávia (ASC). 

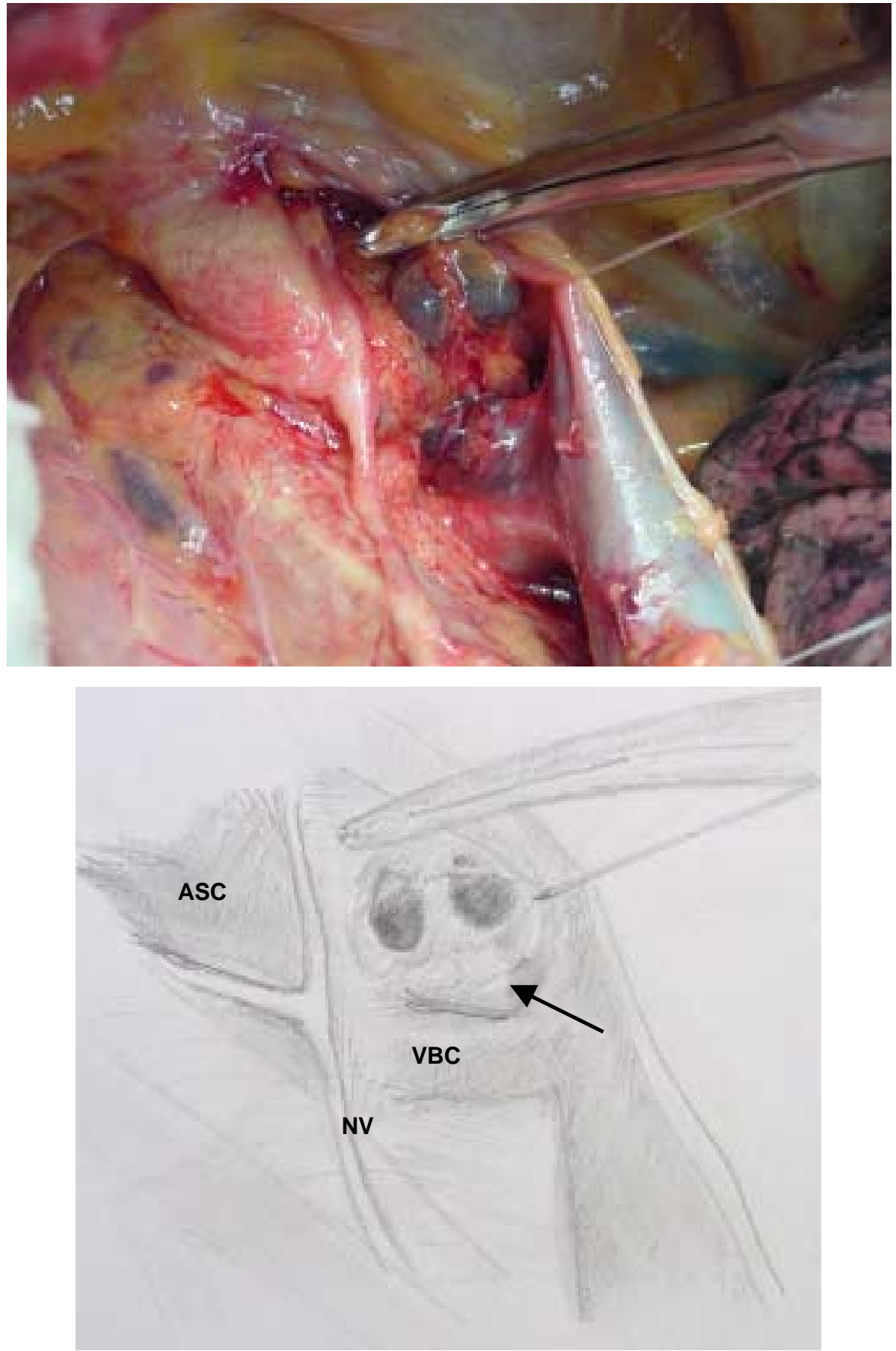

Fig. 3 - Dissecção dos linfonodos justapostos ao ângulo venoso (seta) compreendido pelo encontro das veias braquiocefálicas (VBC). ASC: artéria subclávia. NV: nervo vago.

- Cadeia linfonodal no2 (linfonodos paratraqueais superiores): localizada lateralmente à parede traqueal à direita (2R) e à esquerda (2L). Limitou-se 
cranialmente pela margem superior da veia braquiocefálica esquerda e caudalmente pela linha imaginária acima da margem superior do arco aórtico (Fig. 4 e 5). 

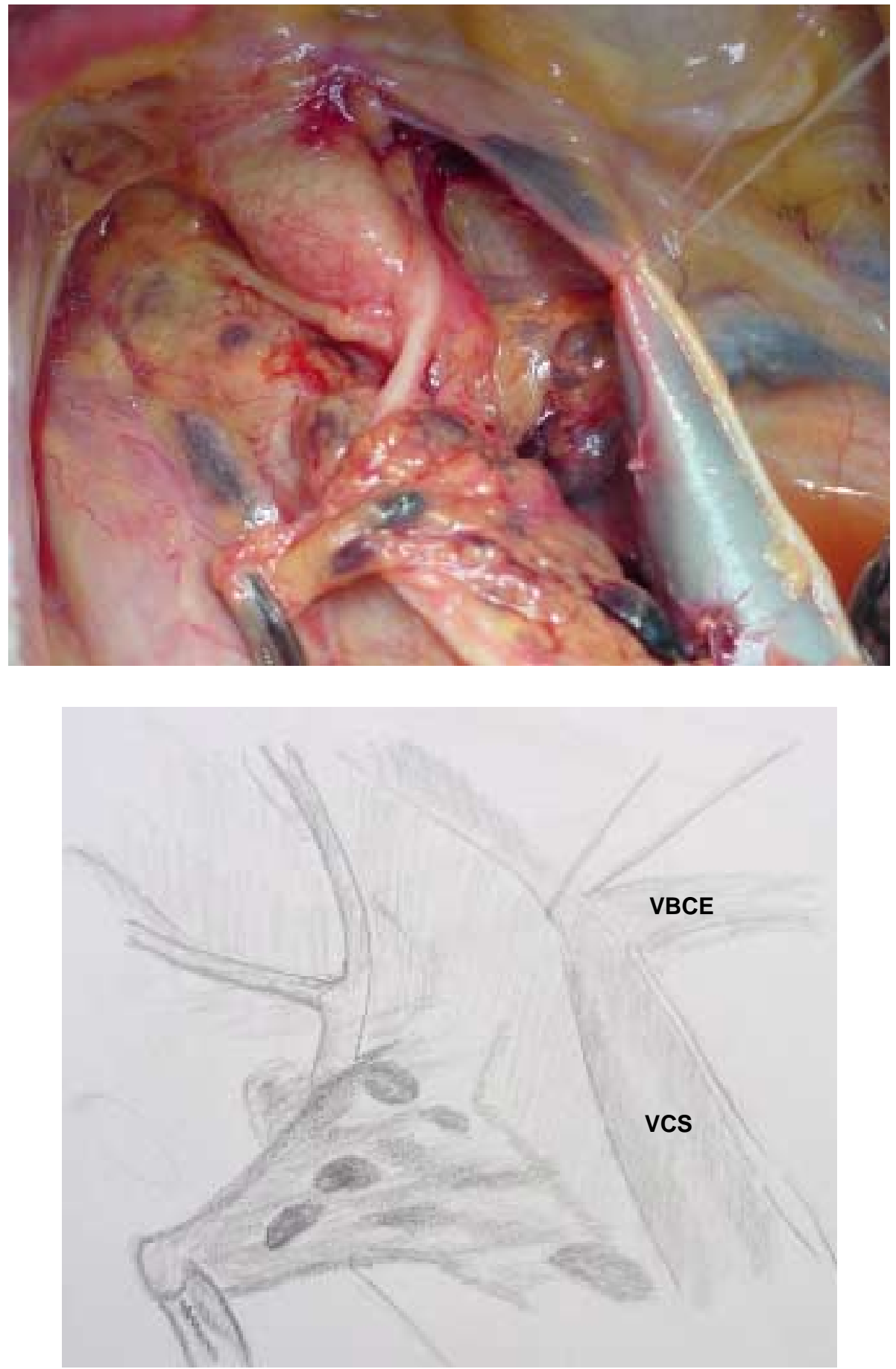

Fig. 4 - Linfonodos da cadeia 2R sendo tracionados pela pinça. Limite cranial definido pela margem superior da veia braquiocefálica esquerda (VBCE). VCS: veia cava superior. 

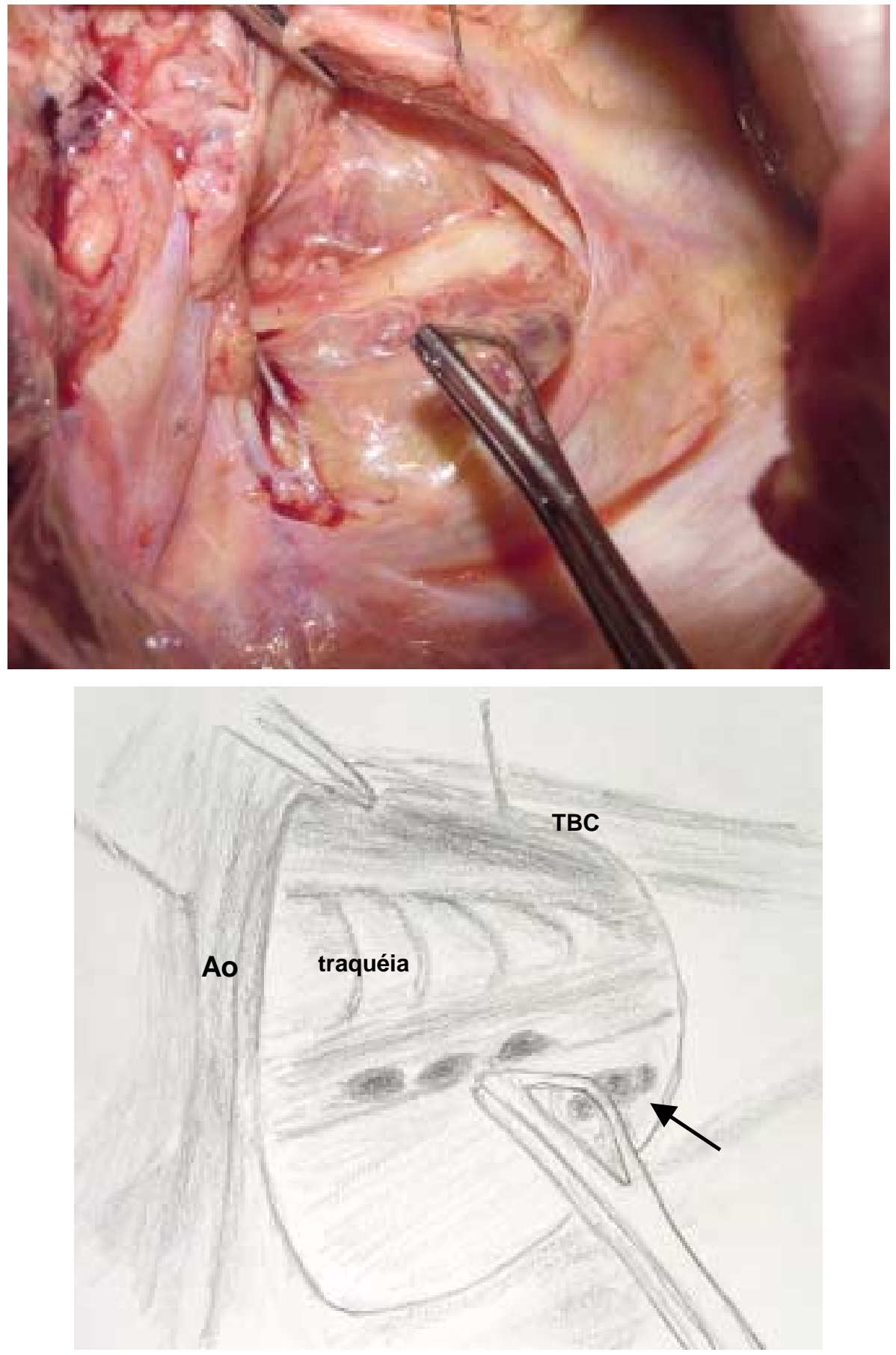

Fig 5. Dissecção da região paratraqueal esquerda, com deslocamento inferior do arco aórtico (Ao). Linfonodos da cadeia 2L sendo tracionados pela pinça (seta). TBC = tronco braquiocefálico.

- Cadeias linfonodais $\mathrm{n}-3 a$ e $\mathrm{n}-3 \mathrm{p}$ (linfonodos pré-vasculares e retrotraqueais): a cadeia linfonodal $\mathrm{n}-3$ a foi delimitada anteriormente à traquéia e posteriormente à veia cava superior. A cadeia $n-3 p$ foi localizada 
em posição retrotraqueal, entre a traquéia e a parede anterior do esôfago (Fig.6).
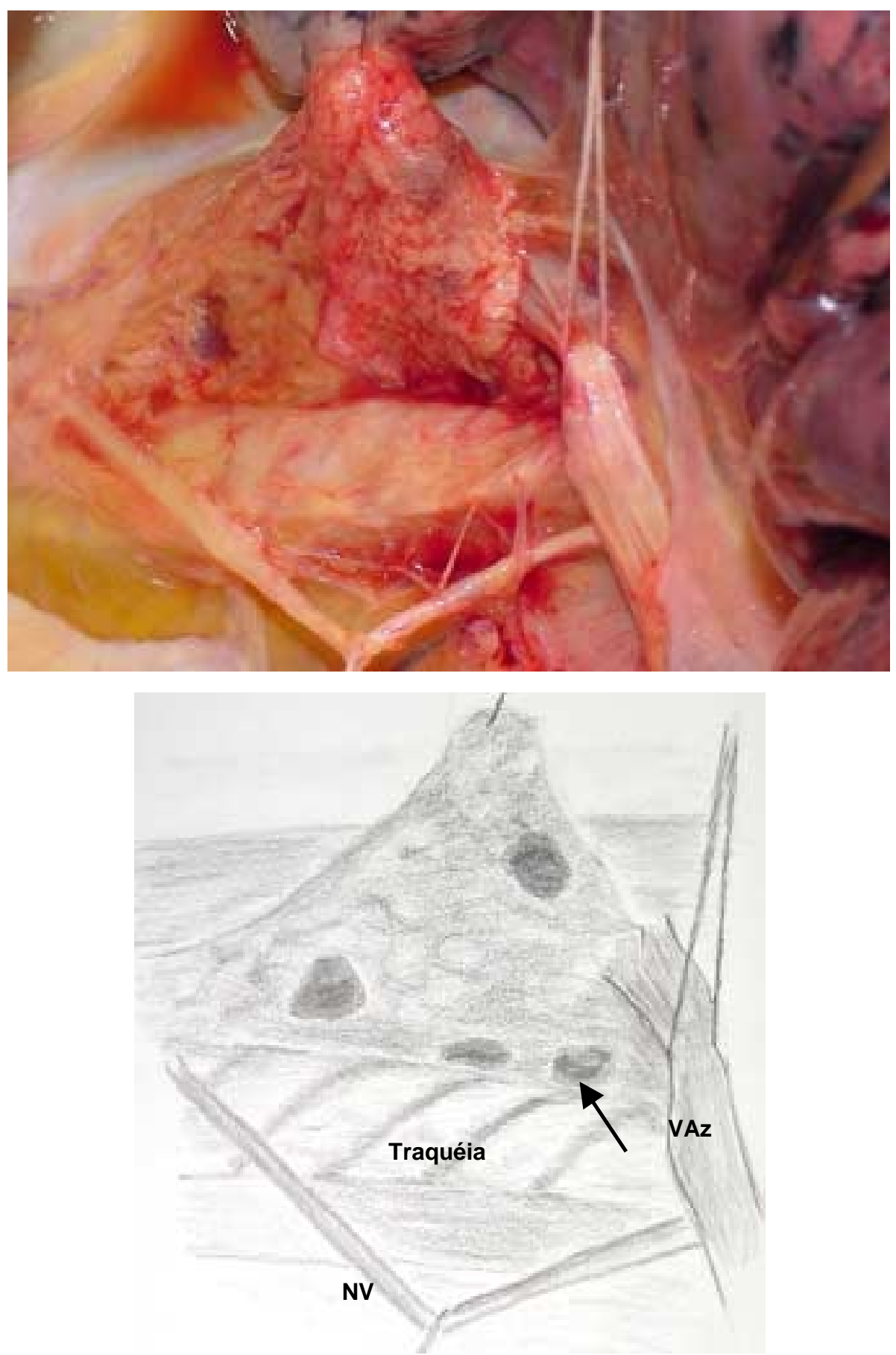

Fig. 6 - Dissecção da região paratraqueal direita. Pode-se observar a presença dos linfonodos da cadeia 3a no bloco linfoadiposo (seta) sendo retirado à região anterior da traquéia, acima da veia ázigos (VAz) tracionada pelo reparo. NV: nervo vago. 
- Cadeia linfonodal nำ (linfonodos paratraqueais inferiores): correspondeu aos linfonodos situados entre o nível da margem superior do arco aórtico e o nível da margem superior do brônquios lobares respectivos a cada lado, direito (4R) e esquerdo (4L), contidos pela pleura mediastinal. À esquerda, compreendeu os linfonodos situados medialmente ao ligamento arterioso (Fig. 7 e 8). 

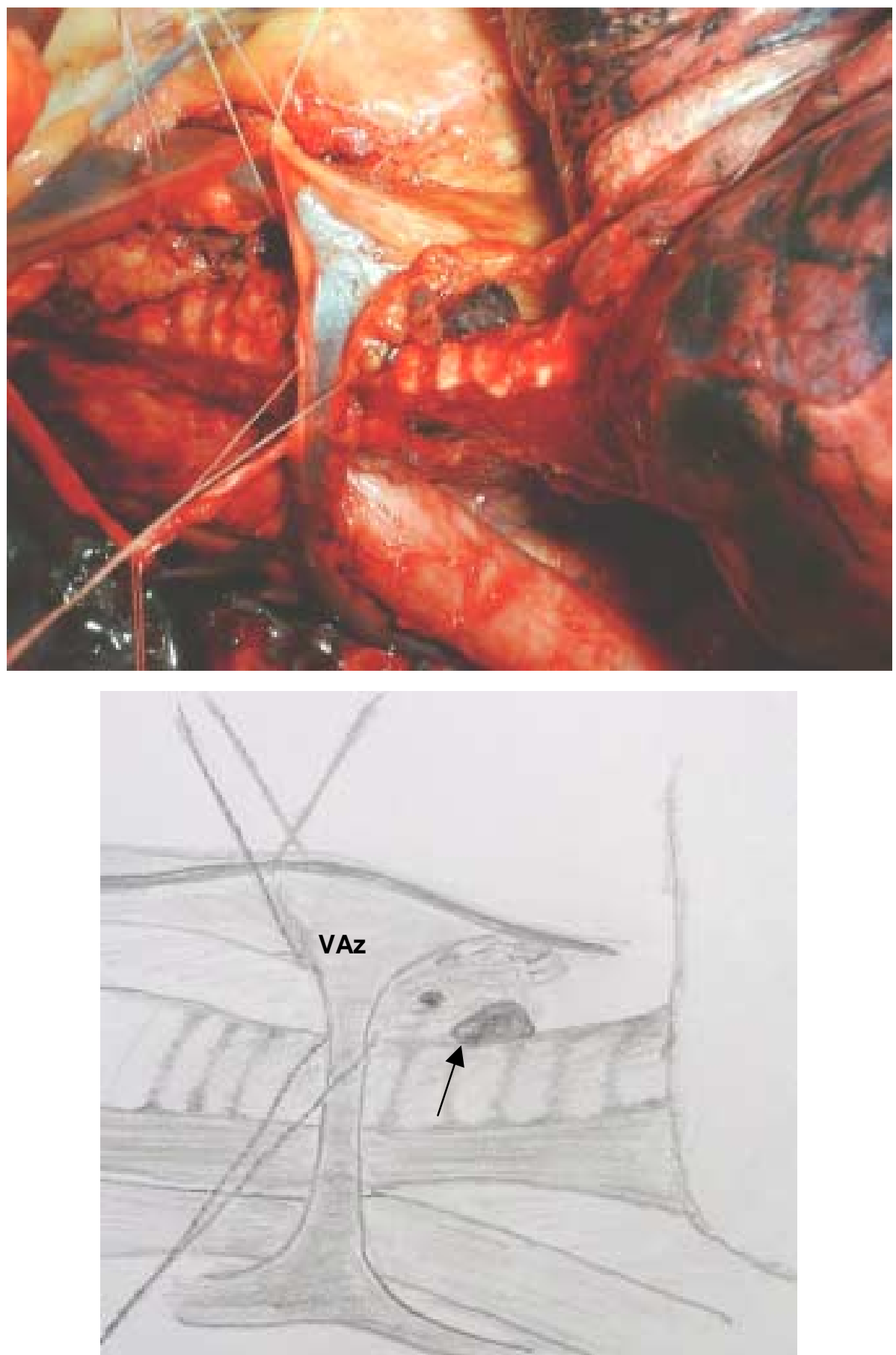

Fig. 7 - Dissecção da região paratraqueal direita. Observa-se a presença dos linfonodos da cadeia 4R (seta) abaixo da veia ázigos (VAz). 

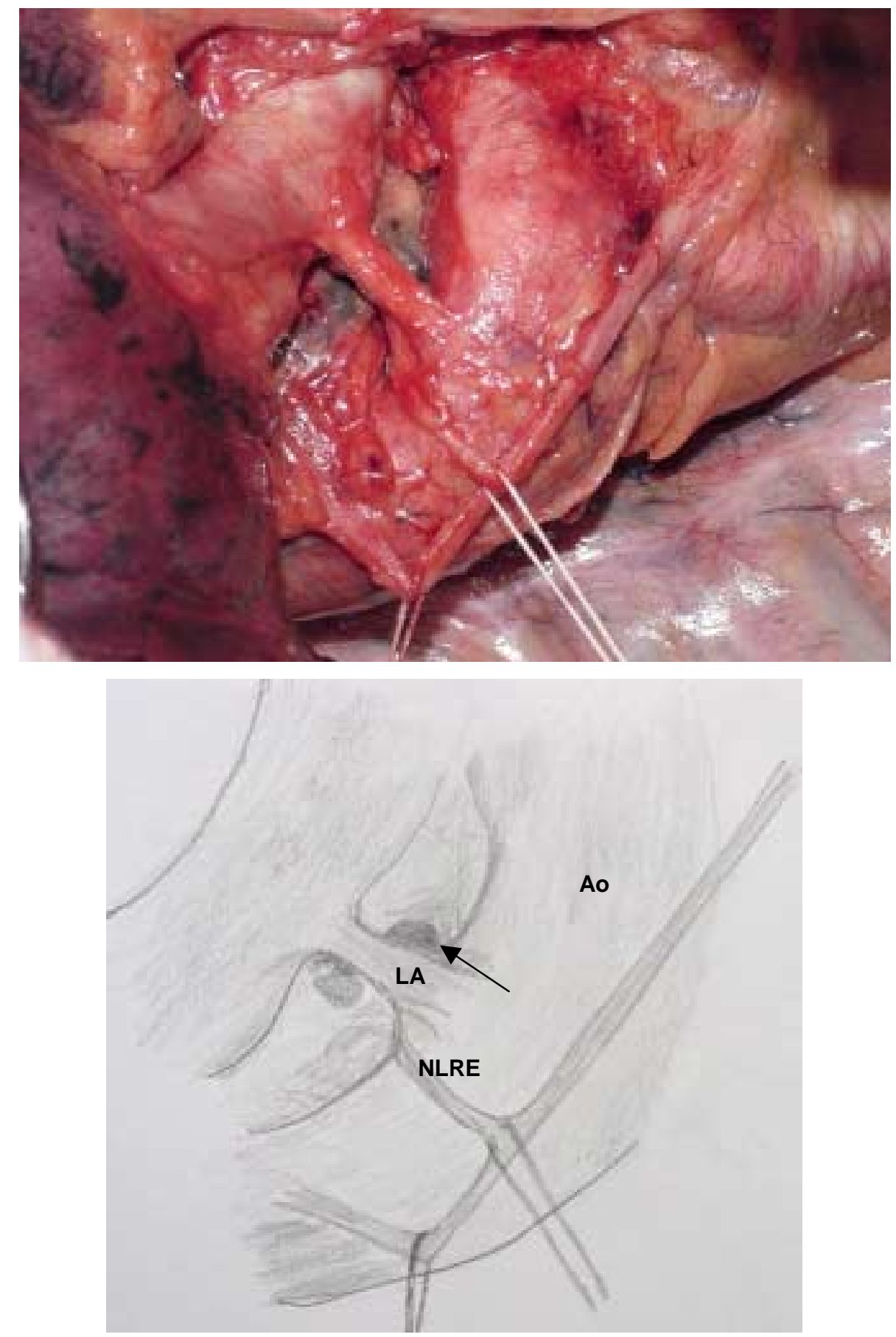

Fig. 8 - Dissecção da janela aorto-pulmonar. Reparado o nervo laríngico recorrente esquerdo (NLRE) em sua emergência do nervo vago. Observa-se a presença da cadeia 4L (seta), medialmente ao ligamento arterioso (LA). Ao: aorta. 
- Cadeia linfonodal nำ (linfonodos subaórticos): foi localizada lateralmente ao ligamento arterioso, ou à aorta ou à artéria pulmonar esquerda e proximais ao primeiro ramo desta (Fig. 9). 

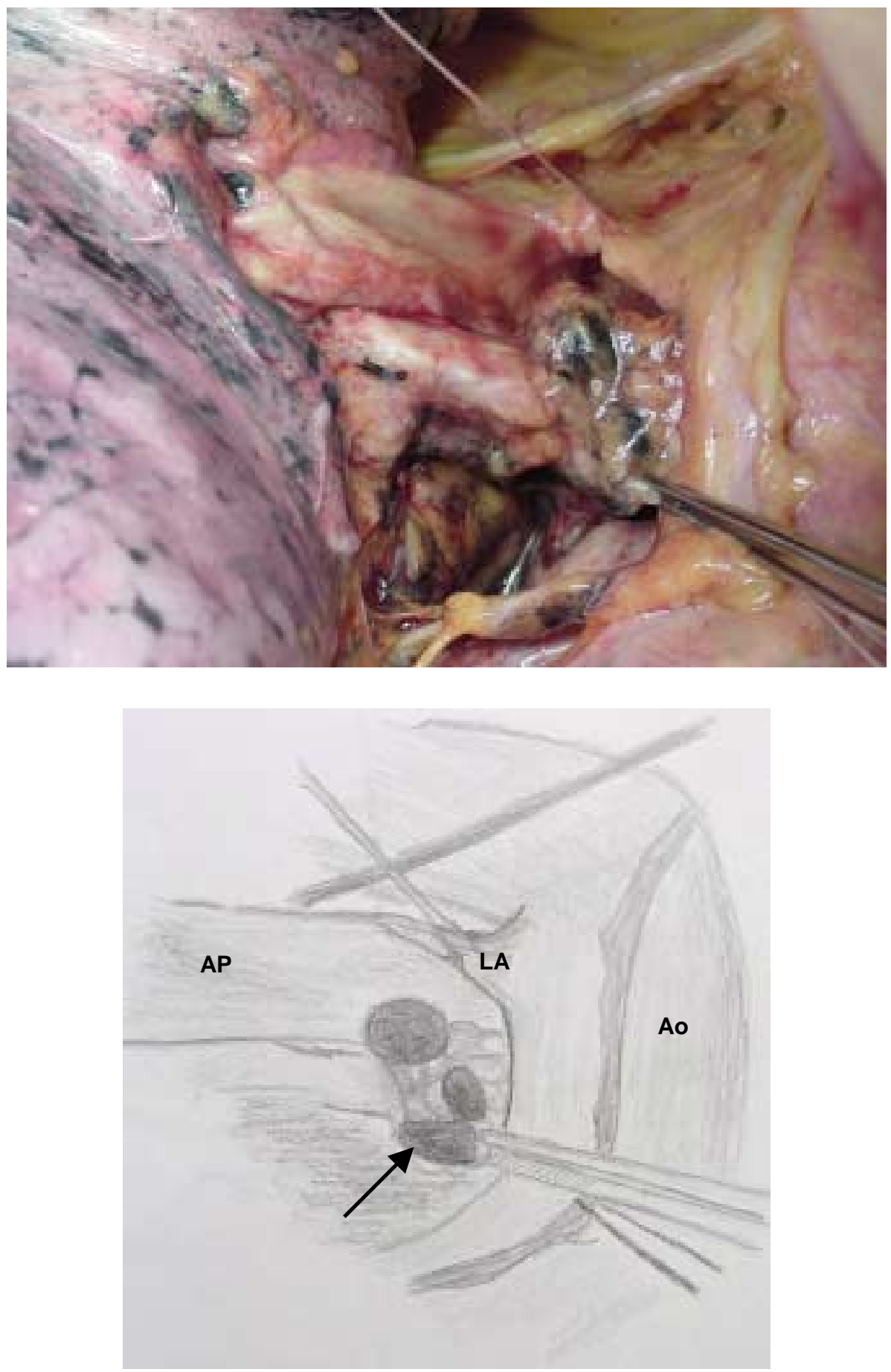

Fig. 9 - Dissecção da janela aorto-pulmonar. Reparado o ligamento arterioso (LA) entre a aorta (Ao) e a artéria pulmonar (AP), enquanto se traciona o bloco linfoadiposo da cadeia 5 na pinça (seta). 
- Cadeia linfonodal nํ6 (linfonodos para-aórticos): compreendeu os linfonodos situados anterior e lateralmente à aorta ascendente e ao arco aórtico, ou à artéria inominada, abaixo de uma linha tangencial à margem superior do arco aórtico (Fig. 10). 

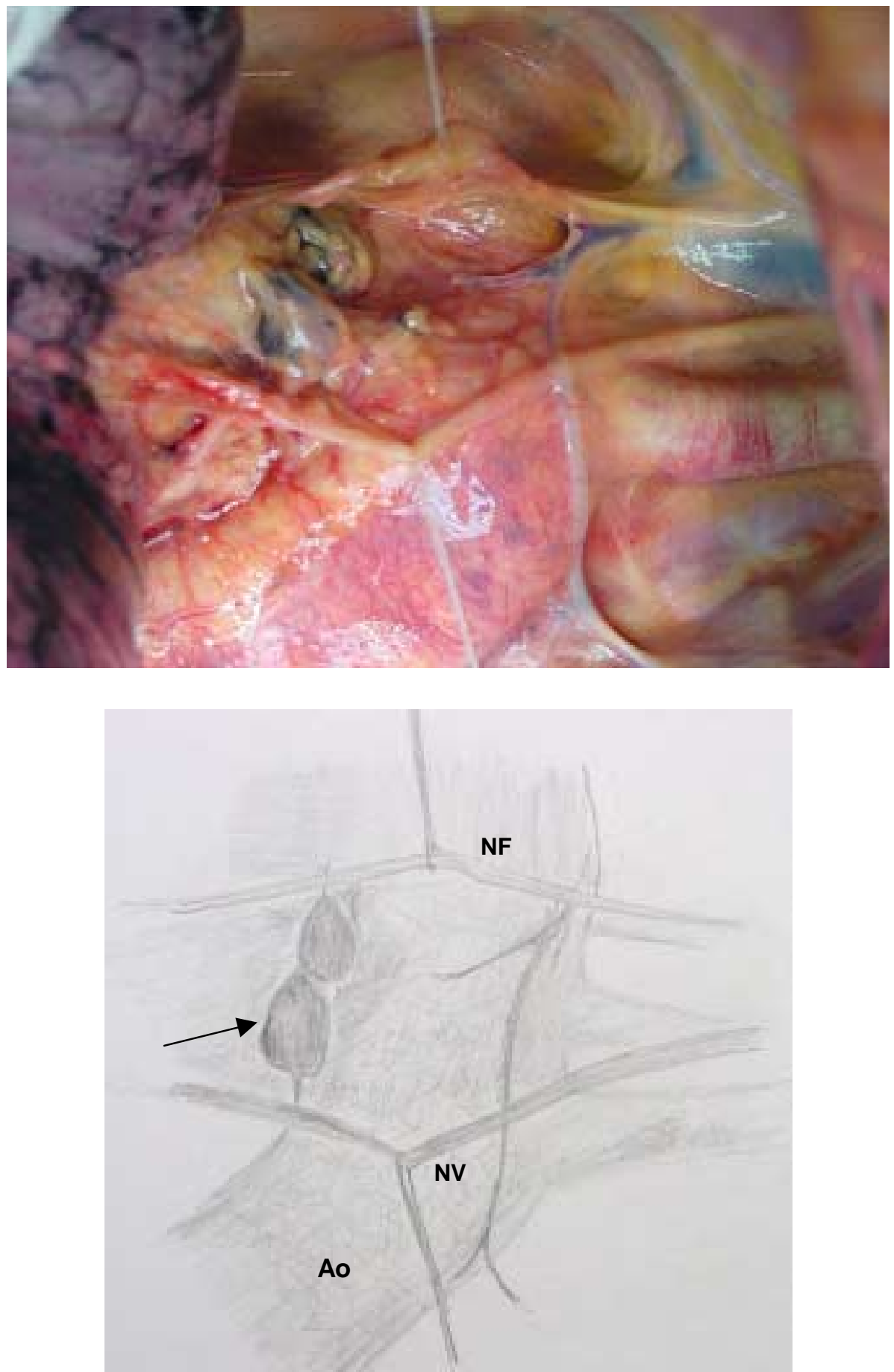

Fig. 10 - Reparados os nervos frênico (NF) e vago (NV), observa-se o bloco linfoadiposo da cadeia 6 (seta) sobre o arco aórtico (Ao).

- Cadeia linfonodal no7 (linfonodos subcarinais): foi aquela situada sob o ângulo de bifurcação da carina principal (Fig. 11). 

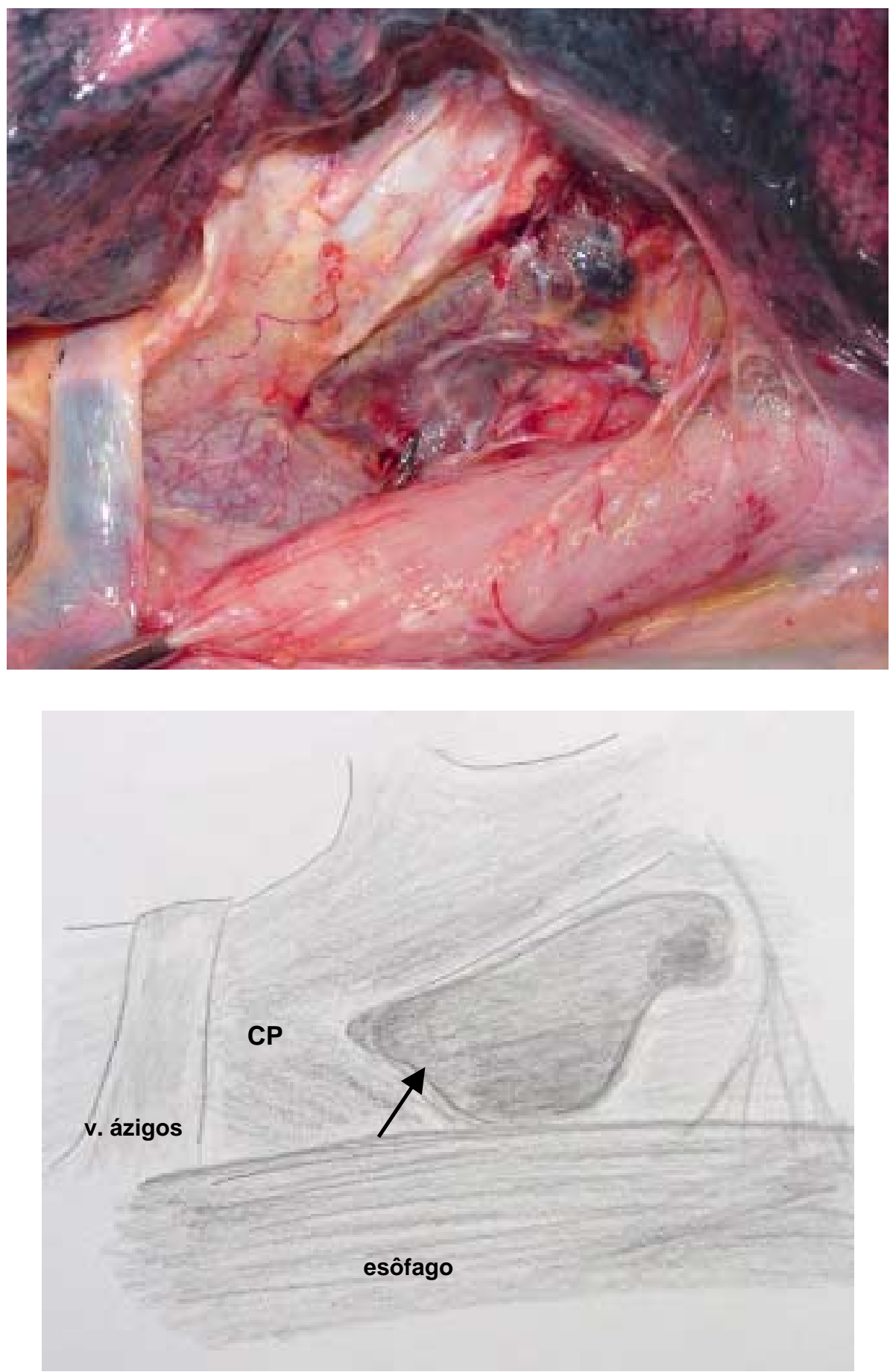

Fig. 11 - Dissecção da região subcarinal vista pelo hemitórax direito. A cadeia 7 (seta) pode ser observada abaixo da carina principal (CP). 
- Cadeia linfonodal no8 (linfonodos paraesofágicos): compreendeu os linfonodos situados ao lado da parede do esôfago, excluindo-se os linfonodos subcarinais.

- Cadeia no 9 (linfonodos do ligamento pulmonar): esta cadeia compreendeu os linfonodos mais caudais do mediastino posterior à direita (9R) e à esquerda (9L). Incluiu os linfonodos dentro do ligamento pulmonar e os que se localizam abaixo da veia pulmonar inferior (Fig. 12). 

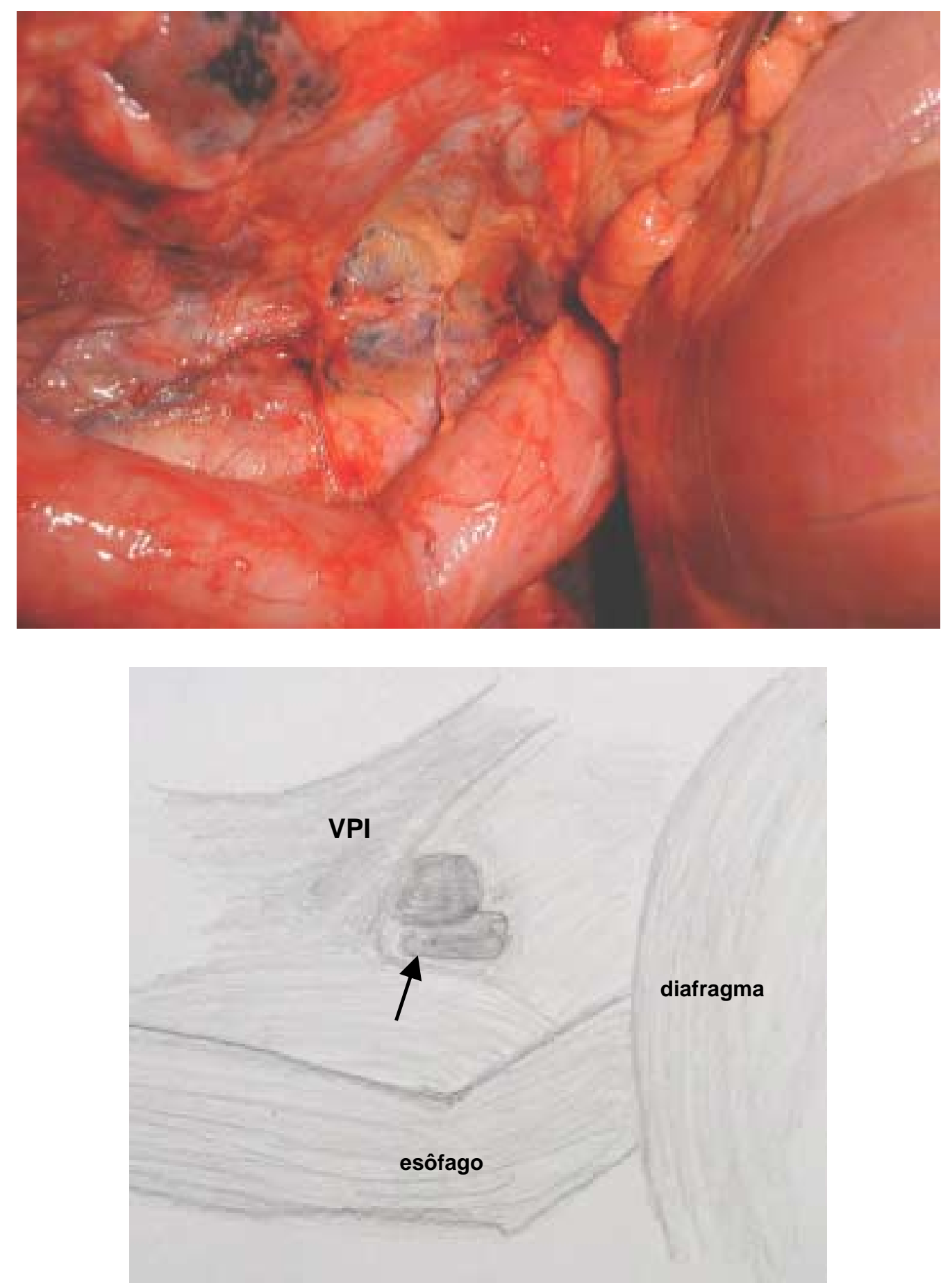

Fig. 12 - Cadeia 9 (seta) vista pelo hemitórax direito, à frente do esôfago e abaixo da veia pulmonar inferior (VPI).

A topografia das diversas cadeias linfonodais do mediastino foi preservada pela dissecção in situ das estruturas mediastinais, segundo 
modificações da técnica de dissecção originalmente descrita por NARUKE (1993).

O bloco visceral do mediastino não foi removido, utilizando-se técnica operatória na dissecção. Isto possibilitou a manutenção da sintopia das cadeias linfonodais e seus limites com as estruturas e divisões anatômicas do mediastino.

A dissecção e a ressecção linfonodal foi radical, isto é, foram removidos todos os linfonodos com a gordura mediastinal circunjacente dentro dos limites anatômicos definidos.

\subsection{Individualização dos linfonodos}

Os blocos linfoadiposos foram acondicionados em recipientes separados e identificados segundo a nomenclatura atual, sendo a seguir fixados em solução de formalina $10 \%$ tamponada.

Sete dias após a fixação em solução aquosa de formalina, os linfonodos foram separados do tecido gorduroso mediastinal, por dissecção minuciosa sobre prancha e, em seguida, fotografados. Foi realizada a contagem dos linfonodos por cadeia e os dados anotados nas fichas do protocolo. 


\subsection{Registro digital das imagens}

Realizou-se a obtenção das imagens por meio de máquina fotográfica digital marca "Sony" modelo Mavica-FD97, que foram armazenadas em meio magnético com resolução de $1024 \times 768$ pixels com 24 bits para cores, comprimidas por modo jpeg. Para tanto, as peças anatômicas foram dispostas sobre vidro, superposto a tecido de fundo homogêneo, ao lado de régua milimetrada e identificação da cadeia. A máquina fotográfica ficou fixa em estativa a $4 \mathrm{~cm}$ das peças, que foram iluminadas por duas fontes de luz, dispostas de maneira a eliminar sombras (Fig. 13).

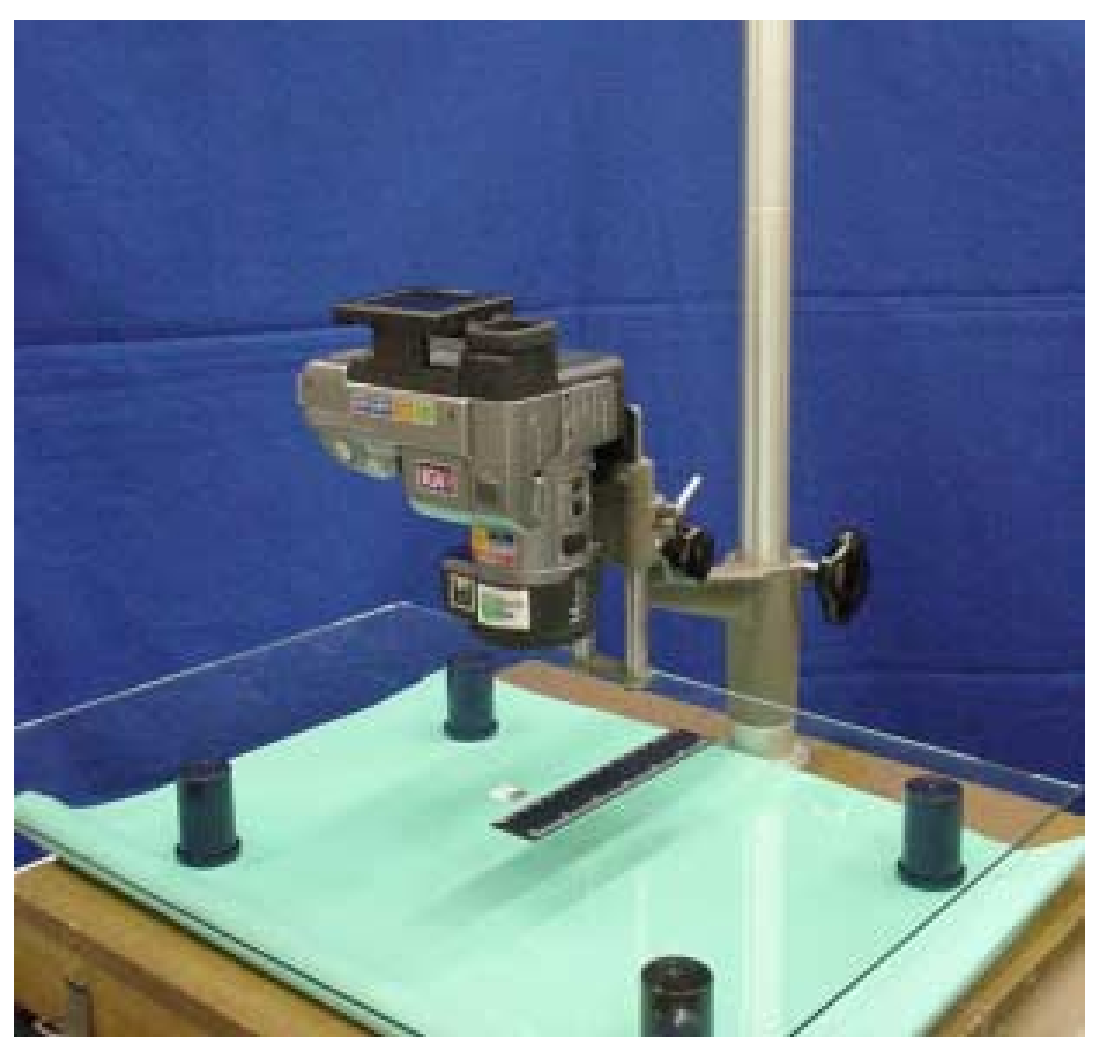

Fig. 13 - Montagem do equipamento para o registro digital da imagem do linfonodo. 


\subsection{Estudo histológico}

Todos os linfonodos foram emblocados em parafina e identificados de acordo com sua cadeia.

Dos blocos de parafina contendo os linfonodos identificados em cada cadeia mediastinal foram realizadas secções histológicas, coradas pela hematoxilina-eosina.

A observação das lâminas sob lupa de pequeno aumento permitiu realizar a contagem dos linfonodos pós-fixação, verificando a presença ou ausência de coalescência linfonodal (Fig. 14).

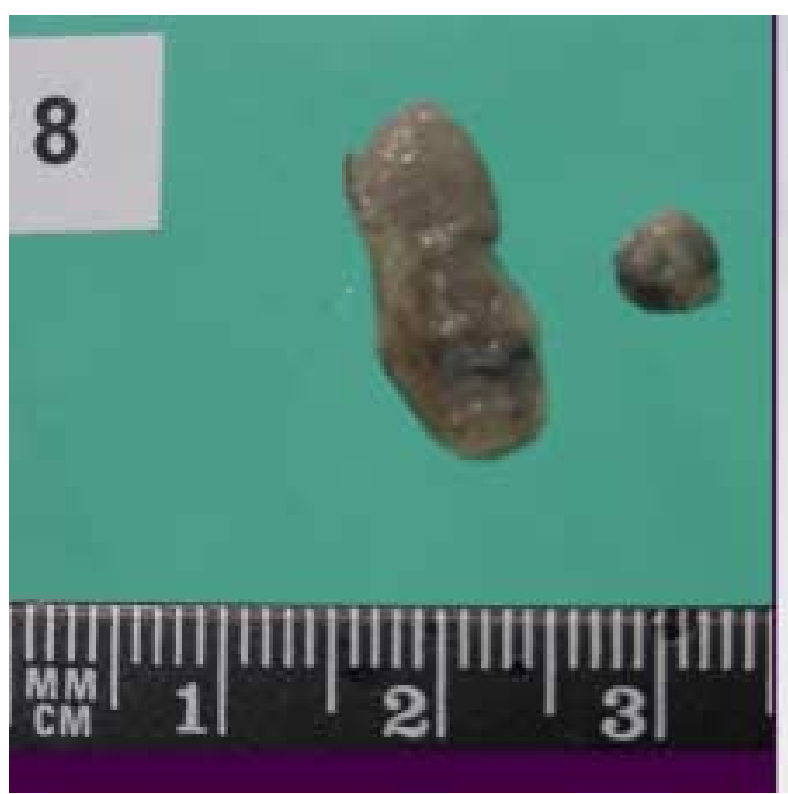

Fig. 14 - Contagem macroscópica dos linfonodos ao lado de régua milimetrada e à lâmina corada pelo $\mathrm{HE}$, para a avaliação de coalescência linfonodal.

A análise histológica dos cortes foi realizada por um patologista, sem a informação da causa mortis. Todos os linfonodos foram examinados com 
aumentos consecutivos de 40, 100 e 400 vezes em microscópio óptico Nikon Eclipse E200. Comprovou-se a existência do tecido linfático sem processo patológico ativo. A análise também permitiu separar eventuais tecidos nãolinfáticos incluídos na dissecção. Os tecidos não-linfáticos fotografados tiveram suas imagens demarcadas para exclusão da mensuração.

\subsection{Mensuração dos linfonodos no computador}

O processamento das imagens foi realizado por meio do programa de computador UTHSCA "Image Toll for Windows version 3.0" da Universidade do Texas "Health Science Center in San Antonio". As medidas foram calibradas para uma linha traçada sobre uma distância conhecida $(10 \mathrm{~mm})$ sobre a régua milimetrada em cada imagem. Cada linfonodo teve seu perímetro demarcado, sendo calculada a área e medidos os diâmetros maior e menor pelo computador (Fig. 15). Foram consecutivamente calculados as médias e desvios padrões de todos os valores obtidos para cada cadeia linfonodal. 


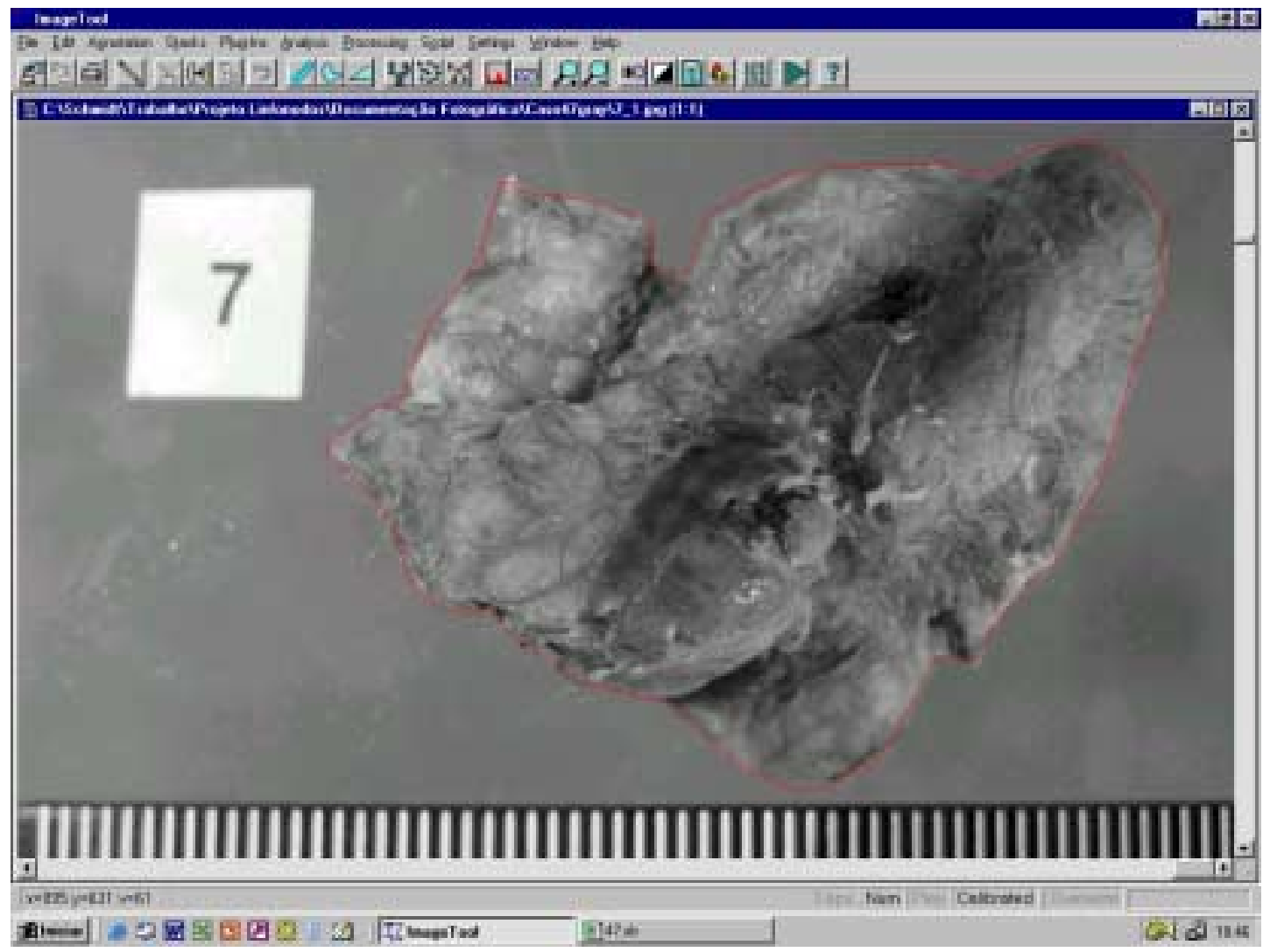

Fig. 15 - Delimitação do perímetro linfonodal para a realização das medidas por meio do computador.

\subsection{Parâmetros avaliados}

Para a análise da amostra foram considerados seguintes parâmetros:

a. Cadeias linfonodais: consideradas presentes as cadeias linfonodais que à dissecção apresentaram um ou mais linfonodos;

b. Número de linfonodos: dissecados da gordura mediastinal de acordo com cada cadeia;

c. Formato dos linfonodos: classificados por meio da análise visual das imagens do registro digital; 
d. Histologia

i. Coalescência linfonodal: determinada pela recontagem do número de linfonodos à lâmina sob pequeno aumento.

ii. Valor de coalescência: expressa em porcentagem, em uma relação do número de linfonodos contados na lâmina (n_lam) corada pelo hematoxilina-eosina, sobre o número de linfonodos contados macroscopicamente à dissecção em prancha (n_linf); (Valor de coalescência $=$ n_lam*100 / n_linf)

iii. Granulomas cicatriciais: presença ou ausência.

e. Tamanhos linfonodais:

i. Área: determinada por meio do programa de computador pelo número de pontos no polígono, sendo fornecido o valor final de acordo com a unidade utilizada na calibração, no caso, em milímetros quadrados;

ii. Eixo maior: considerada como a reta mais longa que pôde ser desenhada dentro do polígono, em milímetros;

iii. Eixo menor: o tamanho da maior reta, em milímetros, que pôde ser desenhada no polígono, perpendicular ao eixo maior;

Estes parâmetros foram cotejados com os dados obtidos de idade, peso, altura, sexo, raça e causa mortis. Esta foi definida pelo estudo necroscópico, tendo sido classificada em doença congestiva, quando havia edema pulmonar, ou não-congestiva.

Foi realizada a análise de associações e correlações, sendo os dados organizados para apresentação da seguinte forma:

a) descrição dos dados obtidos; 
b) análise do número linfonodal e suas associações com as variáveis qualitativas e correlações com as quantitativas;

c) análise dos tamanhos linfonodais e suas associações com as variáveis qualitativas e correlações com as quantitativas;

d) análise das correlações e associações dos parâmetros avaliados entre si.

\subsection{Análise estatística}

Quanto à análise descritiva, foram observados os valores mínimos e máximos e utilizados os cálculos de médias e desvio padrão para as variáveis quantitativas. Foi utilizado o cálculo do Coeficiente de Variação (CV = desvio padrão*100 / média) para determinação do parâmetro que apresentou menores diferenças entre valores de grandezas equiparáveis. Para as variáveis qualitativas foram calculadas as freqüências absolutas e relativas.

Com relação à análise estatística, para se testar a homogeneidade de grupos em relação às proporções foi utilizado o teste qui-quadrado ou o teste exato de Fisher. Este foi indicado para a comparação das proporções quando as caselas de respostas apresentaram freqüências esperadas menor do 5 .

Foi utilizado o teste não-paramétrico de Wilcoxon na comparação dos valores observados na mesma unidade amostral. Para comparação de vários grupos foi utilizada a Análise de Variância a um fator com comparações múltiplas através do teste de Bonferroni. Para a comparação entre dois 
grupos foi utilizado o teste $\mathrm{t}$ de Student para amostras independentes. Quando a suposição de normalidade dos dados foi rejeitada, foi utilizado o teste não-paramétrico de Mann-Whitney. O estudo da correlação entre dois valores foi realizado através do coeficiente de correlação de Pearson (ROSNER, 1986).

Todos os testes foram realizados admitindo-se o nível de significância de $5 \%$. 
5. RESULTADO 


\section{Resultados}

\subsection{Cadeias e número de linfonodos}

Foram dissecadas 485 cadeias. A média de presença das diversas cadeias à dissecção do mediastino foi de $74,6 \%$. As cadeias $2 \mathrm{R}, 4 \mathrm{R}$ e 7 foram as mais freqüentemente encontradas à dissecção (GRÁFICO 1).

GRÁFICO 1 - PORCENTUAL DE PRESENÇA DAS CADEIAS À DISSECÇÃO.

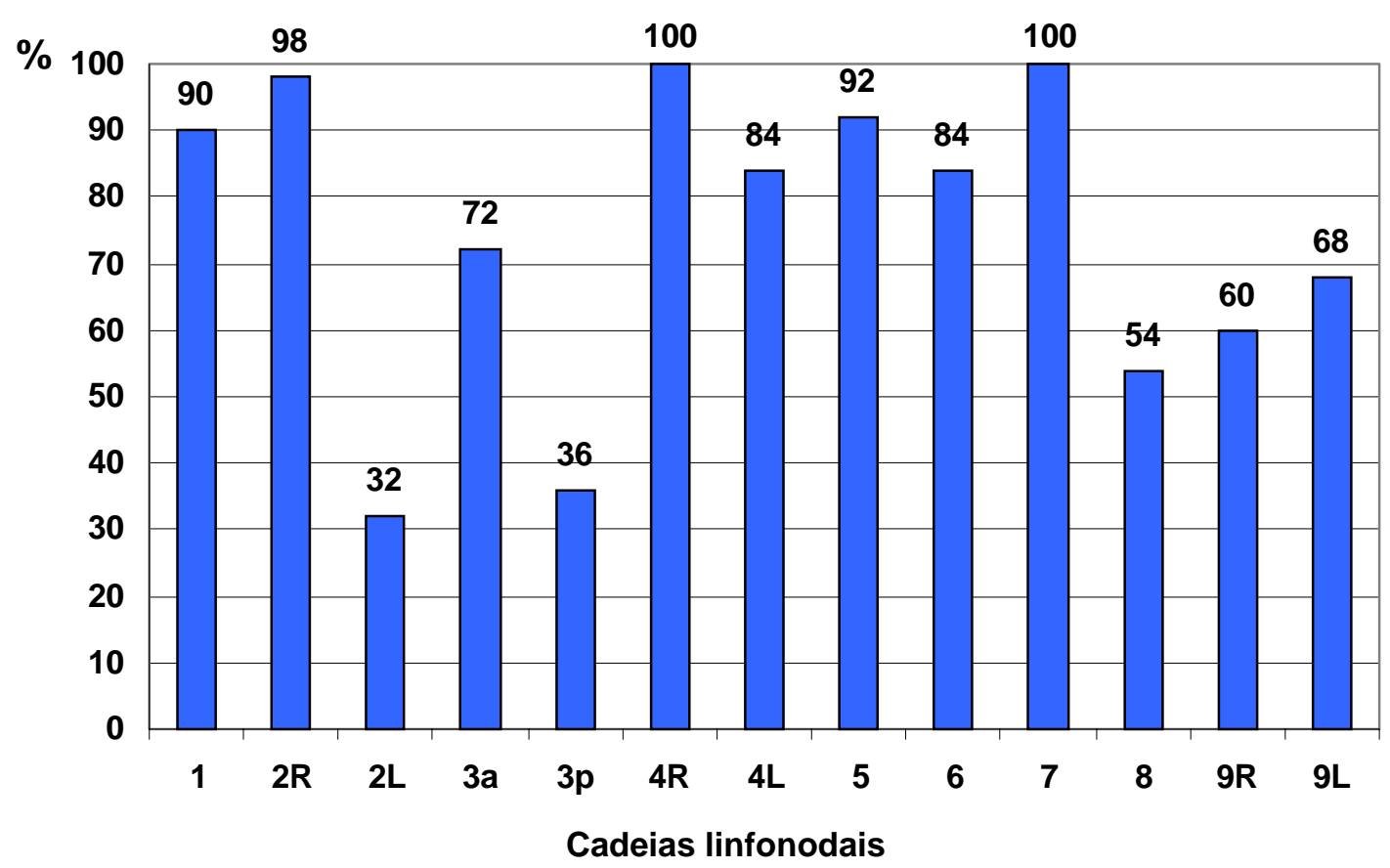

Encontraram-se 1742 linfonodos com média de 2,58 \pm 1,89 linfonodos por cadeia e média de $34,8 \pm 12,2$ linfonodos por caso. No mediastino à direita, foram encontrados em média $21,2 \pm 8,5$ linfonodos e à esquerda, 13,6 $\pm 6,3$ 
linfonodos. A região que conteve o maior número de linfonodos foi a $2 \mathrm{R}$, tendo compreendido $15,6 \%$ do total de linfonodos dissecados (TABELA 1).

TABELA 1 - NÚMERO DE LINFONODOS, MÉDIA, DESVIO PADRÃO E PORCENTUAL POR CADEIA

\begin{tabular}{lcccr}
\hline Cadeia & Linfonodos & média & DP & \multicolumn{1}{c}{$\%$} \\
\hline 1 & 116 & 2,58 & 1,89 & 6,63 \\
$2 \mathrm{R}$ & 276 & 5,52 & 4,48 & 15,57 \\
$2 \mathrm{~L}$ & 55 & 3,24 & 1,95 & 3,32 \\
$3 \mathrm{a}$ & 87 & 2,29 & 1,56 & 5,06 \\
$3 \mathrm{p}$ & 36 & 1,89 & 1,33 & 2,25 \\
$4 \mathrm{R}$ & 229 & 4,58 & 3,02 & 12,82 \\
$4 \mathrm{~L}$ & 150 & 3,49 & 2,93 & 8,94 \\
5 & 188 & 4,09 & 2,06 & 10,62 \\
6 & 210 & 5,00 & 3,37 & 11,92 \\
7 & 205 & 4,10 & 2,68 & 11,75 \\
8 & 57 & 2,04 & 1,45 & 3,26 \\
$9 \mathrm{R}$ & 61 & 2,03 & 1,71 & 3,71 \\
$9 \mathrm{~L}$ & 72 & 2,12 & 1,74 & 4,16 \\
\hline Total & 1742 & 2,58 & 1,89 & 100,0 \\
\hline \hline
\end{tabular}

O número de linfonodos redefinido para cada cadeia de acordo com sua contagem na lâmina para determinação da diferença de linfonodos coalescentes está expressa na TABELA 2. O número determinado na recontagem representou 9\% a mais do total de linfonodos à dissecção. 
TABELA 2 - LINFONODOS À DISSECÇÃO E NA LÂMINA, NÚMERO DE LINFONODOS COALESCENTES E PORCENTUAIS DA COALESCÊNCIA POR CADEIA

\begin{tabular}{ccccc}
\hline Cadeia & $\begin{array}{c}\text { Linfonodos à } \\
\text { Dissecção }\end{array}$ & $\begin{array}{c}\text { Linfonodos à } \\
\text { Lâmina }\end{array}$ & $\begin{array}{c}\text { Linfonodos } \\
\text { coalescentes }\end{array}$ & $\begin{array}{c}\text { Valor de } \\
\text { Coalescência (\%) }\end{array}$ \\
\hline 1 & 116 & 125 & 9 & 107,76 \\
$2 \mathrm{R}$ & 276 & 296 & 20 & 107,25 \\
$2 \mathrm{~L}$ & 55 & 59 & 4 & 107,27 \\
$3 \mathrm{a}$ & 87 & 97 & 10 & 111,49 \\
$3 \mathrm{p}$ & 36 & 37 & 1 & 102,78 \\
$4 \mathrm{R}$ & 229 & 250 & 21 & 109,17 \\
$4 \mathrm{~L}$ & 150 & 158 & 8 & 105,33 \\
5 & 188 & 206 & 18 & 109,57 \\
6 & 210 & 221 & 11 & 105,24 \\
7 & 205 & 243 & 38 & 118,54 \\
8 & 57 & 62 & 5 & 108,77 \\
$9 \mathrm{R}$ & 61 & 66 & 5 & 108,20 \\
$9 \mathrm{~L}$ & 72 & 80 & 8 & 111,11 \\
\hline Total & 1742 & 1900 & 158 & 109,07 \\
\hline \hline
\end{tabular}

\subsection{Formato linfonodal}

Foi observada a presença de formato ovalar ou riniforme em $73,2 \%$ dos linfonodos. Cerca de 9,7\% apresentaram formato irregular ou misto. Os linfonodos eram retangulares ou triangulares em $11 \%$ e alongados ou em formato de "8" em 6,1\% (TABELA 3). 
TABELA 3 - CLASSIFICAÇÃO DOS LINFONODOS QUANTO À FORMA

\begin{tabular}{lr}
\hline Forma & $\%$ \\
\hline Ovalar & 64,89 \\
Irregular & 9,67 \\
Riniforme & 8,27 \\
Triangular & 5,98 \\
Retangular & 5,09 \\
Alongado & 4,20 \\
Em "8" & 1,90 \\
\hline \hline
\end{tabular}

\subsection{Histologia}

A alteração histológica mais comumente observada foi a histiocitose sinusoidal, em sua maioria, em grau leve. Foi caracterizada por discreta dilatação dos seios subcapsulares e trabeculares, repletos parcial ou completamente por histiócitos nativos uniformes em tamanho, com amplo citoplasma e núcleo arredondado ou ovalar. A antracose também foi aspecto freqüentemente observado. A autólise do material, inerente ao período entre a morte e a oportunidade da dissecção, também esteve presente em maior ou menor grau em alguns casos. Dez linfonodos em oito casos apresentaram granulomas não-ativos (Fig. 16) ou fibrocalcificação. Raros linfonodos apresentaram sinais de estimulação antigênica, caracterizada por formação de folículos linfóides, com ou sem centros germinativos. 


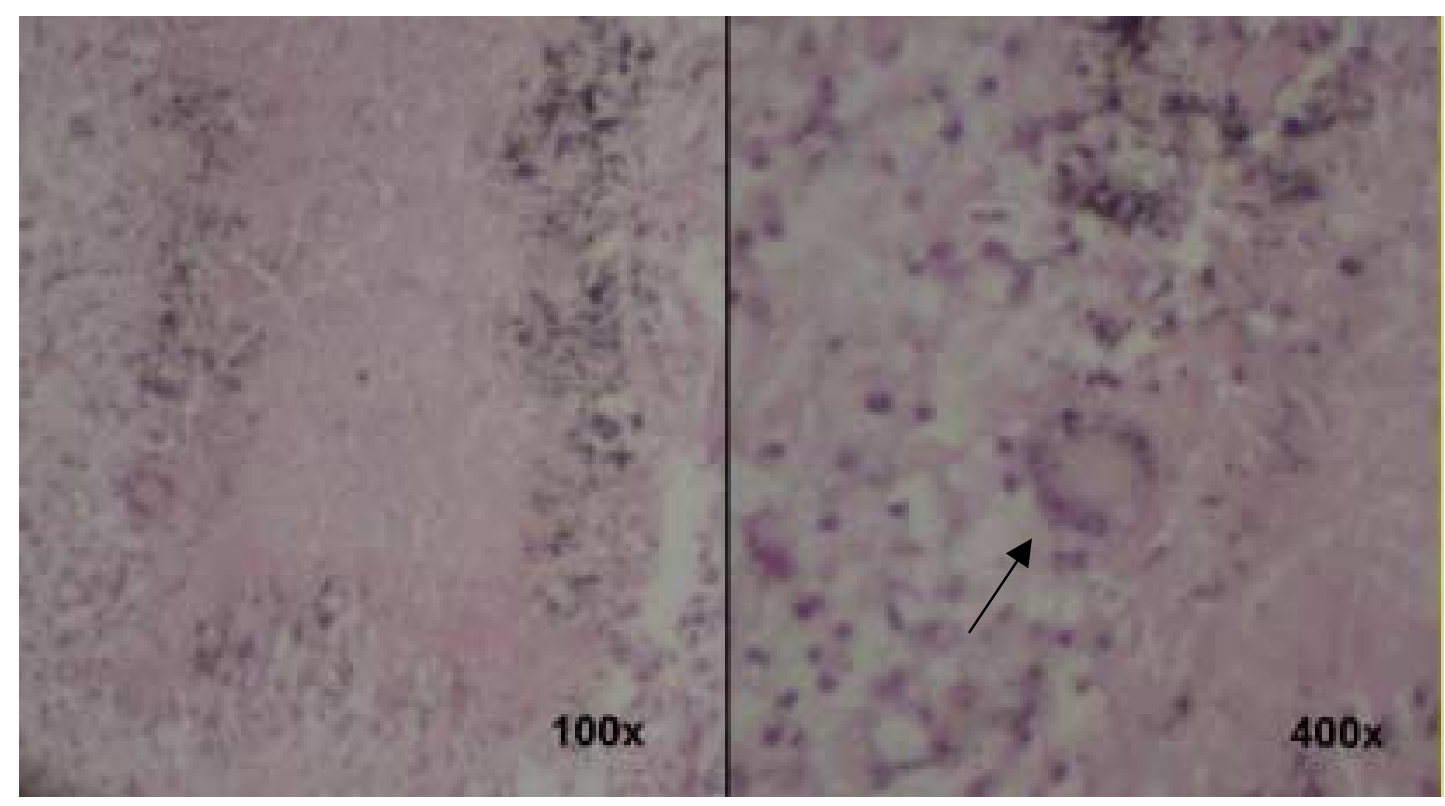

Fig. 16 - Fotomicrografia. Coloração por HE em linfonodo mediastinal. Observa-se a presença de granuloma não-ativo com gigantócito (seta) em aumentos de 100 e 400 vezes. 


\subsection{Tamanhos linfonodais}

As médias com respectivos desvios padrões dos tamanhos linfonodais estão expressas na TABELA 4.

TABELA 4 - MÉDIA DAS MEDIDAS DOS LINFONODOS POR CADEIA

\begin{tabular}{lrrrrrr}
\hline Cadeia & $\begin{array}{c}\text { Área } \\
\left(\mathrm{mm}^{2}\right)\end{array}$ & DP & $\begin{array}{c}\text { Eixo maior } \\
(\mathrm{mm})\end{array}$ & DP & $\begin{array}{c}\text { Eixo menor } \\
(\mathrm{mm})\end{array}$ & DP \\
\hline 1 & 46,18 & 35,78 & 8,91 & 3,66 & 6,00 & 2,33 \\
2R & 48,23 & 50,47 & 8,96 & 4,41 & 5,66 & 2,56 \\
2L & 31,00 & 24,58 & 7,57 & 2,98 & 4,78 & 1,97 \\
3a & 63,20 & 62,65 & 10,88 & 6,27 & 6,35 & 2,53 \\
3p & 43,64 & 34,68 & 8,57 & 3,39 & 5,59 & 2,50 \\
4R & 115,32 & 126,72 & 13,72 & 7,91 & 8,30 & 3,78 \\
$4 \mathrm{~L}$ & 47,84 & 38,23 & 9,10 & 4,32 & 5,61 & 2,35 \\
5 & 68,25 & 48,44 & 10,98 & 4,38 & 6,91 & 2,39 \\
6 & 46,87 & 34,95 & 9,11 & 4,04 & 5,63 & 1,97 \\
7 & 195,59 & 126,48 & 18,75 & 7,28 & 10,92 & 4,05 \\
8 & 59,83 & 52,11 & 11,24 & 6,19 & 5,81 & 2,43 \\
9R & 37,47 & 34,54 & 8,67 & 4,32 & 5,12 & 2,04 \\
9L & 51,01 & 47,38 & 9,37 & 4,69 & 5,92 & 2,30 \\
\hline Média & 72,89 & 83,98 & 10,93 & 6,13 & 6,65 & 3,20 \\
\hline \hline
\end{tabular}

Para a definição de um valor referencial do tamanho dos linfonodos mediastinais por cadeias, foram determinados os tamanhos linfonodais para 0 valor padrão máximo para o intervalo de confiança de 95\% (média $\left.+22^{*} \mathrm{DP}\right)$. Demonstraram-se valores para o eixo menor acima de $10 \mathrm{~mm}$ na maioria das cadeias, com exceção das cadeias 2L, 6 e 9R (TABELA 5). 
TABELA 5 - TAMANHO PADRÃO MÁXIMO PARA ÁREA, EIXO MAIOR E EIXO MENOR (MÉDIA + 2*DP)

\begin{tabular}{lccc}
\hline Região & Área $\left(\mathrm{mm}^{2}\right)$ & Eixo maior $(\mathrm{mm})$ & Eixo menor $(\mathrm{mm})$ \\
\hline 1 & 117,73 & 16,23 & 10,66 \\
$2 \mathrm{~L}$ & 80,17 & 13,53 & 8,71 \\
$2 \mathrm{R}$ & 149,17 & 17,79 & 10,78 \\
$3 \mathrm{a}$ & 188,51 & 23,42 & 11,42 \\
$3 \mathrm{p}$ & 112,99 & 15,35 & 10,59 \\
$4 \mathrm{~L}$ & 124,29 & 17,74 & 10,31 \\
$4 \mathrm{R}$ & 268,76 & 29,54 & 15,87 \\
5 & 165,13 & 19,75 & 11,68 \\
6 & 116,77 & 17,20 & 9,56 \\
7 & 348,56 & 33,30 & 19,02 \\
8 & 164,04 & 23,63 & 10,67 \\
$9 \mathrm{~L}$ & 145,77 & 18,76 & 10,53 \\
9R & 106,55 & 17,31 & 9,19 \\
\hline \hline
\end{tabular}

Para a escolha do tipo de medida que pudesse apresentar menor variabilidade, foram determinados os coeficientes de variação para a área, eixo menor e eixo maior. Em negrito estão demarcados os menores coeficientes de variação para cada cadeia, que refletem a porcentagem de variação para cada tipo de medida. As medidas do eixo menor apresentaram menores variações na maioria das cadeias linfonodais. Estes dados estão expressos na TABELA 6. 
TABELA 6 - COEFICIENTES DE VARIAÇÃO DAS MEDIDAS DE ÁREA, EIXO MAIOR E MENOR.

\begin{tabular}{lccc}
\hline Região & Área & Maior & Menor \\
\hline 1 & 77,477 & 41,091 & $\mathbf{3 8 , 9 4 0}$ \\
2L & 79,291 & $\mathbf{3 9 , 3 1 9}$ & 41,193 \\
2R & 104,639 & 49,210 & $\mathbf{4 5 , 2 2 3}$ \\
3a & 99,133 & 57,624 & $\mathbf{3 9 , 9 0 0}$ \\
3p & 79,456 & 39,603 & 44,749 \\
$4 \mathrm{~L}$ & 79,917 & 47,441 & $\mathbf{4 1 , 9 3 1}$ \\
$4 \mathrm{R}$ & $\mathbf{2 3 , 1 6 9}$ & 57,661 & 45,607 \\
5 & 70,971 & 39,928 & $\mathbf{3 4 , 5 1 8}$ \\
6 & 74,580 & 44,410 & $\mathbf{3 4 , 9 9 6}$ \\
7 & $\mathbf{1 3 , 5 4 1}$ & 38,814 & 37,111 \\
8 & 87,098 & 55,084 & $\mathbf{4 1 , 8 0 0}$ \\
9L & 92,885 & 50,112 & $\mathbf{3 8 , 8 5 0}$ \\
9R & 92,177 & 49,808 & $\mathbf{3 9 , 7 8 1}$ \\
\hline \hline
\end{tabular}

\subsection{As diversas variáveis e o número linfonodal}

Analisou-se a correlação entre o número de linfonodos e as variáveis idade, peso e altura através do coeficiente de correlação de Pearson. Foi observado, por meio dos valores obtidos, que o número de linfonodos não apresentou correlação significativa com estes fatores. A presença ou ausência das cadeias não se correlacionou com as diversas variáveis.

Também foram analisadas as possíveis associações entre o sexo, raça e congestão para o número de linfonodos por cadeia. Observou-se que não há diferença entre os sexos, ou entre as raças, para o número de linfonodos. A causa mortis foi estudada para o grupo de doenças congestivas e as nãocongestivas, também se evidenciando a ausência de diferença do número de linfonodos nestes grupos. 


\subsection{As diversas variáveis e os tamanhos dos linfonodos}

O tamanho dos linfonodos foi analisado de acordo com o sexo, raça e causa mortis. Estas não se associaram a variações dos tamanhos linfonodais. Também não houve correlação dos tamanhos dos linfonodos em função de idade, altura, peso ou valor de coalescência.

\subsection{Comparações entre os parâmetros analisados}

\subsubsection{O número de linfonodos e os outros parâmetros avaliados}

O número de linfonodos aumentou à proporção do aumento do número de cadeias linfonodais presentes $(p<0,01)$. A comparação do número linfonodal com o valor de coalescência, por sua vez, demonstrou correlação significativa $(p<0,05)$ entre a diminuição do número de linfonodos e 0 aumento do valor de coalescência (GRÁFICO 2). 
GRÁFICO 2 - NÚMERO LINFONODAL E O VALOR DE COALESCÊNCIA.

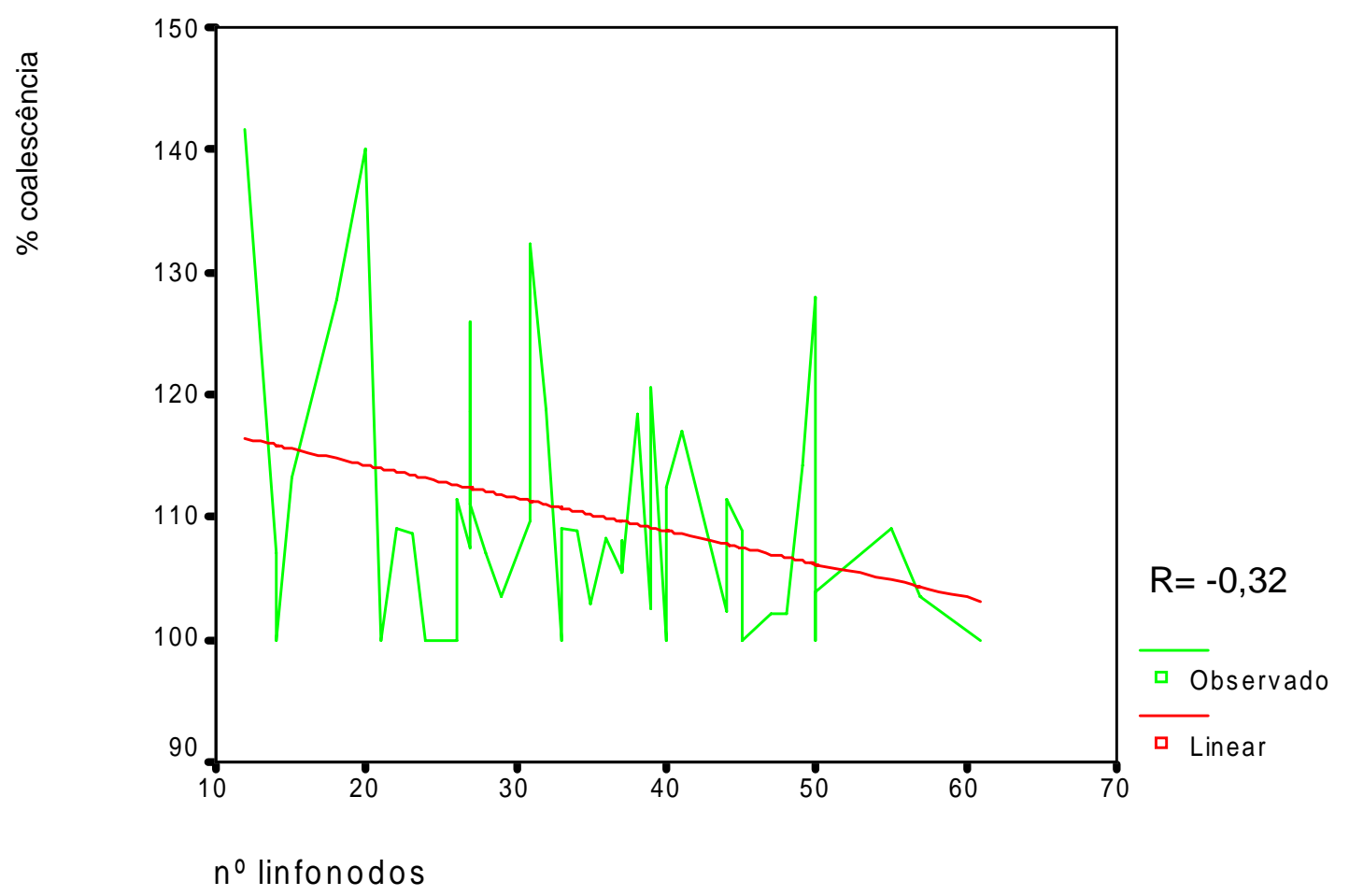

O tamanho do eixo maior apresentou-se significantemente menor $(p<0,05)$ à medida que aumentou o número de linfonodos (GRÁFICO 3). Os valores do eixo menor e área, embora não-significantes, também tenderam a diminuir à medida que aumentou o número de linfonodos. 
GRÁFICO 3 -NÚMERO DE LINFONODOS E O EIXO MAIOR.

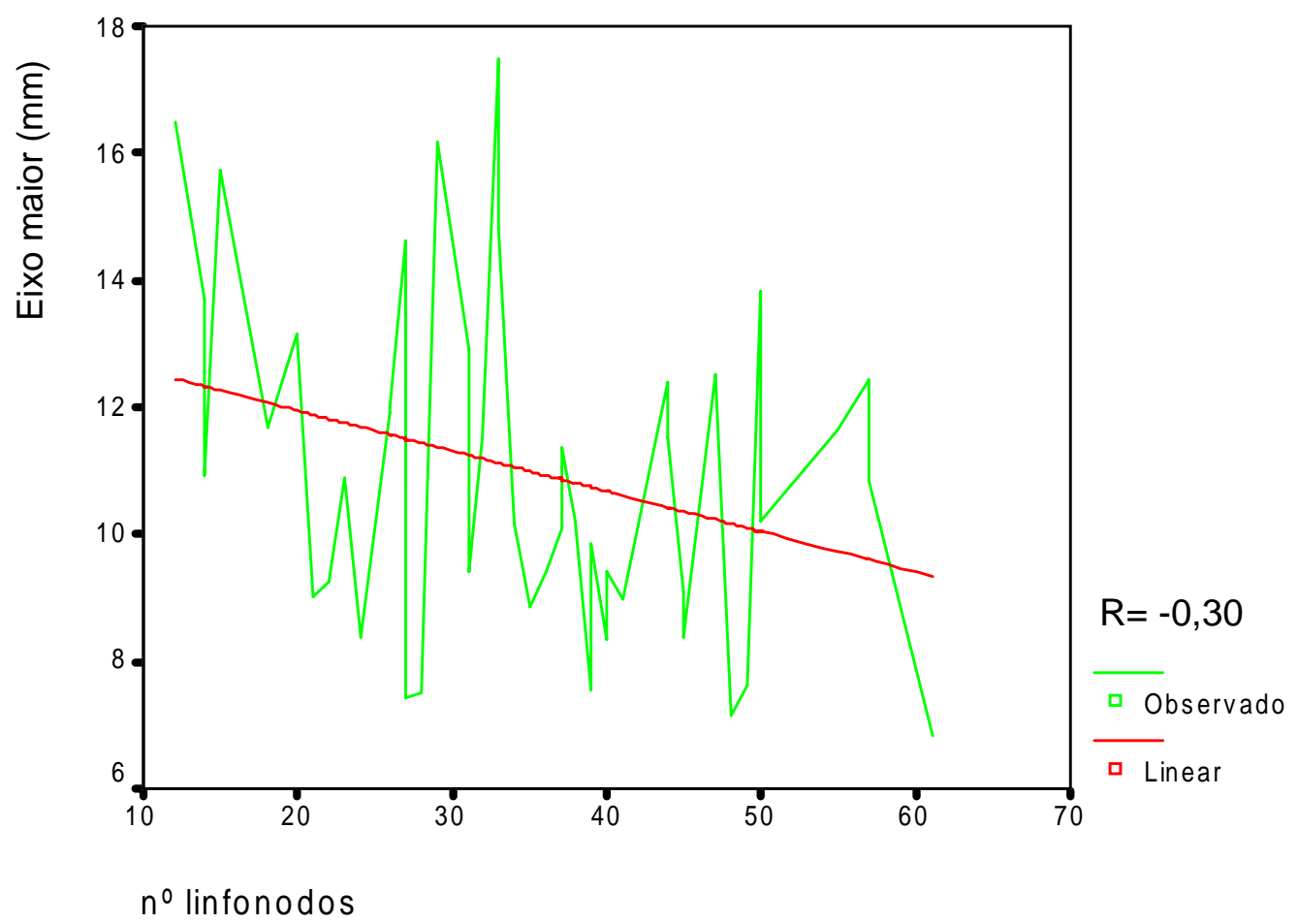

\subsubsection{O tamanho linfonodal e os outros parâmetros avaliados.}

Através da análise de variância observou-se diferença significativa do tamanho dos linfonodos $(p<0,001)$. Por meio das comparações múltiplas realizadas através do teste de Bonferroni, observou-se diferença significativa da cadeia 7 para as demais $(p<0,05)$. A cadeia $4 R$ diferiu significativamente de quase todas as outras $(p<0,05)$, exceto das cadeias $3 a, 3 p$ e 5 . As demais cadeias não diferiram entre si (GRÁFICOS 4, 5 e 6). 
GRÁFICO 4 - MÉDIAS DO EIXO MENOR E DE SEUS DESVIOS PADRÕES NAS DIVERSAS CADEIAS.

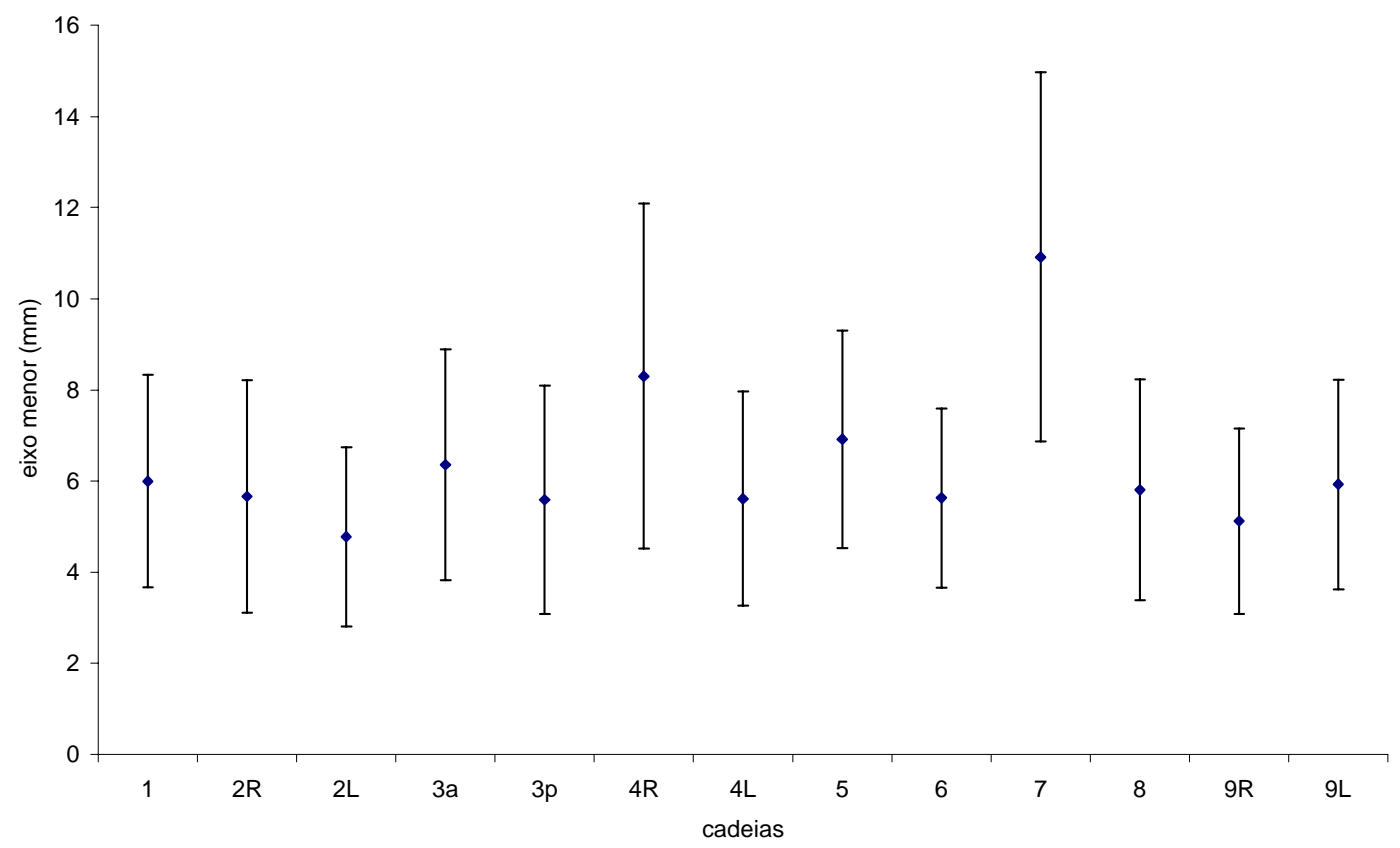

GRÁFICO 5 - MÉDIAS DO EIXO MAIOR E DE SEUS DESVIOS PADRÕES NAS DIVERSAS CADEIAS.

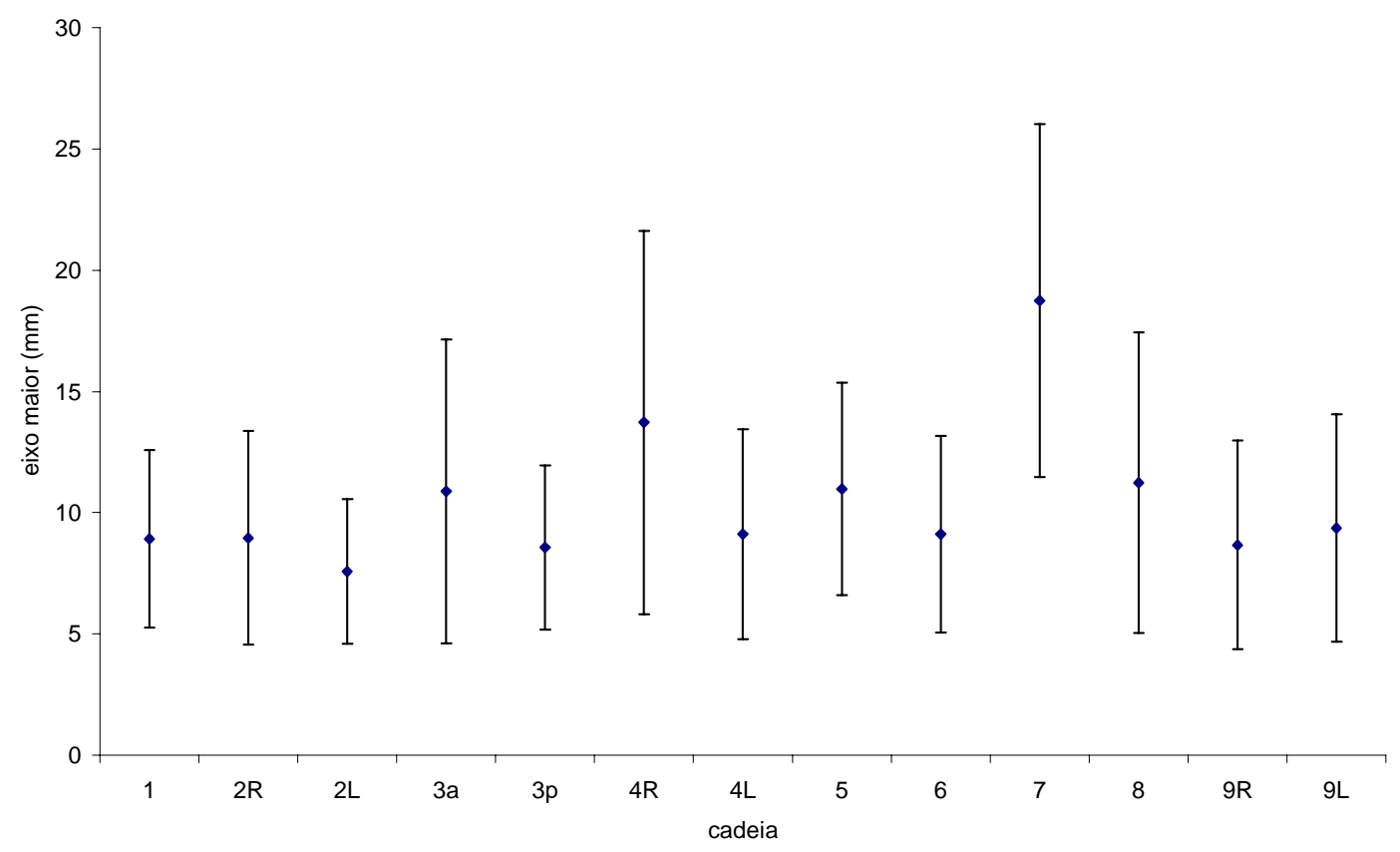


GRÁFICO 6 - MÉDIAS DA ÁREA E DE SEUS DESVIOS PADRÕES NAS DIVERSAS CADEIAS (em $\left.\mathrm{mm}^{2}\right)$.

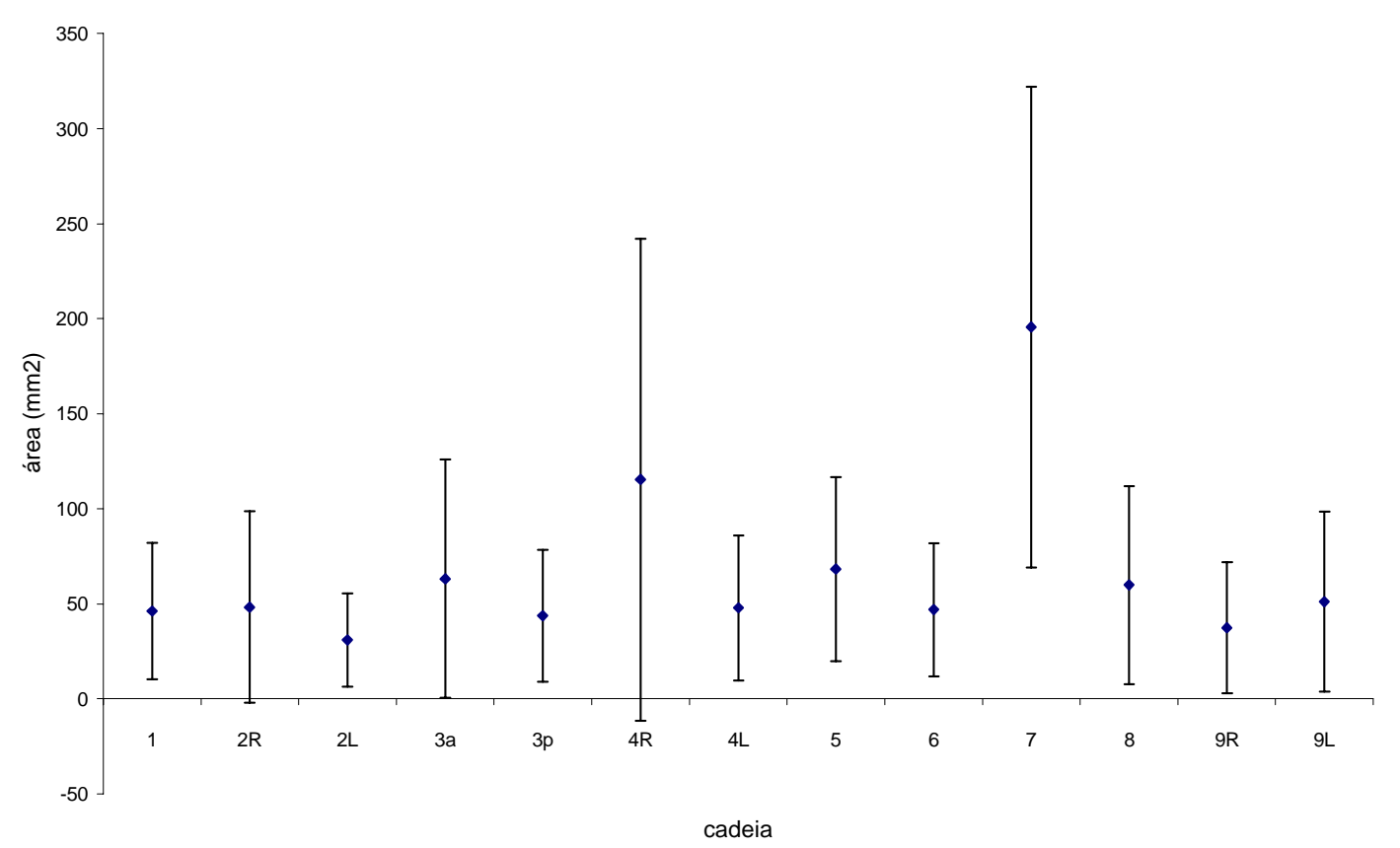

Quanto à analise do tamanho dos linfonodos em comparação direta com os dados de histologia, não se evidenciou a presença de correlações ou associações significativas com estes parâmetros. 


\subsubsection{Comparações entre os parâmetros histológicos.}

Por meio do teste T para amostras independentes verificou-se que a presença de granulomas correlacionou-se de forma significante a um maior valor de coalescência (TABELA 7).

TABELA 7 - ANÁLISE DE ASSOCIAÇÃO ENTRE A VALOR DE COALESCÊNCIA E A PRESENÇA DE GRANULOMA.

\begin{tabular}{|c|c|c|c|c|}
\hline & granuloma & $\mathrm{n}$ & Média & DP \\
\hline $\begin{array}{l}\text { Valor } \\
\text { coalescência }\end{array}$ & $\frac{\text { presente }}{\text { ausente }}$ & $\frac{08}{42}$ & $\begin{array}{l}121,46 \\
108,12\end{array}$ & $\begin{array}{c}14,92 \\
7,63\end{array}$ \\
\hline & & \multicolumn{3}{|c|}{$\begin{array}{l}\text { Teste T para amostras } \\
\text { independentes }\end{array}$} \\
\hline Valor de coa & lescência & \multicolumn{3}{|c|}{$p<0,001^{*}$} \\
\hline
\end{tabular}

As diversas tabelas com a demonstração dos testes que não demonstraram significância estatística estão disponíveis nos ANEXOS. 
6. DISCUSSÃO 


\section{Discussão}

\subsection{Considerações sobre o número de linfonodos}

Há interesse em se determinar o número de linfonodos presentes no mediastino em vista da dissecção linfonodal no câncer de pulmão. Sendo que a dissecção linfonodal radical, com esvaziamento completo do mediastino, é de eficácia terapêutica discutível, entende-se que a representação de todo o mediastino pode revelar com exatidão o estádio patológico do câncer de pulmão.

NARUKE et al. (1999) revisaram as dissecções linfonodais de 1815 pacientes portadores de neoplasia pulmonar que foram submetidos a dissecção linfonodal regrada do mediastino para determinar os linfonodos preferencialmente acometidos (linfonodo sentinela). Sugeriram que, quando 0 linfonodo sentinela está acometido, a dissecção linfonodal completa deve ser realizada.

KIYONO et al. (1988) encontraram em média 30 linfonodos à dissecção bilateral do mediastino em cadáveres. HOKSCH et al. (2000), dissecando cadáveres por videotoracoscopia e toracotomia subseqüente, encontraram média de 31 linfonodos com a inclusão das regiões hilares. NOMORI et al. (2001) encontraram uma média de 18 linfonodos à direita e 13 
à esquerda quando dissecados por toracotomia anterior limitada e 20 à direita e 15 à esquerda quando dissecados por videotoracoscopia.

Os trabalhos brasileiros com dissecção linfonodal revelam um baixo número de linfonodos dissecados no mediastino. FERNANDES (1992) descreveu uma média de 12,7士7,76 linfonodos ressecados em 50 doentes de câncer de pulmão. RODRIGUES et al. (1997), em estudo sobre os fatores prognósticos no câncer de pulmão, identificou retrospectivamente uma média de 14,8 linfonodos dissecados por doente em 65 esvaziamentos radicais unilaterais. PEREIRA et al. (2004), em recente estudo com 46 doentes submetidos a ressecção linfonodal para tratamento de carcinóides brônquicos, identificou, de modo retrospectivo, uma variação de um a 25 linfonodos retirados, com média de 6,5 55,4 linfonodos por doente. O número de linfonodos ressecados na população brasileira, entretanto, parece ser similar ao encontrado em outras populações. Neste estudo foram encontrados números semelhantes ao de NOMORI et al. (2001), tendo sido dissecados por toracotomia em média 21,2 linfonodos no mediastino à direita e 13,6 à esquerda.

A contagem do número de linfonodos foi afetada pela característica de fusão ou coalescência, tendo-se encontrado números diferentes na contagem dos linfonodos dissecados e na recontagem dos mesmos nas lâminas. As fusões linfonodais foram freqüentemente encontradas, estando presentes em $32,2 \%$ das cadeias dissecadas neste estudo.

Embora tenha sido sugerido por GLAZER et al. (1985) um ligeiro aumento no número de linfonodos com o avanço da idade e um número 
maior de linfonodos nas mulheres, no presente estudo este fenômeno não foi observado. A amostra apresentou uma média de idade mais alta. Houve também um menor número de mulheres. Isso pode ter selecionado uma população em que a variação do número linfonodal não foi importante.

\subsection{Considerações sobre o tamanho linfonodal}

No fluxo linfático, os linfonodos são órgãos linfóides periféricos conectados por meio de linfáticos aferentes e eferentes. Mantém as funções de linfopoiese, filtração da linfa e processamento de antígenos. Vários fatores podem influir no tamanho dos linfonodos mediastinais. A adenomegalia pode ser a primeira manifestação de algumas doenças neoplásicas, primárias ou metastáticas, assim como de algumas doenças inflamatórias ou granulomatosas.

MURRAY et al. (1995) observaram que a tuberculose causou um aumento residual dos linfonodos mediastinais. GUPTA et al. (2000) compararam a eficácia da tomografia por emissão de pósitrons (PET scan) com a tomografia na detecção de acometimento linfonodal por neoplasia. Nos oito linfonodos maiores que $3 \mathrm{~cm}$ que encontraram, três apresentavam granulomas, tendo observado menor especificidade do PET scan para estes tamanhos (75\%).

Similarmente, no presente estudo, as medidas do eixo maior foram significantemente maiores nos casos em que se observaram granulomas cicatriciais em alguns linfonodos. A incidência de doenças granulomatosas 
pode afetar o valor referencial adotado para o tamanho linfonodal. Achados de acometimento por neoplasia em linfonodos menores que $1 \mathrm{~cm}$ em populações com alta incidência de doenças granulomatosas foram comprovadamente menores (FERNANDEZ, 1992).

ERLY et al. (2003), em estudo tomográfico dos linfonodos mediastinais de pacientes portadores de insuficiência cardíaca grave, em programa de transplante cardíaco, encontraram aumento linfonodal em $81 \%$ dos pacientes que apresentavam fração de ejeção calculada ao ecocardiograma menor que $35 \%$. O aumento linfonodal foi maior principalmente na região pré-traqueal (cadeia 3a). O aumento linfonodal não se associou com o achado de congestão pulmonar. No presente estudo, o tamanho linfonodal também não apresentou alterações significativas com a presença de congestão pulmonar.

Embora existam controvérsias quanto à definição de um valor ideal, o limite máximo de $1 \mathrm{~cm}$ no eixo menor foi utilizado para linfonodos por vários autores (LIBSHITZ e McKENNA, 1984; GLAZER et al., 1985; McLOUD et al., 1991; MURRAY et al., 1995; ARITA et al., 1996; ERLY et al., 2003).

Neste estudo, os valores dos tamanhos linfonodais foram superiores aos encontrados por outros autores. O GRÁFICO 6 demonstra a comparação das médias do eixo menor linfonodal relatados pelos autores, levando-se em conta as modificações dos descritores dos mapas das cadeias linfonodais. 


\section{GRÁFICO 6 - TAMANHO DAS MÉDIAS DO EIXO MENOR DO LINFONODOS MEDIASTINAIS SEGUNDO O AUTOR.}

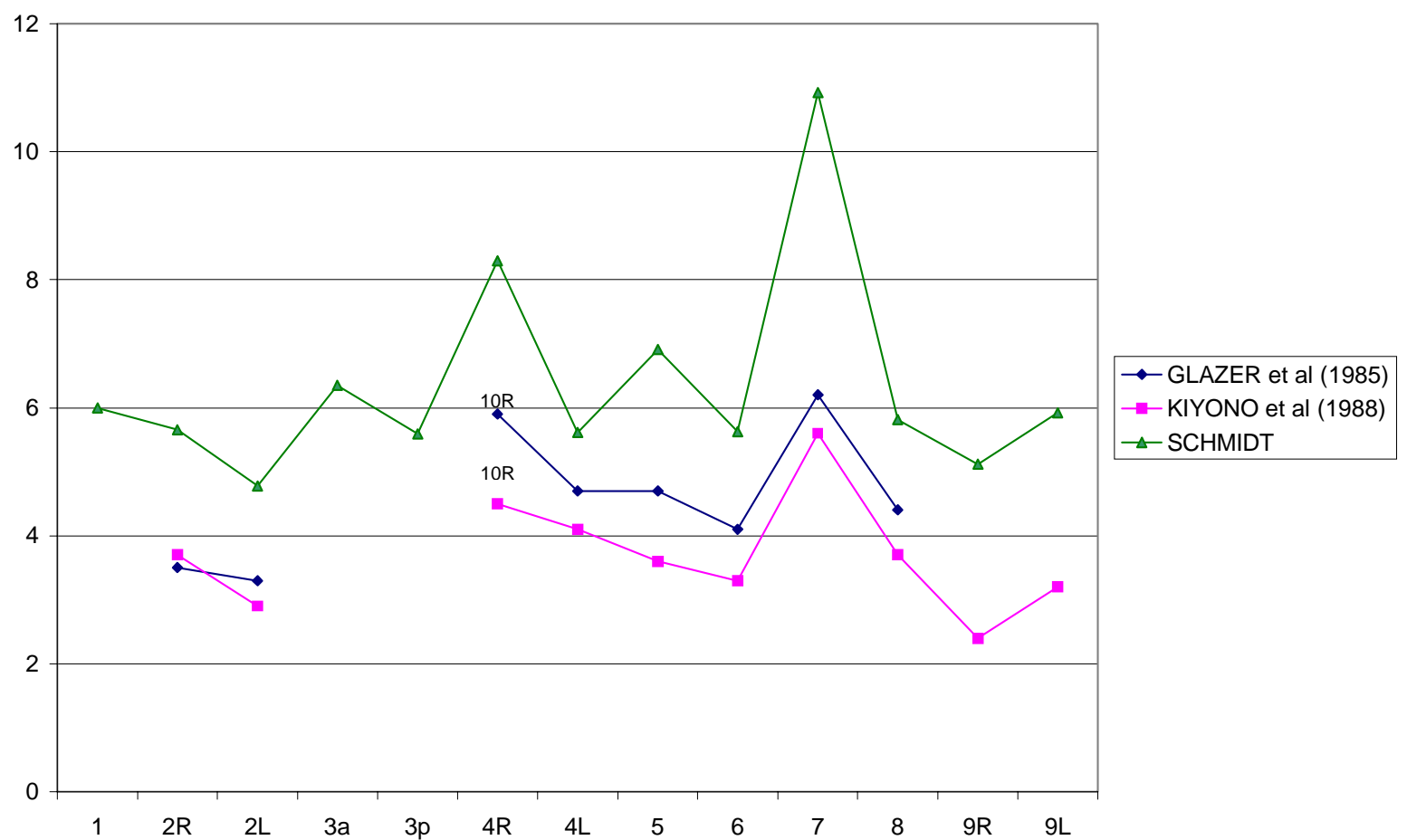

O tamanho dos linfonodos não foi uniforme entre as cadeias, tendo sido encontradas médias do eixo menor para a cadeia 7 significativamente maiores do que as demais. A cadeia 4R demonstrou a segunda maior média, o que é coincidente com o estudo de GENEREUX e HOWIE (1984) no qual houve uma diferença significativa das dimensões dos linfonodos entre aqueles localizados no mediastino superior em relação aos contíguos à carina.

A utilização do valor determinado para o intervalo de confiança de $95 \%$ definiu para o eixo menor um valor de até $12 \mathrm{~mm}$ para a maioria das cadeias linfonodais, com exceção das cadeias $4 \mathrm{R}$ e 7 . Valores máximos diferentes para cada região do mediastino foram adotados por KIYONO et al. (1988). Na 
TABELA 8, as regiões subcarinal (cadeia 7) e paratraqueal direita baixa (cadeia 4R) são classificadas de modo independente das demais de acordo com seu tamanho padrão máximo.

TABELA 8 - CLASSIFICAÇÃO SEGUNDO O TAMANHO PADRÃO MÁXIMO (MÉDIA + 2*DP) DAS CADEIAS LINFONODAIS.

\begin{tabular}{|l|c|c|c|}
\hline Cadeia & Área $\left(\mathrm{mm}^{2}\right)$ & Eixo maior $(\mathrm{mm})$ & Eixo menor $(\mathrm{mm})$ \\
\hline 7 & 350 & 34 & 20 \\
\hline $4 \mathrm{R}$ & 270 & 30 & 16 \\
\hline As demais & 190 & 24 & 12 \\
\hline
\end{tabular}

\subsection{Considerações sobre o método de medida}

A utilização do método de mensuração digital para a definição dos eixos e área de cada linfonodo, facilmente definiu os eixos principais e a área de estruturas linfonodais irregulares, apresentando vantagens em relação ao método de aferição por paquímetro utilizado por outros autores. Foi mais preciso e não dependeu da subjetividade na definição dos eixos maior e o menor. À semelhança da maneira de aferição dos equipamentos de imagem, foi possível definir a área linfonodal. Estes dados poderão servir de base para estudos em que interessa a expressão de um sinal radiológico por área, tais 
como a tomografia computadorizada, os métodos cintilográficos ou de emissão de pósitrons.

Embora fosse esperado que os valores obtidos para área pudessem representar com mais acurácia o tamanho linfonodal, assim como proposto por GLAZER et al. (1985), as medidas apresentaram coeficientes de variação mais altos na maioria das cadeias. Apresentaram menor variação apenas para os linfonodos das cadeias 4R e 7. Portanto, representou um parâmetro mais seguro para a avaliação de alterações do tamanho em linfonodos grandes que eram, geralmente, irregulares.

\subsection{Considerações sobre a localização dos linfonodos no mediastino.}

Há necessidade de um padrão de definições para as cadeias linfonodais de forma a permitir as comparações de resultados entre diferentes amostras populacionais. No entanto, a definição das posições das cadeias mediastinais descritas no mapa segundo NARUKE/ATS-LCSG1 pode gerar discrepâncias.

CAPLAN (1990) apresentou o linfonodo do ângulo braquiocefálico à direita, citando a descrição original de BARTEL, em 1909, como o linfonodo mais inferior ao grupo da cadeia braquiocefálica direita, localizado no mediastino anterior (pré-visceral) superior. MOUNTAIN e DRESSLER (1997), porém, referem-se apenas aos linfonodos da cadeia 1 como aqueles

\footnotetext{
${ }^{1}$ American Thoracic Society - Lung Cancer Study Group
} 
localizados acima de uma linha horizontal imaginária traçada acima da borda superior da veia braquiocefálica esquerda, de onde ela ascende para a esquerda e cruza em frente à traquéia na linha média. Há diferença de localização e, provavelmente, de conexões linfáticas entre os linfonodos localizados no ângulo venoso compreendido pela veia braquiocefálica à direita e pelos linfonodos encontrados junto à alça do nervo recorrente ao nível da artéria subclávia direita. Poderia ser considerado mais adequado nomear como cadeia 1a (anterior) os linfonodos compreendidos pelo ângulo venoso das veias braquiocefálicas e o como cadeia $1 p$ (posterior) os linfonodos justapostos à alça do nervo recorrente.

A individualização das cadeias linfonodais ressecadas fora do paciente acrescenta subjetividade à denominação das cadeias. Baseia-se em divisões por aspectos visíveis apenas à tomografia e não observáveis durante a dissecção. As cadeias localizadas à direita da traquéia apresentam-se em um bloco linfoadiposo único, separado, muitas vezes com dificuldade, em três cadeias numeradas como 2R, 3a e 4R. A dificuldade de se definir as cadeias na região paratraqueal direita poderia ser resolvida com a adoção de uma única nomenclatura para os linfonodos localizados desde o ângulo obtuso formado pela traquéia com o brônquio principal direito até aqueles localizados à margem superior da veia ázigos, como proposto por NARUKE et al. (1978). Estes autores definiram esta região como a cadeia $4 \mathrm{R}$ e, acima desta, à direita da traquéia até abaixo dos linfonodos da região 1 , como cadeia $2 \mathrm{R}$.

A adoção de técnica operatória na dissecção dos cadáveres desta pesquisa procurou reproduzir as peculiaridades do acesso às cadeias 
linfonodais segundo os mapas existentes, preservando-se a sintopia. Algumas características ficaram evidentes quando da realização das dissecções dos linfonodos mediastinais. As cadeias linfonodais apresentaram grande variabilidade de posição. Raramente todas as cadeias estavam presentes em um mesmo indivíduo. Os linfonodos em geral não estavam evidentes, sendo necessária sua busca no mediastino de forma diligente durante a dissecção. $\mathrm{O}$ acesso a algumas cadeias linfonodais foi mais fácil no cadáver do que seria no paciente, mormente às cadeias $2 \mathrm{~L}$ e $4 \mathrm{~L}$ compreendidas entre a aorta e a traquéia. Nesta situação, a aorta túrgida poderia apresentar maiores dificuldades para sua mobilização e dificultar a ressecção linfonodal. 
7. CONCLUSÕES 


\section{Conclusões}

A distribuição, número e tamanho dos linfonodos não apresentaram alterações significativas para o intervalo de idades estudado. Não sofreu influência do sexo, raça, peso, altura ou causa mortis.

O tamanho linfonodal aumentou em função da coalescência por processos granulomatosos, com conseqüente diminuição do número total dos linfonodos mediastinais. 
8. ANEXOS 
ANEXO A - MAPA DAS CADEIAS LINFONODAIS SEGUNDO

NARUKE/ATS-LCSC $C^{2}$

(MOUNTAIN; DRESLER,1997)

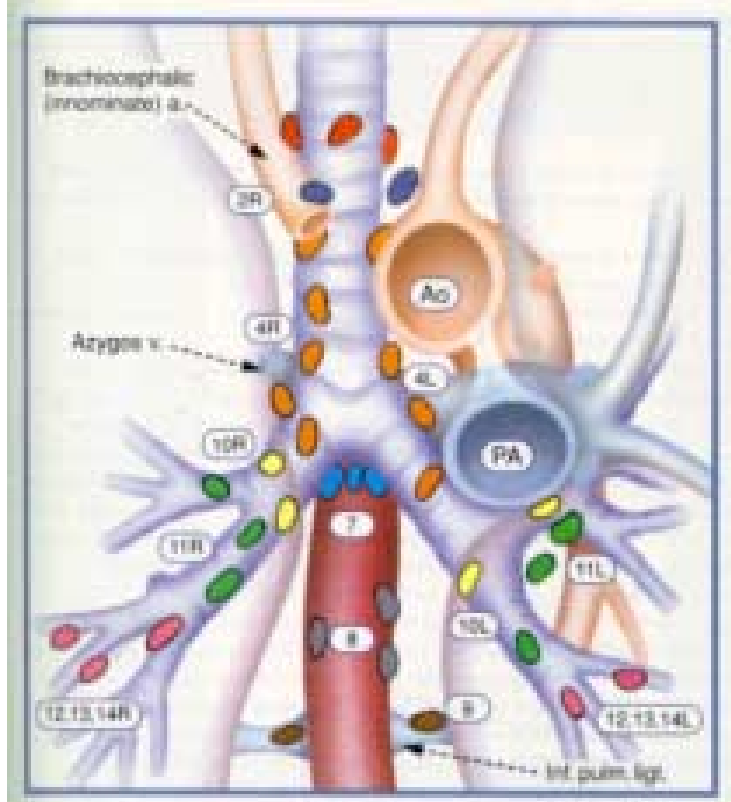

Superior Mediastinal Nodes

1 Highest Mediastinal

- 2 Upper Paratracheal

3 Pre-vascular and Retrotracheal

- 4 Lower Paratracheal (including Azygos Nodes)

$N_{3}=$ singie digh, ipailateral

$\mathrm{N}_{3}=$ single digl, esniraiateral ar supractavicutar

\section{Aortic Nodes}

5 Subaortic (A-P window)

6 Para-aortic (ascending aorta or phrenic)

\section{Inferior Mediastinal Nodes}

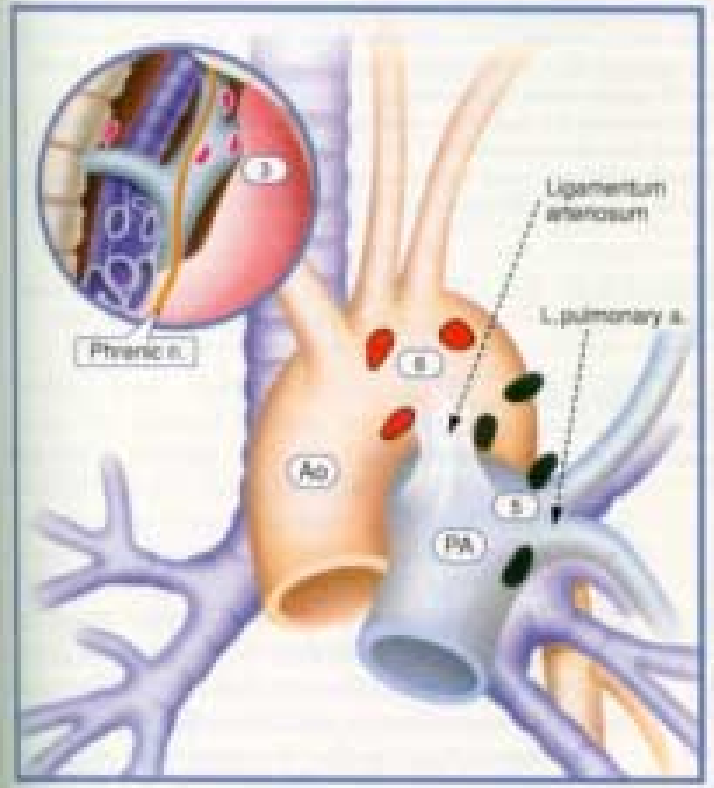

7 Subcarinal

8 Paraesophageal (below carina)

9 Pulmonary Ligament

\section{$\mathbf{N}_{1}$ Nodes}

10 Hilar

11 Interlobar

12 Lobar

13 Segmental

14 Subsegmental

\footnotetext{
${ }^{2}$ American Thoracic Society - Lung Cancer Study Group
} 


\section{ANEXO B - RELAÇÃO DOS CASOS DISSECADOS}

\begin{tabular}{|c|c|c|c|c|c|c|c|c|}
\hline Caso & Idade & Sexo & Altura $(\mathrm{cm})$ & Peso (kg) & Raça & Causa Mortis 1 & Causa Mortis 2 & Causa Mortis 3 \\
\hline 1 & 59 & $\mathrm{M}$ & 178 & 70 & Branco & Edema pulmonar & Cardiopatia hipertrofica & HAS \\
\hline 2 & 70 & M & 180 & 80 & Branco & Edema pulmonar & Trombose VE & Cardiopatia hipertrófica \\
\hline 3 & 41 & M & 171 & 59 & Negro & Edema pulmonar & Cardiopatia hipertrofica & HAS \\
\hline 4 & 83 & M & 160 & 31 & Branco & Broncopneumonia & DPOC & \\
\hline 5 & 48 & M & 180 & 71 & Branco & Edema pulmonar & $\begin{array}{l}\text { Pericardite aguda fibrino } \\
\text { hemorrágica }\end{array}$ & \\
\hline 6 & 90 & $\mathrm{~F}$ & 170 & 66 & Pardo & Indeterminada & & \\
\hline 8 & 81 & M & 170 & 56 & Pardo & Edema pulmonar & IAM & Cardiopatia hipertrófica \\
\hline 9 & 61 & $\mathrm{~F}$ & 168 & 58 & Branco & IAM & & \\
\hline 10 & 78 & M & 180 & 80 & Branco & Trombose mesentérica & & \\
\hline 11 & 66 & $\mathrm{~F}$ & 150 & 65 & Negro & Edema pulmonar & IAM & \\
\hline 12 & 43 & $\mathrm{~F}$ & 170 & 114 & Negro & Edema pulmonar & & \\
\hline 13 & 56 & M & 170 & 70 & Branco & Insuf cardiaca & Miocardiopatia isquêmica & \\
\hline 14 & 74 & M & 180 & 75 & Branco & Insuf respiratória & DPOC & \\
\hline 16 & 46 & $\mathrm{~F}$ & 160 & 55 & Branco & Insuf respiratória & Broncopneumonia & \\
\hline 17 & 77 & $\mathrm{~F}$ & 160 & 50 & Branco & Edema pulmonar & Cardiopatia hipertrofica & \\
\hline 18 & 42 & M & 180 & 70 & Branco & Edema pulmonar & ICC & \\
\hline 19 & 48 & M & 180 & 80 & Branco & Edema pulmonar & IAM & \\
\hline 20 & 77 & M & 180 & 68 & Branco & Empiema de vesícula & Colecistopatia crônica calculosa & \\
\hline 21 & 52 & M & 170 & 75 & Branco & Edema pulmonar & IAM & HAS \\
\hline 22 & 62 & M & 170 & 63 & Negro & Edema pulmonar & HAS & \\
\hline 23 & 42 & M & 180 & 66 & Branco & Pancreatite aguda hemorrágica & Etilismo crônico & \\
\hline 24 & 45 & M & 180 & 75 & Branco & IAM & Coronarioesclerose & HAS \\
\hline 25 & 48 & M & 180 & 80 & Pardo & Edema pulmonar & HAS & \\
\hline 26 & 45 & M & 170 & 70 & Branco & Edema pulmonar & IAM & Cardiopatia hipertrófica \\
\hline
\end{tabular}




\begin{tabular}{|c|c|c|c|c|c|c|c|c|}
\hline Caso & Idade & Sexo & Altura $(\mathrm{cm})$ & Peso (kg) & Raça & Causa Mortis 1 & Causa Mortis 2 & Causa Mortis 3 \\
\hline 27 & 57 & $\mathrm{M}$ & 170 & 78 & Branco & IAM & Aterosclerose & \\
\hline 28 & 51 & $\mathrm{~F}$ & 160 & 70 & Branco & Cardiopatia hipertrofica & HAS & \\
\hline 29 & 61 & M & 175 & 80 & Branco & Trauma craniano & & \\
\hline 30 & 65 & M & 180 & 80 & Branco & Edema pulmonar & IAM & Arterioesclerose \\
\hline 31 & 53 & M & 170 & 70 & Branco & Broncopneumonia aspirativa & & \\
\hline 32 & 57 & M & 180 & 85 & Branco & Edema pulmonar & Miocardiopatia isquêmica & Arterioesclerose \\
\hline 33 & 84 & M & 170 & 70 & Branco & Edema pulmonar & IAM & Miocardiopatia isquêmica \\
\hline 34 & 73 & M & 170 & 60 & Branco & Cirrose hepática mista & Etilismo crônico & \\
\hline 35 & 47 & M & 180 & 65 & Branco & Edema pulmonar & IAM & HAS \\
\hline 36 & 67 & $\mathrm{~F}$ & 170 & 67 & Negro & Edema pulmonar & Miocardiopatia isquêmica & HAS \\
\hline 37 & 65 & M & 175 & 75 & Branco & Edema pulmonar & HAS & \\
\hline 38 & 44 & M & 180 & 85 & Branco & Anasarca & Cirrose hepática mista & \\
\hline 39 & 63 & M & 180 & 75 & Branco & Miocardioesclerose & Aterosclerose & \\
\hline 40 & 75 & $\mathrm{~F}$ & 160 & 60 & Branco & Edema pulmonar & HAS & \\
\hline 41 & 49 & M & 170 & 63 & Branco & AVC isquêmico & & \\
\hline 42 & 38 & M & 180 & 78 & Branco & Edema pulmonar & Miocardiopatia isquêmica & \\
\hline 43 & 61 & M & 180 & 78 & Negro & Tromboembolismo pulmonar & & \\
\hline 44 & 55 & M & 180 & 76 & Branco & Edema pulmonar & Diabete melito & \\
\hline 45 & 47 & $\mathrm{~F}$ & 170 & 69 & Pardo & Hemorragia digestiva alta & Cirrose hepática mista & Etilismo crônico \\
\hline 46 & 83 & M & 180 & 77 & Branco & Broncopneumonia & Etilismo crônico & \\
\hline 47 & 50 & M & 185 & 75 & Negro & Tromboembolismo pulmonar & Miocardiopatia isquêmica & Ateroesclerose \\
\hline 48 & 68 & $\mathrm{~F}$ & 170 & 65 & Branco & Edema pulmonar & Miocardiopatia isquêmica & Ateroesclerose \\
\hline 49 & 36 & M & 180 & 70 & Branco & Broncoaspiração & Esofagite crônica ulcerada & Etilismo crônico \\
\hline 50 & 65 & $\mathrm{~F}$ & 170 & 95 & Branco & Edema pulmonar & HAS & \\
\hline
\end{tabular}


ANEXO C - NÚMERO DE CADEIAS ENCONTRADAS À DISSECÇÃO

\begin{tabular}{lcrc}
\hline \multicolumn{1}{c}{ Cadeia } & Presentes & Ausentes & \% presença \\
\hline 1 & 45 & 5 & 90 \\
$2 \mathrm{R}$ & 49 & 1 & 98 \\
$2 \mathrm{~L}$ & 16 & 34 & 32 \\
$3 \mathrm{a}$ & 36 & 14 & 72 \\
$3 \mathrm{p}$ & 18 & 32 & 36 \\
$4 \mathrm{R}$ & 50 & 0 & 100 \\
$4 \mathrm{~L}$ & 42 & 8 & 84 \\
5 & 46 & 4 & 92 \\
6 & 42 & 8 & 84 \\
7 & 50 & 0 & 100 \\
8 & 27 & 23 & 54 \\
$9 \mathrm{R}$ & 30 & 20 & 60 \\
$9 \mathrm{~L}$ & 34 & 16 & 68 \\
\hline Total & 485 & 165 & $74,6 \%$ \\
\hline \hline
\end{tabular}


ANEXO D - MEDIDAS DA ÁREA LINFONODAL POR CADEIA

\begin{tabular}{|c|c|c|c|c|c|c|c|c|c|c|c|c|c|c|}
\hline & & 1 & $2 R$ & $2 \mathrm{~L}$ & $3 a$ & $3 p$ & 4R & 4L & 5 & 6 & 7 & 8 & 9R & $9 \mathrm{~L}$ \\
\hline Caso & 1 & 113,35 & & 89,47 & 91,11 & 103,63 & 72,09 & 66,64 & 247,28 & 32,48 & 61,92 & 44,26 & 22,48 & \\
\hline Caso & 2 & 23,24 & 46,53 & & 39,63 & 19,67 & 23,92 & & 17,39 & 19,75 & 121,43 & 61,04 & & 25,35 \\
\hline Caso & 3 & 24,56 & 42,9 & & 53,77 & & 87,29 & & 44,83 & & 73,15 & 136,55 & 45,15 & \\
\hline Caso & 4 & & 50,86 & & 36,06 & 54,58 & 52,42 & 94,87 & & 49,37 & 158,53 & 25,06 & 22,02 & \\
\hline Caso & 5 & 28,23 & 28,99 & 46,8 & 57 & & 543 & & 82,61 & 112,68 & 281,24 & & 52,81 & 80,21 \\
\hline Caso & 6 & 163,6 & 60,73 & & & & 72,19 & & 71,88 & 39,99 & 249,81 & 9,13 & 52,69 & 62,83 \\
\hline Caso & 7 & 34,08 & 42,91 & & & & 256,7 & 46,02 & 115,14 & & 613,2 & 52,76 & & \\
\hline aso & 8 & 35,64 & 108,04 & & & & 29,41 & 47,4 & & 59,14 & 71,8 & 11,35 & 10,96 & 59,25 \\
\hline Caso & 9 & 52,87 & 32,74 & 32,6 & 175 & & 129,05 & & & & 132,71 & & & \\
\hline aso & 10 & 45,41 & 42,81 & & 30,08 & 29,5 & 99,99 & & 66,57 & & 159,28 & 122,56 & & 16,85 \\
\hline aso & 11 & 14,78 & 24,95 & & & & 99,69 & 116,68 & 75,82 & 50,63 & 136,81 & 44,76 & 22,48 & 5,01 \\
\hline aso & 12 & & 20,5 & & & & 33,2 & & 162,41 & 14,44 & . 26,71 & 15,03 & & 21,75 \\
\hline aso & 13 & 54,31 & 33,54 & 75,96 & & & 127,33 & 119,77 & 83,1 & 75,67 & 255,68 & & & 35,92 \\
\hline aso & 14 & 35,08 & 35,63 & 46,08 & 91,09 & & 94,61 & 17 & 32,12 & 98,27 & 244,44 & & 14,62 & \\
\hline aso & 15 & 89,13 & 66,53 & & 86,07 & 12,41 & 98,98 & 93,23 & 103,34 & 5,2 & 182,87 & & 21,8 & 28,64 \\
\hline aso & 16 & 30,94 & 24,86 & & 233,28 & & 83,43 & 27,9 & 40,24 & & 126 & 18,1 & & 46,83 \\
\hline aso & 17 & 50,02 & 38,25 & 20,27 & 314,45 & & 106,81 & 23,73 & 80,38 & 29,79 & 111,88 & & ,85 & 78,25 \\
\hline aso & 18 & 58,69 & 54,64 & 31,58 & 40,58 & 81,34 & 314, & & 42,95 & 163,28 & 174,25 & 132,44 & 3,6 & \\
\hline aso & 19 & 19,09 & 44,73 & & 43,21 & 16,83 & 28,32 & 33,74 & 47,76 & 57,53 & 100,93 & & 52,41 & 52,42 \\
\hline aso & 20 & 65,6 & 51,22 & & & & 89,14 & & 111,76 & 29,27 & 147,4 & & & 92,47 \\
\hline aso & 21 & 21,73 & 46,45 & & 8,32 & 20,37 & 55,65 & 2,84 & 19,08 & 18 & 188 & & & 35,66 \\
\hline aso & 22 & 16,4 & 74,41 & & & & 299,88 & 31,03 & 46,55 & 151 & 281,6 & 21,25 & & \\
\hline aso & 23 & 17,73 & & & 22,91 & & 44,72 & 10,33 & 58,71 & 36,16 & 30,63 & & & 34,79 \\
\hline Caso & 24 & 76,35 & 4,11 & 14,72 & & & 31,65 & 20,07 & 23 , & & 38,32 & & & 32,76 \\
\hline aso & 25 & 38,17 & 23,11 & & 28,07 & 23,11 & 95,28 & 17,02 & 35 , & 59 & 119 & 60,21 & 38,74 & 24,05 \\
\hline aso & 26 & 38,69 & 30,37 & & 8,96 & & 51,19 & 20,33 & 55,64 & & 290 & & & 63,82 \\
\hline aso & 27 & 130,16 & 182,84 & & 35,42 & & 130,7 & 69,31 & 3,4 & 38 & 93,58 & & & 18,15 \\
\hline aso & 28 & 22,01 & 68,59 & & 61,09 & & 132,97 & 115,75 & 58,42 & 57,38 & 420,52 & & 39,02 & 62,15 \\
\hline Caso & 29 & 4,01 & 32,55 & & 32,86 & & 134,35 & 32,22 & 67, & & 247 & & 31,33 & \\
\hline aso & 30 & 39,34 & 34,71 & 9,45 & 125,02 & & 27 & 7,44 & 23,35 & & 128,97 & & & 65,05 \\
\hline aso & 31 & 128,16 & 18,21 & & 43,12 & & 69,82 & 113,57 & 166,61 & 64,29 & & & & 16,25 \\
\hline aso & 32 & 64,15 & 107,64 & & 35,01 & & 157,04 & - 62,02 & & & 228 & & 75,76 & 122,45 \\
\hline aso & 33 & 25,32 & 9,91 & & 59,16 & & 97,64 & 123,95 & 66,49 & 26,88 & 198,16 & 12,81 & 18,23 & \\
\hline aso & 34 & 17,44 & 36,8 & 32,09 & 39,95 & 83,07 & 145,31 & 74,09 & 39,27 &, 5 & 257,5 & 21,82 & & \\
\hline aso & 35 & & 26,09 & 18,76 & & & 672,86 & 109,55 & 112 & & 248,72 & & & \\
\hline Caso & 36 & 10,93 & 16,92 & & & 16,89 & 68,39 & 29,85 & 55,15 & 17,13 & 138,5 & & 11,21 & 32,59 \\
\hline Caso & 37 & 15,93 & 24,22 & 8,05 & 42,4 & 69,48 & 124,39 & 54,69 & 93,57 & & 195,82 & & 49,16 & \\
\hline aso & 38 & 47,29 & 10,38 & & 24,91 & & 31,58 & & 14,34 & 23,47 & 65,72 & 21,13 & 22,61 & 15,46 \\
\hline Caso & 39 & 66,55 & 75,28 & & 105,49 & & 41,96 & 25,11 & 45,09 & 27,12 & 413,08 & 62,13 & 30,47 & \\
\hline Caso & 40 & & 14,48 & & & & 42,48 & & & & 94,31 & & & 53,76 \\
\hline Caso & 41 & 49,16 & 17,69 & & 13,21 & 13,64 & 41,41 & 13,9 & 37,67 & & 79,04 & & & 20,93 \\
\hline Caso & 42 & 10,04 & 56,22 & & 41,47 & & 51,16 & 16,42 & 17,68 & & 111,79 & & & \\
\hline Caso & 43 & 23,16 & 45,17 & & 33,01 & 110,9 & 57,21 & 43,09 & 28,58 & 46,44 & 557,66 & 207,78 & & 207,78 \\
\hline Caso & 44 & 15,03 & 47,4 & & 36,36 & & 8,86 & 7,16 & 15,23 & 7,08 & 198,59 & & 7,85 & 198,59 \\
\hline Caso & 45 & 5,99 & 15,25 & & 70,19 & & 37,35 & 18,15 & 82,16 & & 218,21 & & 105,19 & \\
\hline Caso & 46 & & 18,86 & 7,45 & 33,11 & & 30,07 & & 27,64 & 43,65 & 455,44 & 47,15 & & 7,25 \\
\hline Caso & 47 & 54,96 & 42,3 & 17,68 & & & 177,41 & 8,52 & 175,4 & 59,5 & 325,85 & & & \\
\hline Caso & 48 & 95,02 & 42,81 & & 65,37 & 29,04 & 15,37 & 10,35 & 19,53 & 5,71 & 257,83 & 58,12 & 23,93 & 18,38 \\
\hline Caso & 49 & 89,11 & 321,67 & & & & 343,93 & 61,84 & 124,44 & & 161,63 & & 7,28 & 25,39 \\
\hline Caso & 50 & & 19,36 & 14,09 & & 13,81 & 106,5 & 88,94 & 52,07 & 12,26 & 106,87 & & 7,85 & 22,27 \\
\hline
\end{tabular}

ANEXO E - MEDIDAS DO EIXO MAIOR LINFONODAL POR CADEIA

$\begin{array}{lllllllllllll}1 & 2 \mathrm{R} & 2 \mathrm{~L} & 3 \mathrm{a} & 3 \mathrm{p} & 4 \mathrm{R} & 4 \mathrm{~L} & 5 & 6 & 7 & 8 & 9 \mathrm{R} & 9 \mathrm{~L}\end{array}$




\begin{tabular}{|c|c|c|c|c|c|c|c|c|c|c|c|c|c|c|}
\hline Caso & 1 & 15,83 & & 12,78 & 16,15 & 13,07 & 12,26 & 12,13 & 22,59 & 8,79 & 11,79 & 9,44 & 7,2 & \\
\hline Caso & 2 & 6,02 & 10,24 & & 8,19 & 7,22 & 6,35 & & 5,67 & 5,58 & 17,09 & 10,83 & & 6,38 \\
\hline Caso & 3 & 7,37 & 8,48 & & 11,45 & & 11,52 & & 9,4 & & 12 & 23,12 & 9,96 & \\
\hline Caso & 4 & & 11,01 & & 7,97 & 9,8 & 9,58 & 13,15 & & 9,22 & 17,85 & 6,77 & 5,57 & \\
\hline Caso & 5 & 6,61 & 7,3 & 10,16 & 11,16 & & 34,24 & & 13,61 & 14,13 & 22,36 & & 12,65 & 14,19 \\
\hline Caso & 6 & 17,16 & 11,21 & & & & 10,61 & & 10,72 & 8,42 & 25,58 & 4,73 & 8,41 & 10,32 \\
\hline Caso & 7 & 8,04 & 9,54 & & & & 25,17 & 9,1 & 14,87 & & 44,39 & 11,4 & & \\
\hline Caso & 8 & 7,6 & 15,19 & & & & 7,09 & 9,93 & & 8,67 & 11,08 & 4,52 & 6,17 & 11 \\
\hline aso & 9 & 12,07 & 8,5 & 7,47 & 21,74 & & 17,57 & & & & 14,96 & & & \\
\hline aso & 10 & 8,8 & 8,54 & & 8,14 & 6,4 & 11,17 & & 11,63 & & 16,04 & 21,81 & & 5,44 \\
\hline Caso & 11 & 5,12 & 7,04 & & & & 14,43 & 17,47 & 12,63 & 10,18 & 16,11 & 9,65 & 5,99 & 2,93 \\
\hline Caso & 12 & & 6,39 & & & & 8,47 & & 22,63 & 5,48 & 8,79 & 5,96 & & 6,98 \\
\hline aso & 13 & 9,98 & 8,45 & 12,96 & & & 15,1 & 15,1 & 12,85 & 13,27 & 26,57 & 14,57 & & 9,33 \\
\hline aso & 14 & 7,62 & 7,42 & 9,68 & 15,1 & & 13,68 & 5,48 & 7,35 & 18,13 & 20,88 & & 5,25 & \\
\hline aso & 15 & 14,48 & 10,88 & & 13,34 & 5,13 & 11,68 & 13,88 & 16,13 & 7,88 & 19,31 & & 6,85 & 7,01 \\
\hline aso & 16 & 7,61 & 6,77 & & 30,57 & & 11,98 & 7,25 & 9,13 & 9,77 & 14,81 & 6 & 24,06 & 9,73 \\
\hline aso & 17 & 9,28 & 7,62 & 5,44 & 31,32 & & 14,45 & 6,27 & 11,32 & 7,68 & 19,89 & & 12,59 & 11,32 \\
\hline aso & 18 & 10,41 & 8,82 & 8,72 & 8,16 & 12,86 & 21,2 & 7,67 & 9,22 & 16,54 & 16,94 & 22,45 & 6,12 & \\
\hline aso & 19 & 5,77 & 9,08 & & 8,57 & 6,17 & 7,45 & 8,36 & 12,44 & 11,61 & 12,24 & & 11,28 & 10,68 \\
\hline aso & 20 & 10,78 & 10,25 & & & & 15,57 & & 16,52 & 7,86 & 16,19 & & & 14,96 \\
\hline Caso & 21 & 7,87 & 9,11 & & 4,51 & 6,42 & 13,04 & 2,23 & 5,9 & 5,97 & 20,88 & & & 7,74 \\
\hline Caso & 22 & 5,17 & 19,37 & & & & 28,46 & 8,38 & 8,48 & 25,23 & 28,05 & 6,32 & & \\
\hline Caso & 23 & & 5,91 & & 6,31 & & 9,28 & 4,46 & 10,32 & 9,47 & 6,96 & & & 7,84 \\
\hline Zaso & 24 & 11,8 & 2,84 & & 5,25 & & 8,08 & 6,38 & 5,98 & 8,38 & 7,97 & 8,84 & 5,81 & 7,55 \\
\hline aso & 25 & 7,74 & 7,23 & & 7,89 & 7,23 & 13,84 & 6,03 & 7,98 & 10,9 & 12,42 & 11,16 & 8,53 & 6,78 \\
\hline Zaso & 26 & 11,47 & 7,12 & & 4,29 & & 9,59 & 5,6 & 10,98 & 9,59 & 26,36 & & & 11,3 \\
\hline Caso & 27 & 13,76 & 18,78 & & 6,53 & & 11,8 & 11,17 & 10,89 & 10,29 & 12,54 & & & 6,64 \\
\hline aso & 28 & 6,22 & 11,37 & & 9,96 & & 15,67 & 15,34 & 10,8 & 9,6 & 25,68 & & 7,85 & 11,44 \\
\hline aso & 29 & 2,75 & 7,7 & & 8,3 & & 13,23 & 8 & 12,4 & 7,5 & 29,79 & & 8,44 & \\
\hline aso & 30 & 7,89 & 7,87 & 4,07 & 16,89 & & 6,63 & 3,59 & 6,54 & & 15,37 & & & 10,76 \\
\hline aso & 31 & 15,27 & 5,97 & & 9,82 & & 10,34 & 15,56 & 20,4 & 9,56 & 17,69 & & 7,26 & 4,69 \\
\hline aso & 32 & 10,86 & 15,12 & & 8,4 & & 7,27 & 13,7 & 13,06 & 10,52 & 21,08 & 16,25 & 11,86 & 15,41 \\
\hline Caso & 33 & 6,61 & 4,9 & & 11,19 & & 14,14 & 19,65 & 11,3 & 7,78 & 15,81 & 4,48 & 6,27 & \\
\hline aso & 34 & 5,28 & 7,8 & 9,06 & 8,2 & 13,07 & 16,39 & & 8,57 & 3,39 & 20,99 & 7,33 & & \\
\hline aso & 35 & 10,01 & 6,56 & 5,7 & & & 47,05 & 15,03 & 13,22 & 6,86 & 21,4 & & & \\
\hline aso & 36 & 4,41 & 5,29 & & & 5,44 & 12,13 & 7,39 & 10,66 & 5,47 & 13,66 & & 4,81 & 7,06 \\
\hline Caso & 37 & 4,79 & & 3,92 & 16,59 & 13,79 & 17,35 & 9,83 & 13,72 & 7,82 & 65 & 9,85 & 9,33 & \\
\hline Zaso & 38 & 11,8 & 4,41 & & 7,47 & & 7,25 & & 5,42 & 6,38 & 31 & 6,15 & 5,85 & 5,34 \\
\hline aso & 39 & 9,97 & 11,67 & & 12,57 & & 8,03 & 6,6 & 9,04 & 7,13 & 28,91 & 13,65 & 7,57 & \\
\hline aso & 40 & 5,55 & & & 6,04 & & 11,68 & 3,5 & 5,73 & & 18,5 & & & 9,96 \\
\hline aso & 41 & 9,33 & 6,62 & & 5,25 & 5,91 & 8,79 & 6,04 & 8,46 & & 10,68 & & & 5,84 \\
\hline aso & 42 & 3,92 & & & 9,38 & & 8,1 & 5,83 & 5,66 & 9,05 & 11,17 & 7,51 & & \\
\hline Caso & 43 & 7,51 & 10,11 & & 11,24 & 13,02 & 10,03 & 10,82 & 7,18 & 9,14 & 30,87 & 26,57 & & 26,57 \\
\hline aso & 44 & 5,29 & 11,49 & & 8,87 & & 3,91 & 3,85 & 5,23 & 3,53 & 19,1 & & 13,88 & 19,1 \\
\hline Caso & 45 & 3,86 & & 7,9 & 3,64 & & 8,73 & 5,88 & 11,64 & & 19,59 & & 17,27 & \\
\hline aso & 46 & & 5,89 & 3,94 & 7,9 & & 7,11 & & 6,72 & 9,53 & 32,97 & 10,61 & & 3,86 \\
\hline Caso & 47 & 9,93 & 9,08 & 6,49 & & & 16,35 & 3,81 & 17,59 & 9,61 & 23,01 & & & \\
\hline Caso & 48 & 15,83 & 7,48 & & 14,22 & 6,77 & 5,22 & 5,29 & 5,9 & 3,01 & 23,4 & 12,31 & 6,42 & 6,94 \\
\hline Caso & 49 & 15,37 & 28,67 & & & & 31,85 & 10,34 & 17,47 & & 16,1 & & 4,21 & 7,86 \\
\hline aso & 50 & & 5,95 & 5,3 & & 4,76 & 15,09 & 11,49 & 10,15 & 4,51 & 16,57 & & 4,02 & 6,19 \\
\hline
\end{tabular}

\section{ANEXO F - MEDIDAS DO EIXO MENOR LINFONODAL POR CADEIA}

\begin{tabular}{|c|c|c|c|c|c|c|c|c|c|c|c|c|c|}
\hline & 1 & 2R & $2 \mathrm{~L}$ & $3 a$ & $3 p$ & 4R & $4 \mathrm{~L}$ & 5 & 6 & 7 & 8 & 9R & $9 \mathrm{~L}$ \\
\hline Caso 1 & 9,24 & & 9,27 & 7,77 & 10,66 & 7,1 & 7,06 & 14,7 & 5,26 & 7 & 5,83 & 3,74 & \\
\hline Caso 2 & 5,05 & 5,58 & & 6,84 & 4,33 & 4,84 & & 4,2 & 3,65 & 8,1 & 6,84 & & 5,41 \\
\hline Caso 3 & 4,65 & 6,46 & & 6,28 & & 8,82 & & 6,37 & & 7,79 & 7,96 & 5,79 & \\
\hline Caso 4 & & 5,17 & & 5,3 & 6,05 & 6,08 & 8,17 & & 6,11 & 10,35 & 4,63 & 5,2 & \\
\hline
\end{tabular}




\begin{tabular}{|c|c|c|c|c|c|c|c|c|c|c|c|c|c|c|}
\hline aso & 5 & 5,1 & 5,05 & 5,47 & 6,8 & & 20,92 & & 7,5 & 10,42 & 15,42 & & 5,59 & 7,32 \\
\hline Caso & 6 & 12 & 7,24 & & & & 7,84 & & 8,38 & 5,54 & 10,48 & 2,59 & 6,67 & 8,06 \\
\hline aso & 7 & 5,91 & 5,62 & & & & 13,62 & 6,19 & 10,42 & & 19,88 & 6,35 & & \\
\hline & 8 & 5,99 & 7,67 & & & & 4,29 & 6,33 & & 7,31 & 7,18 & 3,51 & 2,29 & 6,64 \\
\hline & 9 & 5,94 & 5,01 & 5,4 & 10,93 & & 10,95 & & & & 9,42 & & & \\
\hline & 10 & 6,96 & 5,43 & & 4,61 & 6,08 & 8,47 & & 6,32 & & 9,4 & 7,54 & & 4,32 \\
\hline & 11 & 3,7 & 4,62 & & & & 9,08 & 8,2 & 7,71 & 6,57 & 9,01 & & 4,91 & 2,13 \\
\hline aso & 12 & & 4,07 & & & & 5,05 & & 8,94 & 3,52 & 3,81 & 3,24 & & 3,97 \\
\hline aso & 13 & 7,54 & 5,12 & 8,38 & & & 9,88 & 10,93 & 8,07 & 7,81 & 10,45 & 11,51 & & 5,42 \\
\hline & 14 & 5,62 & 5,73 & 6,45 & 7,63 & & 8,83 & 3,99 & 4,94 & 7,61 & 15,25 & & 3,69 & \\
\hline aso & 15 & 9,32 & 6,78 & & 9,23 & 3,33 & 9,29 & 8,86 & 8,58 & 4,19 & 11,17 & & 4,44 & 4,43 \\
\hline & 16 & 5,18 & 3,67 & & 8,72 & & 9,91 & 4,47 & 5,52 & 6,41 & 9,71 & 3,92 & 10,59 & 5,02 \\
\hline aso & 17 & 7,29 & 5,35 & 3,93 & 14,47 & & 9,28 & 4,07 & 7,98 & 4,73 & 8,59 & & 7,3 & 7,82 \\
\hline aso 1 & 18 & 7,26 & 6,72 & 4,52 & 6,15 & 7,58 & 14,47 & 5,27 & 6,1 & 11,25 & 10,03 & 7,85 & 3,68 & \\
\hline aso & 19 & 4,54 & 5,24 & & 5,74 & 3,9 & 4,48 & 5,19 & 5,05 & 6,44 & 7,5 & & & 5,92 \\
\hline aso 2 & 20 & 7,53 & 6,83 & & & & 6,52 & & 9,22 & 5,19 & 11,35 & & & 8,55 \\
\hline aso 2 & 21 & 3,62 & 6,04 & & 2,34 & 3,31 & 6,3 & 1,6 & 3,82 & 4,02 & 10,49 & & & 6,09 \\
\hline aso 2 & 22 & 3,5 & 5,54 & & & & 15 & 4,88 & 6,48 & 9,27 & 12,53 & 3,89 & & \\
\hline aso 2 & 23 & & 3,83 & & 4,88 & & 5,62 & 2,9 & 6,47 & 5,8 & 4,3 & & & 5,83 \\
\hline so & 24 & 8,3 & 1,91 & & 3,76 & & 4,61 & 4,28 & 3,74 & 5,3 & 4,79 & 5,09 & & 5,64 \\
\hline aso 2 & 25 & 5,78 & 4,0 & & 5,14 & 4,04 & 9,7 & 3,88 & 5,2 & 7,42 & 7,99 & 6,44 & & 4,64 \\
\hline aso 2 & 26 & 5,8 & 6,19 & & 2,86 & & 5,49 & 4,1 & 6,83 & 6,63 & 13,81 & & & 7,34 \\
\hline so & 27 & 10,23 & 13,41 & & 5,82 & & 9,83 & 7,6 & 7,45 & 6,68 & 8,89 & & & 4,01 \\
\hline aso & 28 & 3,72 & 6,4 & & 8,09 & & & 10 & 7,27 & 6,4 & & & & 6,52 \\
\hline aso & 29 & 1,88 & 4,67 & & 5,24 & & 10,23 & 5,59 & 7,55 & 4,85 & 11,79 & & 5,12 & \\
\hline aso & 30 & 6,62 & 5,71 & 2,98 & 11,44 & & 4 & 2,54 & 4,54 & & 10,43 & & & 7,94 \\
\hline aso & 31 & 10,61 & 3,79 & & 5,49 & & 7,01 & 8,4 & 10,16 & 6,57 & 13,94 & & & \\
\hline aso & 32 & 7,05 & 9,61 & & 5,37 & & 11,71 & 6,41 & 9,12 & 8,52 & 13,82 & & 8,94 & 11,39 \\
\hline aso & 33 & 4,66 & 2,55 & & 6,53 & & 8 & 8,9 & 7,32 & 4,31 & 8,69 & 3,58 & 3,99 & \\
\hline aso & 34 & 4,19 & 5,53 & 4,46 & 6,33 & 7,89 & 9,36 & 8 & 5,81 & 2,71 & 13,71 & 3,54 & & \\
\hline aso & 35 & 6,03 & 4,69 & 4,45 & & & 18,77 & 9,02 & 10,32 & 4,68 & 15,68 & & & \\
\hline aso 3 & 36 & 3,03 & 4,07 & & & 4,43 & 7,25 & 5,07 & 6,4 & 3,85 & 8,93 & & 3,09 & 4,87 \\
\hline aso 3 & 37 & 3,74 & 4,45 & 2,53 & 4,05 & 6,15 & 9,93 & 5,83 & 7,74 & 4,16 & 10,49 & 4,88 & 6,88 & \\
\hline aso & 38 & 5,54 & 2,73 & & 3,71 & & 5 & & 3,63 & 4,44 & 5,67 & & 3,36 & 4,02 \\
\hline aso 3 & 39 & 8,81 & 7,74 & & 10,85 & & 6,33 & 5,07 & 6,11 & 4,88 & 15,63 & 5,35 & 4,69 & \\
\hline aso & 40 & 3,97 & 3,28 & & 4,67 & & 5,25 & 2,47 & & 4,04 & 6,31 & & & 6,98 \\
\hline aso & 41 & 6,88 & 3,7 & & 3,24 & 2,83 & 5,7 & 3,58 & 5,46 & & 6,46 & & & 4,86 \\
\hline & 42 & 3,46 & 6,98 & & 6,48 & & 5,43 & 4 & 3,95 & 4,22 & 7,81 & & & \\
\hline aso & 43 & 4,22 & 6,84 & & 4,57 & 10,61 & 4,69 & 4,89 & 4,09 & 5,26 & 20,56 & 10,33 & & 10,33 \\
\hline aso & 44 & 3,41 & 5,58 & & 4,86 & & 3 & 2,39 & 3,89 & 2,53 & 11,56 & & 2,69 & 11,56 \\
\hline aso & 45 & 1,77 & 3,45 & 3,67 & 6,72 & & 5,21 & 4,33 & 7,46 & & 12,21 & & 8,26 & \\
\hline aso & 46 & & 4,28 & 2,57 & 5,74 & & 4,82 & & 4,33 & 4,73 & 19,8 & 4,4 & & 2,48 \\
\hline aso & 47 & 7,03 & 6,3 & 3,75 & & & 10,6 & 2 & 11,23 & 6,7 & 16,31 & & & \\
\hline & 48 & 7,79 & 5,47 & & 6,33 & 5,2 & 3,4 & 2,71 & 4,13 & 2,79 & 14,41 & 6,33 & 5,03 & 3,21 \\
\hline & 49 & 9,32 & 17,54 & & & & 13,91 & 6,55 & 10,89 & & 11,56 & & 2,78 & 4,64 \\
\hline aso & 50 & 9,24 & & 9,27 & 7,77 & 10,66 & 7,1 & 7,06 & 14,7 & 5,26 & 7 & 5,83 & 3,74 & \\
\hline
\end{tabular}

\section{ANEXO G - NÚMERO DE LINFONODOS POR CADEIA}

\begin{tabular}{|c|c|c|c|c|c|c|c|c|c|c|c|c|c|c|}
\hline Caso & 1 & $2 \mathrm{R}$ & $2 \mathrm{~L}$ & $3 a$ & $3 p$ & $4 R$ & $4 \mathrm{~L}$ & 5 & 6 & 7 & 8 & $9 R$ & \multicolumn{2}{|c|}{ 9L Subtotal } \\
\hline 1 & 3 & 0 & 2 & 0 & 2 & 3 & 7 & 2 & 0 & 8 & 3 & 1 & 0 & 31 \\
\hline 2 & 1 & 5 & 0 & 2 & 0 & 12 & 0 & 6 & 5 & 4 & 4 & 0 & 1 & 40 \\
\hline 3 & 2 & 3 & 0 & 1 & 0 & 4 & 0 & 3 & 0 & 3 & 1 & 1 & 0 & 18 \\
\hline 4 & 0 & 5 & 0 & 5 & 3 & 7 & 3 & 0 & 9 & 2 & 2 & 1 & 0 & 37 \\
\hline 5 & 3 & 3 & 3 & 5 & 0 & 1 & 0 & 3 & 4 & 3 & 0 & 1 & 1 & 27 \\
\hline 6 & 1 & 5 & 0 & 0 & 0 & 3 & 0 & 4 & 7 & 2 & 1 & 2 & 1 & 26 \\
\hline
\end{tabular}




\begin{tabular}{|c|c|c|c|c|c|c|c|c|c|c|c|c|c|c|}
\hline 7 & 2 & 9 & 0 & 0 & 0 & 3 & 15 & 2 & 0 & 1 & 1 & 0 & 0 & 33 \\
\hline 8 & 1 & 2 & 0 & 0 & 0 & 2 & 1 & 0 & 3 & 9 & 1 & 1 & 1 & 21 \\
\hline 9 & 1 & 4 & 3 & 1 & 0 & 1 & 0 & 0 & 0 & 4 & 0 & 0 & 0 & 14 \\
\hline 10 & 1 & 4 & 0 & 3 & 1 & 6 & 0 & 3 & 0 & 3 & 1 & 0 & 1 & 23 \\
\hline 11 & 1 & 6 & 0 & 0 & 0 & 4 & 1 & 4 & 5 & 9 & 1 & 1 & 2 & 34 \\
\hline 12 & 0 & 5 & 0 & 0 & 0 & 2 & 0 & 1 & 2 & 4 & 1 & 0 & 7 & 22 \\
\hline 13 & 2 & 17 & 4 & 0 & 0 & 5 & 4 & 5 & 8 & 2 & 2 & 0 & 1 & 50 \\
\hline 14 & 1 & 4 & 5 & 4 & 0 & 4 & 4 & 10 & 2 & 2 & 0 & 1 & 0 & 37 \\
\hline 15 & 2 & 6 & 0 & 2 & 2 & 2 & 3 & 3 & 3 & 5 & 0 & 1 & 3 & 32 \\
\hline 16 & 1 & 15 & 0 & 1 & 0 & 4 & 4 & 2 & 6 & 7 & 2 & 1 & 4 & 47 \\
\hline 17 & 1 & 8 & 6 & 1 & 0 & 6 & 8 & 6 & 6 & 4 & 0 & 2 & 2 & 50 \\
\hline 18 & 2 & 8 & 4 & 4 & 5 & 3 & 6 & 8 & 4 & 10 & 1 & 2 & 0 & 57 \\
\hline 19 & 5 & 6 & 0 & 2 & 3 & 4 & 7 & 1 & 4 & 6 & 0 & 1 & 1 & 40 \\
\hline 20 & 3 & 2 & 0 & 3 & 0 & 3 & 0 & 3 & 2 & 3 & 0 & 0 & 1 & 20 \\
\hline 21 & 1 & 2 & 0 & 2 & 3 & 3 & 1 & 4 & 3 & 3 & 0 & 0 & 2 & 24 \\
\hline 22 & 9 & 2 & 0 & 0 & 0 & 1 & 2 & 6 & 1 & 1 & 7 & 0 & 0 & 29 \\
\hline 23 & 0 & 3 & 0 & 2 & 0 & 4 & 9 & 4 & 4 & 12 & 0 & 0 & 1 & 39 \\
\hline 24 & 1 & 5 & 0 & 6 & 0 & 7 & 2 & 5 & 5 & 12 & 2 & 2 & 1 & 48 \\
\hline 25 & 5 & 3 & 0 & 1 & 1 & 3 & 1 & 4 & 7 & 5 & 2 & 2 & 7 & 41 \\
\hline 26 & 1 & 2 & 0 & 1 & 0 & 5 & 5 & 5 & 4 & 3 & 0 & 0 & 1 & 27 \\
\hline 27 & 2 & 2 & 0 & 4 & 0 & 6 & 6 & 6 & 3 & 4 & 0 & 0 & 4 & 37 \\
\hline 28 & 5 & 6 & 0 & 2 & 0 & 4 & 3 & 3 & 10 & 2 & 0 & 8 & 1 & 44 \\
\hline 29 & 3 & 1 & 0 & 1 & 0 & 2 & 1 & 2 & 2 & 1 & 0 & 1 & 0 & 14 \\
\hline 30 & 3 & 5 & 4 & 1 & 0 & 8 & 4 & 7 & 0 & 2 & 0 & 0 & 1 & 35 \\
\hline 31 & 1 & 8 & 0 & 4 & 3 & 5 & 3 & 1 & 16 & 5 & 0 & 6 & 3 & 55 \\
\hline 32 & 5 & 3 & 0 & 5 & 0 & 2 & 1 & 3 & 2 & 3 & 1 & 1 & 1 & 27 \\
\hline 33 & 3 & 2 & 0 & 3 & 0 & 5 & 1 & 8 & 4 & 5 & 2 & 5 & 0 & 38 \\
\hline 34 & 5 & 15 & 2 & 2 & 3 & 4 & 4 & 7 & 1 & 4 & 3 & 0 & 0 & 50 \\
\hline 35 & 1 & 2 & 1 & 0 & 0 & 1 & 1 & 2 & 5 & 2 & 0 & 0 & 0 & 15 \\
\hline 36 & 3 & 8 & 0 & 0 & 1 & 3 & 3 & 4 & 14 & 5 & 3 & 2 & 3 & 49 \\
\hline 37 & 7 & 11 & 7 & 0 & 1 & 3 & 8 & 3 & 6 & 5 & 4 & 2 & 0 & 57 \\
\hline 38 & 3 & 10 & 0 & 3 & 0 & 12 & 0 & 4 & 9 & 6 & 4 & 4 & 6 & 61 \\
\hline 39 & 2 & 6 & 0 & 2 & 0 & 11 & 4 & 6 & 7 & 2 & 1 & 3 & 0 & 44 \\
\hline 40 & 7 & 5 & 0 & 2 & 0 & 2 & 4 & 0 & 2 & 2 & 0 & 0 & 3 & 27 \\
\hline 41 & 3 & 3 & 0 & 2 & 3 & 4 & 2 & 2 & 0 & 6 & 0 & 0 & 2 & 27 \\
\hline 42 & 1 & 5 & 0 & 1 & 0 & 5 & 3 & 2 & 5 & 5 & 1 & 0 & 0 & 28 \\
\hline 43 & 2 & 2 & 0 & 1 & 1 & 5 & 3 & 5 & 10 & 2 & 1 & 0 & 1 & 33 \\
\hline 44 & 3 & 3 & 0 & 5 & 0 & 2 & 1 & 5 & 7 & 2 & 0 & 2 & 1 & 31 \\
\hline 45 & 2 & 16 & 4 & 1 & 0 & 8 & 6 & 4 & 0 & 3 & 0 & 1 & 0 & 45 \\
\hline 46 & 0 & 4 & 5 & 1 & 0 & 12 & 0 & 7 & 5 & 1 & 2 & 0 & 2 & 39 \\
\hline 47 & 3 & 1 & 3 & 0 & 0 & 7 & 3 & 2 & 4 & 3 & 0 & 0 & 0 & 26 \\
\hline 48 & 1 & 3 & 0 & 1 & 2 & 12 & 1 & 5 & 1 & 2 & 3 & 3 & 2 & 36 \\
\hline 49 & 1 & 1 & 0 & 0 & 0 & 1 & 2 & 2 & 0 & 3 & 0 & 1 & 1 & 12 \\
\hline 50 & 0 & 20 & 2 & 0 & 2 & 3 & 3 & 4 & 3 & 3 & 0 & 2 & 3 & \\
\hline
\end{tabular}

ANEXO H - NÚMERO DE LINFONODOS POR CADEIA RECONTADOS À LÂMINA CORADA POR HEMATOXILINA-EOSINA

\begin{tabular}{|c|c|c|c|c|c|c|c|c|c|c|c|c|c|c|}
\hline Caso & 1 & $2 R$ & $2 \mathrm{~L}$ & $3 a$ & $3 p$ & $4 R$ & $4 \mathrm{~L}$ & 5 & 6 & 7 & 8 & 9R & \multicolumn{2}{|c|}{ 9L Subtotal } \\
\hline 1 & 3 & 0 & 3 & 0 & 2 & 5 & 6 & 1 & 0 & 7 & 5 & 2 & 0 & 34 \\
\hline 2 & 1 & 5 & 0 & 2 & 0 & 13 & 0 & 7 & 3 & 5 & 3 & 0 & 1 & 40 \\
\hline 3 & 2 & 3 & 0 & 1 & 0 & 3 & 0 & 3 & 5 & 4 & 1 & 1 & 0 & 23 \\
\hline 4 & 0 & 5 & 0 & 5 & 3 & 9 & 3 & 0 & 9 & 2 & 2 & 1 & 0 & 39 \\
\hline 5 & 3 & 3 & 3 & 5 & 0 & 1 & 2 & 3 & 4 & 3 & 0 & 1 & 1 & 29 \\
\hline 6 & 1 & 5 & 0 & 0 & 0 & 3 & 0 & 4 & 7 & 2 & 1 & 2 & 1 & 26 \\
\hline 7 & 2 & 10 & 0 & 0 & 0 & 3 & 15 & 2 & 0 & 1 & 1 & 0 & 0 & 34 \\
\hline
\end{tabular}




\begin{tabular}{|c|c|c|c|c|c|c|c|c|c|c|c|c|c|c|}
\hline 8 & 1 & 2 & 0 & 0 & 0 & 2 & 1 & 0 & 3 & 9 & 1 & 1 & 1 & 21 \\
\hline 9 & 1 & 4 & 4 & 1 & 0 & 1 & 0 & 0 & 0 & 4 & 0 & 0 & 0 & 15 \\
\hline 10 & 1 & 5 & 0 & 4 & 1 & 6 & 0 & 3 & 0 & 3 & 1 & 0 & 1 & 25 \\
\hline 11 & 1 & 6 & 0 & 0 & 0 & 5 & 2 & 4 & 6 & 9 & 1 & 1 & 2 & 37 \\
\hline 12 & 0 & 5 & 0 & 0 & 0 & 2 & 0 & 2 & 2 & 5 & 1 & 0 & 7 & 24 \\
\hline 13 & 2 & 23 & 4 & 0 & 0 & 5 & 5 & 6 & 11 & 4 & 2 & 0 & 2 & 64 \\
\hline 14 & 1 & 4 & 5 & 4 & 0 & 4 & 4 & 10 & 3 & 4 & 0 & 1 & 0 & 40 \\
\hline 15 & 2 & 6 & 0 & 2 & 2 & 2 & 4 & 6 & 3 & 6 & 0 & 1 & 4 & 38 \\
\hline 16 & 1 & 15 & 0 & 1 & 0 & 4 & 4 & 2 & 6 & 7 & 2 & 2 & 4 & \\
\hline 17 & 1 & 8 & 6 & 1 & 0 & 6 & 8 & 6 & 6 & 4 & 0 & 2 & 2 & 50 \\
\hline 18 & 2 & 8 & 4 & 4 & 5 & 5 & 6 & 8 & 4 & 10 & 1 & 2 & 0 & 59 \\
\hline 19 & 5 & 7 & 0 & 2 & 4 & 4 & 7 & 2 & 4 & 8 & 0 & 1 & 1 & 45 \\
\hline 20 & 3 & 5 & 0 & 3 & 0 & 3 & 0 & 7 & 2 & 4 & 0 & 0 & 1 & 28 \\
\hline 21 & 1 & 2 & 0 & 2 & 3 & 3 & 1 & 4 & 3 & 3 & 0 & 0 & 2 & 24 \\
\hline 22 & 9 & 2 & 0 & 0 & 0 & 1 & 2 & 6 & 2 & 1 & 7 & 0 & 0 & 30 \\
\hline 23 & 0 & 3 & 0 & 2 & 0 & 4 & 9 & 4 & 4 & 12 & 0 & 0 & 2 & 40 \\
\hline 24 & 1 & 5 & 0 & 6 & 0 & 7 & 2 & 5 & 5 & 12 & 2 & 2 & 2 & 49 \\
\hline 25 & 5 & 4 & 0 & 1 & 1 & 4 & 2 & 5 & 7 & 7 & 3 & 2 & 7 & 48 \\
\hline 26 & 1 & 2 & 0 & 1 & 0 & 5 & 5 & 6 & 4 & 5 & 0 & 0 & 1 & 30 \\
\hline 27 & 2 & 2 & 0 & 4 & 0 & 6 & 6 & 6 & 3 & 6 & 0 & 0 & 4 & 39 \\
\hline 28 & 5 & 6 & 0 & 2 & 0 & 4 & 3 & 4 & 10 & 2 & 0 & 8 & 1 & 45 \\
\hline 29 & 3 & 1 & 0 & 1 & 0 & 2 & 1 & 2 & 2 & 1 & 0 & 1 & 0 & 14 \\
\hline 30 & 3 & 5 & 4 & 1 & 0 & 8 & 4 & 7 & 0 & 3 & 0 & 0 & 1 & 36 \\
\hline 31 & 1 & 8 & 0 & 6 & 3 & 6 & 4 & 1 & 16 & 6 & 0 & 6 & 3 & 60 \\
\hline 32 & 5 & 4 & 0 & 5 & 0 & 2 & 1 & 3 & 2 & 4 & 2 & 1 & 3 & 32 \\
\hline 33 & 5 & 2 & 0 & 4 & 0 & 8 & 2 & 8 & 4 & 5 & 2 & 5 & 0 & 45 \\
\hline 34 & 5 & 17 & 2 & 2 & 3 & 4 & 4 & 7 & 1 & 4 & 3 & 0 & 0 & 52 \\
\hline 35 & 1 & 2 & 1 & 0 & 0 & 2 & 1 & 2 & 5 & 3 & 0 & 0 & 0 & 17 \\
\hline 36 & 4 & 9 & 0 & 0 & 1 & 4 & 3 & 4 & 14 & 7 & 5 & 2 & 3 & 56 \\
\hline 37 & 7 & 11 & 7 & 0 & 1 & 3 & 8 & 3 & 6 & 7 & 4 & 2 & 0 & 59 \\
\hline 38 & 3 & 10 & 0 & 3 & 0 & 12 & 0 & 4 & 9 & 6 & 4 & 4 & 6 & 61 \\
\hline 39 & 2 & 6 & 0 & 4 & 0 & 12 & 4 & 6 & 7 & 2 & 1 & 5 & 0 & 49 \\
\hline 40 & 8 & 5 & 0 & 2 & 0 & 3 & 4 & 0 & 2 & 5 & 0 & 0 & 5 & 34 \\
\hline 41 & 3 & 3 & 0 & 2 & 3 & 5 & 3 & 2 & 0 & 7 & 0 & 0 & 2 & 30 \\
\hline 42 & 1 & 5 & 0 & 1 & 0 & 5 & 3 & 2 & 7 & 5 & 1 & 0 & 0 & 30 \\
\hline 43 & 2 & 2 & 0 & 1 & 1 & 5 & 3 & 5 & 10 & 5 & 1 & 0 & 1 & 36 \\
\hline 44 & 5 & 4 & 0 & 9 & 0 & 3 & 1 & 5 & 7 & 4 & 0 & 2 & 1 & 41 \\
\hline 45 & 2 & 16 & 4 & 1 & 0 & 10 & 6 & 6 & 0 & 3 & 0 & 1 & 0 & 49 \\
\hline 46 & 0 & 5 & 7 & 1 & 0 & 12 & 0 & 9 & 5 & 4 & 2 & 0 & 2 & 47 \\
\hline 47 & 3 & 1 & 3 & 0 & 0 & 10 & 3 & 2 & 4 & 3 & 0 & 0 & 0 & 29 \\
\hline 48 & 1 & 3 & 0 & 1 & 2 & 12 & 1 & 5 & 1 & 4 & 3 & 4 & 2 & \\
\hline 49 & 4 & 2 & 0 & 0 & 0 & 1 & 2 & 3 & 0 & 3 & 0 & 1 & 1 & 17 \\
\hline 50 & 0 & 20 & 2 & 0 & 2 & 3 & 3 & 4 & 3 & 3 & 0 & 2 & 3 & \\
\hline
\end{tabular}


ANEXO I - ANÁLISE DE CORRELAÇÕES ENTRE O NÚMERO DE LINFONODOS COM A IDADE, PESO E ALTURA.

\begin{tabular}{|c|c|c|c|c|c|}
\hline & & n_linf & idade & peso & altura \\
\hline \multirow{3}{*}{ N_LINF } & Pearson Correlation & 1,000 &,- 001 &, 010 &,- 089 \\
\hline & Sig. (2-tailed) & & ,992 & ,947 &, 541 \\
\hline & $\mathrm{N}$ & 50 & 50 & 50 & 50 \\
\hline
\end{tabular}

\section{ANEXO J - ANÁLISE DE ASSOCIAÇÃO ENTRE O NÚMERO DE LINFONODOS COM O SEXO.}

\begin{tabular}{|c|c|c|c|c|c|}
\hline \multicolumn{6}{|c|}{ Group Statistics } \\
\hline & SEXC & $\mathrm{N}$ & Mean & Std. Deviation & Std. Error Mean \\
\hline \multirow{2}{*}{ N_LINF } & masc & 38 & 34,29 & 12,39 & 2,01 \\
\hline & fem & 12 & 36,58 & 11,96 & 3,45 \\
\hline
\end{tabular}

Independent Samples Test

\begin{tabular}{|c|c|c|c|c|c|c|c|c|c|c|}
\hline & \multicolumn{2}{|c|}{$\begin{array}{l}\text { Levene's Test } \\
\text { for Equality of } \\
\text { Variances }\end{array}$} & \multicolumn{7}{|c|}{ t-test for Equality of Means } \\
\hline & & \multirow[t]{2}{*}{$\mathrm{F}$} & \multirow[t]{2}{*}{ Sig. } & \multirow[t]{2}{*}{$\mathrm{t}$} & \multirow[t]{2}{*}{ df } & \multirow[t]{2}{*}{$\begin{array}{l}\text { Sig. (2- } \\
\text { tailed) }\end{array}$} & \multirow[t]{2}{*}{$\begin{array}{c}\text { Mean } \\
\text { Difference }\end{array}$} & \multirow[t]{2}{*}{$\begin{array}{l}\text { Std. Error } \\
\text { Difference }\end{array}$} & \multicolumn{2}{|c|}{$\begin{array}{l}95 \% \text { Confidence } \\
\text { Interval of the } \\
\text { Difference }\end{array}$} \\
\hline & & & & & & & & & Lower & Upper \\
\hline \multirow[b]{2}{*}{ N_LINF } & \begin{tabular}{|l|} 
Equal \\
variances \\
assumed
\end{tabular} & 008 & 931 &,- 56 & 48 & ,576 & $-2,29$ & 4,07 & $-10,4$ & 5,89 \\
\hline & $\begin{array}{l}\text { Equal } \\
\text { variances } \\
\text { not } \\
\text { assumed }\end{array}$ & & &,- 57 & 19,071 & ,573 & $-2,29$ & 3,99 & $-10,6$ & 6,06 \\
\hline
\end{tabular}


ANEXO K - ANÁLISE DE ASSOCIAÇÃO ENTRE O NÚMERO DE LINFONODOS COM A RAÇA.

Group Statistics

\begin{tabular}{|l|l||l||l||r||r||}
\hline \multirow{2}{*}{} & RAÇA & N & Mean & Std. Deviation & Std. Error Mean \\
\hline \hline \multirow{2}{*}{ N_LINF } & branco & 39 & 35,85 & 12,65 & 2,03 \\
\cline { 2 - 6 } & não branco & 11 & 31,27 & 10,18 & 3,07 \\
\hline
\end{tabular}

\begin{tabular}{|c|c|c|c|c|c|c|c|c|c|c|}
\hline & \multicolumn{2}{|c|}{$\begin{array}{l}\text { Levene' } \\
\text { s Test } \\
\text { for } \\
\text { Equality } \\
\text { of } \\
\text { Varianc } \\
\text { es }\end{array}$} & \multicolumn{7}{|c|}{ t-test for Equality of Means } \\
\hline & & \multirow[t]{2}{*}{$F$} & \multirow[t]{2}{*}{ Sig } & \multirow[t]{2}{*}{$\mathrm{t}$} & \multirow[t]{2}{*}{ df } & \multirow[t]{2}{*}{$\begin{array}{l}\text { Sig. } \\
(2- \\
\text { taile } \\
\text { d) }\end{array}$} & \multirow[t]{2}{*}{$\begin{array}{l}\text { Mean } \\
\text { Differen } \\
\text { ce }\end{array}$} & \multirow[t]{2}{*}{$\begin{array}{l}\text { Std. } \\
\text { Error } \\
\text { Differen } \\
\text { ce }\end{array}$} & \multicolumn{2}{|c|}{$\begin{array}{c}95 \% \\
\text { Confidenc } \\
\text { e Interval } \\
\text { of the } \\
\text { Difference }\end{array}$} \\
\hline & & & & & & & & & $\begin{array}{c}\text { Low } \\
\text { er }\end{array}$ & $\begin{array}{l}\text { Upp } \\
\text { er }\end{array}$ \\
\hline \multirow{2}{*}{$\begin{array}{l}\mathrm{N} \mathrm{LI} \\
\mathrm{NF}\end{array}$} & $\begin{array}{l}\text { Equal } \\
\text { varianc } \\
\text { es } \\
\text { assum } \\
\text { ed } \\
\end{array}$ & $\begin{array}{r}61 \\
6\end{array}$ & $\begin{array}{r}43 \\
6\end{array}$ & $\begin{array}{r}1,10 \\
0\end{array}$ & 48 & 277 & 4,57 & 4,16 & 3,79 & $\begin{array}{r}12,9 \\
3\end{array}$ \\
\hline & $\begin{array}{l}\text { Equal } \\
\text { varianc } \\
\text { es not } \\
\text { assum } \\
\text { ed }\end{array}$ & & & $\begin{array}{r}1,24 \\
4\end{array}$ & $\begin{array}{r}19,6 \\
36\end{array}$ & 228 & 4,57 & 3,68 & 3,11 & $\begin{array}{r}12,2 \\
5\end{array}$ \\
\hline
\end{tabular}


ANEXO L - ANÁLISE DE ASSOCIAÇÃO ENTRE O NÚMERO DE LINFONODOS COM A CONGESTÃO.

Group Statistics

\begin{tabular}{||l||l||l||l||r||r||}
\hline \hline & Congestão & N & Mean & Std. Deviation & Std. Error Mean \\
\hline \hline \multirow{2}{*}{ N_LINF } & presente & 26 & 34,96 & 12,35 & 2,42 \\
\cline { 2 - 6 } & ausente & 24 & 34,71 & 12,31 & 2,51 \\
\hline
\end{tabular}

\begin{tabular}{|c|c|c|c|c|c|c|c|c|c|c|}
\hline & \multicolumn{2}{|c|}{$\begin{array}{c}\text { Levene' } \\
\text { s Test } \\
\text { for } \\
\text { Equality } \\
\text { of } \\
\text { Varianc } \\
\text { es }\end{array}$} & \multicolumn{7}{|c|}{ t-test for Equality of Means } \\
\hline & & \multirow[t]{2}{*}{$\mathrm{F}$} & \multirow[t]{2}{*}{ Sig } & \multirow[t]{2}{*}{$\mathrm{t}$} & \multirow[t]{2}{*}{$d f$} & \multirow[t]{2}{*}{$\begin{array}{l}\text { Sig. } \\
(2- \\
\text { taile } \\
\text { d) }\end{array}$} & \multirow[t]{2}{*}{$\begin{array}{c}\text { Mean } \\
\text { Differen } \\
\text { ce }\end{array}$} & \multirow[t]{2}{*}{$\begin{array}{c}\text { Std. } \\
\text { Error } \\
\text { Differen } \\
\text { ce }\end{array}$} & \multicolumn{2}{|c|}{$\begin{array}{c}95 \% \\
\text { Confidence } \\
\text { Interval of } \\
\text { the } \\
\text { Difference }\end{array}$} \\
\hline & & & & & & & & & $\begin{array}{c}\text { Low } \\
\text { er }\end{array}$ & $\begin{array}{c}\text { Upp } \\
\text { er }\end{array}$ \\
\hline \multirow{2}{*}{$\begin{array}{l}\mathrm{N} \text { LLI } \\
\mathrm{NF}\end{array}$} & $\begin{array}{l}\text { Equal } \\
\text { varianc } \\
\text { es } \\
\text { assum } \\
\text { ed }\end{array}$ & $\begin{array}{r}, 00 \\
3\end{array}$ & ,95 & $\begin{array}{r}, 07 \\
3\end{array}$ & 48 & ,942 & ,25 & 3,49 & 6,77 & 7,27 \\
\hline & $\begin{array}{l}\text { Equal } \\
\text { varianc } \\
\text { es not } \\
\text { assum } \\
\text { ed }\end{array}$ & & & $\begin{array}{r}, 07 \\
3\end{array}$ & $\begin{array}{r}47,70 \\
4\end{array}$ & ,942 & ,25 & 3,49 & $6,77^{-}$ & 7,27 \\
\hline
\end{tabular}


ANEXO M - ANÁLISE DE CORRELAÇÕES ENTRE O NúMERO DE CADEIAS PRESENTES COM A IDADE, PESO E ALTURA.

\begin{tabular}{||l||r|r||r||r||r||}
\hline \multicolumn{2}{|c|}{} & cadeias presentes & idade & altura & peso \\
\hline \hline \multirow{3}{*}{ cadeias presentes } & Pearson Correlation & 1,000 &, 021 &, 069 &, 065 \\
\cline { 2 - 6 } & Sig. (2-tailed) &, &, 884 &, 633 &, 654 \\
\cline { 2 - 6 } & $\mathrm{N}$ & 50 & 50 & 50 & 50 \\
\hline
\end{tabular}

ANEXO N - ANÁLISE DE ASSOCIAÇÃO ENTRE O NÚMERO DE CADEIAS PRESENTES COM O SEXO.

\begin{tabular}{|c|c|c|c|c|c|}
\hline \multicolumn{6}{|c|}{ Group Statistics } \\
\hline & SEXO & $\mathrm{N}$ & Mean & Std. Deviation & Std. Error Mean \\
\hline \multirow{2}{*}{ cadeias presentes } & masc & 38 & 9,58 & 1,33 & 22 \\
\hline & fem & 12 & 9,33 & 1,72 &, 50 \\
\hline
\end{tabular}

Independent Samples Test

\begin{tabular}{|c|c|c|c|c|c|c|c|c|c|c|}
\hline & \multicolumn{2}{|c|}{$\begin{array}{c}\text { Levene's } \\
\text { Test for } \\
\text { Equality } \\
\text { of } \\
\text { Variance } \\
\text { s }\end{array}$} & \multicolumn{7}{|c|}{ t-test for Equality of Means } \\
\hline & & \multirow[t]{2}{*}{$\mathrm{F}$} & \multirow[t]{2}{*}{ Sig. } & \multirow[t]{2}{*}{$\mathrm{t}$} & \multirow[t]{2}{*}{$d f$} & \multirow{2}{*}{$\begin{array}{c}\text { Sig. } \\
(2- \\
\text { tailed } \\
\quad)\end{array}$} & \multirow{2}{*}{$\begin{array}{c}\text { Mean } \\
\text { Differenc } \\
e\end{array}$} & \multirow{2}{*}{$\begin{array}{c}\text { Std. Error } \\
\text { Differenc } \\
\text { e }\end{array}$} & \multicolumn{2}{|c|}{$\begin{array}{c}95 \% \\
\text { Confidence } \\
\text { Interval of the } \\
\text { Difference }\end{array}$} \\
\hline & & & & & & & & & $\begin{array}{c}\text { Lowe } \\
r\end{array}$ & $\begin{array}{c}\text { Uppe } \\
\text { r }\end{array}$ \\
\hline \multirow{2}{*}{$\begin{array}{l}\text { cadeias } \\
\text { presente } \\
\mathrm{s}\end{array}$} & $\begin{array}{l}\text { Equal } \\
\text { variance } \\
\text { assumed }\end{array}$ & ,75 & ,38 &, 51 & 48 & ,61 & ,25 & 47, &,- 71 & 1,20 \\
\hline & \begin{tabular}{|l} 
Equal \\
variance \\
not \\
assumed
\end{tabular} & & & , 453 & $\begin{array}{r}15,35 \\
3\end{array}$ & 657 & ,25 &, 54 &,- 91 & 1,40 \\
\hline
\end{tabular}


ANEXO O - ANÁLISE DE ASSOCIAÇÃO ENTRE O NÚMERO DE CADEIAS PRESENTES COM A RAÇA.

Group Statistics

\begin{tabular}{||l||l||l||r||r||r||}
\hline \hline & RAÇA & N & Mean & Std. Deviation & Std. Error Mean \\
\hline \hline \multirow{2}{*}{ cadeias presentes } & branco & 39 & 9,64 & 1,40 &, 22 \\
\cline { 2 - 6 } & não branco & 11 & 9,09 & 1,45 &, 44 \\
\hline \hline
\end{tabular}

\begin{tabular}{|c|c|c|c|c|c|c|c|c|c|c|}
\hline & \multicolumn{2}{|c|}{$\begin{array}{c}\text { Levene' } \\
\text { s Test } \\
\text { for } \\
\text { Equality } \\
\text { of } \\
\text { Varianc } \\
\text { es }\end{array}$} & \multicolumn{7}{|c|}{ t-test for Equality of Means } \\
\hline & & \multirow[t]{2}{*}{$\mathrm{F}$} & \multirow[t]{2}{*}{ Sig } & \multirow[t]{2}{*}{$\mathrm{t}$} & \multirow[t]{2}{*}{$d f$} & \multirow[t]{2}{*}{$\begin{array}{l}\text { Sig. } \\
(2- \\
\text { taile } \\
\text { d) }\end{array}$} & \multirow[t]{2}{*}{$\begin{array}{c}\text { Mean } \\
\text { Differen } \\
\text { ce }\end{array}$} & \multirow[t]{2}{*}{$\begin{array}{c}\text { Std. } \\
\text { Error } \\
\text { Differen } \\
\text { ce }\end{array}$} & \multicolumn{2}{|c|}{\begin{tabular}{|c|}
$95 \%$ \\
Confidenc \\
e Interval \\
of the \\
Difference
\end{tabular}} \\
\hline & & & & & & & & & $\begin{array}{c}\text { Low } \\
\text { er }\end{array}$ & $\begin{array}{c}\text { Upp } \\
\text { er }\end{array}$ \\
\hline \multirow{2}{*}{$\begin{array}{l}\text { cadeia } \\
\text { s } \\
\text { present } \\
\text { es }\end{array}$} & $\begin{array}{l}\text { Equal } \\
\text { varianc } \\
\text { es } \\
\text { assum } \\
\text { ed }\end{array}$ & $\begin{array}{r}, 07 \\
9\end{array}$ & $\begin{array}{r}, 78 \\
0\end{array}$ & $\begin{array}{r}1,14 \\
0\end{array}$ & 48 & ,260 &, 55 & ,48 &,- 42 & 1,52 \\
\hline & $\begin{array}{l}\text { Equal } \\
\text { varianc } \\
\text { es not } \\
\text { assum } \\
\text { ed }\end{array}$ & & & $\begin{array}{r}1,12 \\
1\end{array}$ & $\begin{array}{r}15,7 \\
38\end{array}$ & ,279 &, 55 & ,49 &,- 49 & 1,59 \\
\hline
\end{tabular}


ANEXO P - ANÁLISE DE ASSOCIAÇÃO ENTRE O NÚMERO DE CADEIAS PRESENTES COM A CONGESTÃO.

Group Statistics

\begin{tabular}{||l||l||l||r||r||r||}
\hline \hline & Congestão & N & Mean & Std. Deviation & Std. Error Mean \\
\hline \hline \multirow{2}{*}{ cadeias presentes } & presente & 26 & 9,77 & 1,50 &, 30 \\
\cline { 2 - 6 } & ausente & 24 & 9,25 & 1,29 &, 26 \\
\hline \hline
\end{tabular}

Independent Samples Test

\begin{tabular}{|c|c|c|c|c|c|c|c|c|c|c|}
\hline & \multicolumn{2}{|c|}{$\begin{array}{l}\text { Levene's } \\
\text { Test for } \\
\text { Equality } \\
\text { of } \\
\text { Variance } \\
\text { s }\end{array}$} & \multicolumn{7}{|c|}{ t-test for Equality of Means } \\
\hline & & \multirow[t]{2}{*}{$\mathrm{F}$} & \multirow[t]{2}{*}{ Sig. } & \multirow[t]{2}{*}{$t$} & \multirow[t]{2}{*}{ df } & \multirow[t]{2}{*}{$\begin{array}{l}\text { Sig. } \\
(2- \\
\text { tailed })\end{array}$} & \multirow[t]{2}{*}{$\begin{array}{c}\text { Mean } \\
\text { Differenc } \\
e\end{array}$} & \multirow[t]{2}{*}{$\begin{array}{c}\text { Std. Error } \\
\text { Differenc } \\
\text { e }\end{array}$} & \multicolumn{2}{|c|}{$\begin{array}{c}95 \% \\
\text { Confidence } \\
\text { Interval of the } \\
\text { Difference }\end{array}$} \\
\hline & & & & & & & & & Lower & Upper \\
\hline \multirow{2}{*}{$\begin{array}{l}\text { cadeias } \\
\text { presente } \\
\text { s }\end{array}$} & $\begin{array}{l}\text { Equal } \\
\text { variance } \\
\text { s } \\
\text { assumed }\end{array}$ & 90 & ,34 & 1,30 & 48 & 199, &, 52 & ,40 &,- 28 & 1,32 \\
\hline & $\begin{array}{l}\text { Equal } \\
\text { variance } \\
\text { s not } \\
\text { assumed }\end{array}$ & & & 1,31 & 47,77 & , 196 &, 52 & ,40 &,- 28 & 1,32 \\
\hline
\end{tabular}


ANEXO Q - ANÁLISE DE CORRELAÇÕES ENTRE OS TAMANHOS DOS LINFONODOS COM A IDADE, PESO E ALTURA E VALOR DE COALESCÊNCIA.

\begin{tabular}{|c|c|c|c|c|c|c|c|c|}
\hline & & área & $\begin{array}{l}\text { eixo } \\
\text { maior }\end{array}$ & $\begin{array}{c}\text { eixo } \\
\text { menor }\end{array}$ & idade & alt & peso & $\begin{array}{l}\text { Valor } \\
\text { coal. }\end{array}$ \\
\hline \multirow{3}{*}{ ÁREA } & $\begin{array}{l}\text { Pearson } \\
\text { Correlation }\end{array}$ & 1,000 &, $\left.9533^{(*}\right)$ &, $935\left(^{* \star}\right)$ &,- 050 & ,096 &,- 164 & , 150 \\
\hline & Sig. (2-tailed) & & ,000 & ,000 & ,732 & ,507 & ,254 & 300 \\
\hline & $\mathrm{N}$ & 50 & 50 & 50 & 50 & 50 & 50 & 50 \\
\hline \multirow{3}{*}{ eixo maior } & $\begin{array}{l}\text { Pearson } \\
\text { Correlation }\end{array}$ &, $\left.9533^{(* *}\right)$ & 1,000 &, $925\left(^{* *}\right)$ &,- 005 & ,016 &,- 204 & ,210 \\
\hline & Sig. (2-tailed) &, 000 & &, 000 & ,970 & (912 & ,156 &, 143 \\
\hline & $\mathrm{N}$ & 50 & 50 & 50 & 50 & 50 & 50 & 50 \\
\hline \multirow{3}{*}{$\begin{array}{l}\text { eixo } \\
\text { menor }\end{array}$} & $\begin{array}{l}\text { Pearson } \\
\text { Correlation }\end{array}$ &, $935\left(^{* \star}\right)$ &, $925\left(^{* *}\right)$ & 1,000 &,- 006 & ,076 &,- 195 & ,202 \\
\hline & Sig. (2-tailed) & , 000 & , 000 & & ,965 & ,602 & , 174 & , 159 \\
\hline & $\mathrm{N}$ & 50 & 50 & 50 & 50 & 50 & 50 & 50 \\
\hline \multirow{3}{*}{ IDADE } & $\begin{array}{l}\text { Pearson } \\
\text { Correlation }\end{array}$ &,- 050 &,- 005 &,- 006 & 1,000 &,$- 285\left(^{*}\right)$ &,$- 290\left(^{*}\right)$ &,- 059 \\
\hline & Sig. (2-tailed) & ,732 - - & 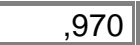 & ,965 - r & & , 045 & , 041 & 682 \\
\hline & $\mathrm{N}$ & 50 & 50 & 50 & 50 & 50 & 50 & 50 \\
\hline \multirow{3}{*}{ ALT } & $\begin{array}{l}\text { Pearson } \\
\text { Correlation }\end{array}$ & ,096 & ,016 & ,076 &,$- 285\left(^{*}\right)$ & 1,000 &, $471\left(^{* *}\right)$ & , 161 \\
\hline & Sig. (2-tailed) & ,507 & .912 & ,602 & ,045 & & , 001 & 263 \\
\hline & $\mathrm{N}$ & 50 & 50 & 50 & 50 & 50 & 50 & 50 \\
\hline \multirow{3}{*}{ PESO } & $\begin{array}{l}\text { Pearson } \\
\text { Correlation }\end{array}$ &,- 164 &,- 204 &,- 195 &,$- 290\left(^{*}\right)$ &, $471\left(^{* \star}\right)$ & 1,000 &,- 005 \\
\hline & Sig. (2-tailed) & ,254 & , 156 & , 174 & ,041 & , 001 & & ,970 \\
\hline & $\mathrm{N}$ & 50 & 50 & 50 & 50 & 50 & 50 & 50 \\
\hline \multirow{3}{*}{ porc_coal } & $\begin{array}{l}\text { Pearson } \\
\text { Correlation }\end{array}$ & , 150 & 210 & 202 &,- 059 & , 161 &,- 005 & 1,000 \\
\hline & Sig. (2-tailed) & 300 &, 143 &, 159 & ,682 & ,263 & ,970 & \\
\hline & $\mathrm{N}$ & 50 & 50 & 50 & 50 & 50 & 50 & 50 \\
\hline \multicolumn{9}{|c|}{${ }^{* *}$ Correlation is significant at the 0.01 level (2-tailed). } \\
\hline & $\mathrm{n}$ is significant a & & (2-tailed). & & & & & \\
\hline
\end{tabular}




\section{ANEXO R - ANÁLISE DE ASSOCIAÇÃO ENTRE A ÁREA DOS LINFONODOS COM O SEXO.}

\section{Group Statistics}

\begin{tabular}{|l|l||l|l||r|r|}
\hline \hline & SEXO & N & Mean & Std. Deviation & Std. Error Mean \\
\hline \hline \multirow{2}{*}{ ÁREA } & masc & 38 & 76,43 & 35,40 & 5,74 \\
\cline { 2 - 6 } & fem & 12 & 65,70 & 23,58 & 6,80 \\
\hline
\end{tabular}

\begin{tabular}{|c|c|c|c|c|c|c|c|c|c|c|}
\hline & \multicolumn{2}{|c|}{$\begin{array}{l}\text { Levene's } \\
\text { Test for } \\
\text { Equality of } \\
\text { Variances }\end{array}$} & \multicolumn{7}{|c|}{ t-test for Equality of Means } \\
\hline & & \multirow[t]{2}{*}{$\mathrm{F}$} & \multirow[t]{2}{*}{ Sig. } & \multirow[t]{2}{*}{$\mathrm{t}$} & \multirow[t]{2}{*}{$d f$} & \multirow{2}{*}{$\begin{array}{c}\text { Sig. } \\
(2- \\
\text { tailed } \\
\quad)\end{array}$} & \multirow{2}{*}{$\begin{array}{c}\text { Mean } \\
\text { Differenc } \\
e\end{array}$} & \multirow{2}{*}{$\begin{array}{l}\text { Std. Error } \\
\text { Differenc } \\
e\end{array}$} & \multicolumn{2}{|c|}{$\begin{array}{c}95 \% \\
\text { Confidence } \\
\text { Interval of the } \\
\text { Difference }\end{array}$} \\
\hline & & & & & & & & & $\begin{array}{c}\text { Lowe } \\
r\end{array}$ & $\begin{array}{c}\text { Uppe } \\
r\end{array}$ \\
\hline \multirow{2}{*}{$\begin{array}{l}\text { ÁRE } \\
A\end{array}$} & \begin{tabular}{|l} 
Equal \\
variance \\
s \\
assumed \\
\end{tabular} & 1,345 & 252, & ,980 & 48 & 332, & 10,73 & 10,95 & 11,28 & 32,75 \\
\hline & $\begin{array}{l}\text { Equal } \\
\text { variance } \\
\text { s not } \\
\text { assumed }\end{array}$ & & & 1,205 & $\begin{array}{r}28,01 \\
6\end{array}$ & ,238 & 10,73 & 8,90 & $-7,50$ & 28,97 \\
\hline
\end{tabular}




\section{ANEXO S - ANÁLISE DE ASSOCIAÇÃO ENTRE A ÁREA DOS LINFONODOS COM A RAÇA.}

\begin{tabular}{|c|c|c|c|c|c|}
\hline \multicolumn{6}{|c|}{ Group Statistics } \\
\hline & RAÇA & $\mathrm{N}$ & Mean & Std. Deviation & Std. Error Mean \\
\hline \multirow{2}{*}{ ÁREA } & branco & 39 & 74,12 & 34,07 & 5,45 \\
\hline & não branco & 11 & 72,93 & 30,69 & 9,25 \\
\hline
\end{tabular}

Independent Samples Test

\begin{tabular}{|c|c|c|c|c|c|c|c|c|c|c|}
\hline & $\begin{array}{l}\text { Levene's } \\
\text { Test for }\end{array}$ & \multicolumn{8}{|c|}{ t-test for Equality of Means } \\
\hline & & \multirow[t]{2}{*}{$\mathrm{F}$} & \multirow[t]{2}{*}{ Sig. } & \multirow[t]{2}{*}{$\mathrm{t}$} & \multirow[t]{2}{*}{$d f$} & \multirow[t]{2}{*}{$\begin{array}{l}\text { Sig. (2- } \\
\text { tailed) }\end{array}$} & \multirow[t]{2}{*}{$\begin{array}{c}\text { Mean } \\
\text { Difference }\end{array}$} & \multirow[t]{2}{*}{$\begin{array}{l}\text { Std. Error } \\
\text { Difference }\end{array}$} & \multicolumn{2}{|c|}{$\begin{array}{c}95 \% \\
\text { Confidence } \\
\text { Interval of the } \\
\text { Difference }\end{array}$} \\
\hline & & & & & & & & & Lower & Upper \\
\hline \multirow[b]{2}{*}{ ÁREA } & $\begin{array}{l}\text { Equal } \\
\text { variances } \\
\text { assumed }\end{array}$ & ,000 & 1,000 & 105 & 48 & ,917 & 1,19 & 11,40 & $-21,73$ & 24,11 \\
\hline & $\begin{array}{l}\text { Equal } \\
\text { variances } \\
\text { not } \\
\text { assumed }\end{array}$ & & & 111 & 17,597 & ,913 & 1,19 & 10,74 & $-21,41$ & 23,80 \\
\hline
\end{tabular}




\section{ANEXO T - ANÁLISE DE ASSOCIAÇÃO ENTRE A ÁREA DOS LINFONODOS COM A CONGESTÃO.}

\begin{tabular}{|l||l||l||r|r||r||}
\multicolumn{9}{c|}{ Group Statistics } \\
\hline \multirow{2}{*}{ Congestão } & N & Mean & Std. Deviation & Std. Error Mean \\
\hline \hline \multirow{2}{*}{ ÁREA } & presente & 26 & 69,56 & 37,99 & 7,45 \\
\cline { 2 - 6 } & ausente & 24 & 78,51 & 26,74 & 5,45 \\
\hline \hline
\end{tabular}

Independent Samples Test

\begin{tabular}{|c|c|c|c|c|c|c|c|c|c|c|}
\hline & \multicolumn{2}{|c|}{$\begin{array}{l}\text { Levene's } \\
\text { Test for } \\
\text { Equality of } \\
\text { Variances }\end{array}$} & \multicolumn{7}{|c|}{ t-test for Equality of Means } \\
\hline & & \multirow[t]{2}{*}{$\mathrm{F}$} & \multirow[t]{2}{*}{ Sig. } & \multirow[t]{2}{*}{$\mathrm{t}$} & \multirow[t]{2}{*}{$d f$} & \multirow[t]{2}{*}{$\begin{array}{c}\text { Sig. } \\
(2- \\
\text { tailed })\end{array}$} & \multirow[t]{2}{*}{$\begin{array}{c}\text { Mean } \\
\text { Difference }\end{array}$} & \multirow[t]{2}{*}{$\begin{array}{l}\text { Std. Error } \\
\text { Difference }\end{array}$} & \multicolumn{2}{|c|}{$\begin{array}{c}95 \% \\
\text { Confidence } \\
\text { Interval of the } \\
\text { Difference }\end{array}$} \\
\hline & & & & & & & & & Lower & Upper \\
\hline \multirow[b]{2}{*}{ ÁREA } & \begin{tabular}{|l} 
Equal \\
variances \\
assumed
\end{tabular} & 2,97 & ,091 &,- 95 & 48 & ,34 & $-8,95$ & 9,36 & $-27,78$ & 9,87 \\
\hline & $\begin{array}{l}\text { Equal } \\
\text { variances } \\
\text { not } \\
\text { assumed }\end{array}$ & & &,- 97 & 44,96 & ,33 & $-8,95$ & 9,23 & $-27,56$ & 9,65 \\
\hline
\end{tabular}


ANEXO U - ANÁLISE DE ASSOCIAÇÃO ENTRE A ÁREA DOS LINFONODOS COM A PRESENÇA DE GRANULOMA.

\begin{tabular}{l}
\multicolumn{9}{c|}{ Group Statistics } \\
\begin{tabular}{|l|l|r||l||r||r||}
\hline \hline & granuloma & N & Mean & Std. Deviation & Std. Error Mean \\
\hline \hline \multirow{2}{*}{ ÁREA } & presente & 8 & 77,80 & 30,65 & 10,83 \\
\cline { 2 - 6 } & ausente & 42 & 73,11 & 33,79 & 5,21 \\
\hline \hline
\end{tabular}
\end{tabular}

\begin{tabular}{|c|c|c|c|c|c|c|c|c|c|c|}
\hline & \multicolumn{2}{|c|}{$\begin{array}{l}\text { Levene's } \\
\text { Test for } \\
\text { Equality } \\
\text { of } \\
\text { Variance } \\
\text { s }\end{array}$} & & \multicolumn{6}{|c|}{ t-test for Equality of Means } \\
\hline & & \multirow[t]{2}{*}{$\mathrm{F}$} & \multirow[t]{2}{*}{ Sig } & \multirow[t]{2}{*}{$\mathrm{t}$} & \multirow[t]{2}{*}{ df } & \multirow[t]{2}{*}{$\begin{array}{l}\text { Sig. } \\
(2- \\
\text { taile } \\
\text { d) }\end{array}$} & \multirow[t]{2}{*}{$\begin{array}{c}\text { Mean } \\
\text { Differen } \\
\text { ce }\end{array}$} & \multirow[t]{2}{*}{$\begin{array}{l}\text { Std. } \\
\text { Error } \\
\text { Differen } \\
\text { ce }\end{array}$} & \multicolumn{2}{|c|}{\begin{tabular}{|c}
$95 \%$ \\
Confidence \\
Interval of \\
the \\
Difference \\
\end{tabular}} \\
\hline & & & & & & & & & $\begin{array}{c}\text { Low } \\
\text { er }\end{array}$ & $\begin{array}{c}\text { Upp } \\
\text { er }\end{array}$ \\
\hline \multirow{2}{*}{$\begin{array}{l}\text { ÁRE } \\
\text { A }\end{array}$} & $\begin{array}{l}\text { Equal } \\
\text { varianc } \\
\text { es } \\
\text { assume } \\
\text { d }\end{array}$ & $\begin{array}{r}86 \\
1\end{array}$ & $\begin{array}{r}35 \\
8\end{array}$ & $\begin{array}{r}\text {,36 } \\
5\end{array}$ & 48 & ,717 & 4,69 & 12,86 & $\mid \begin{array}{r}21,1 \\
7\end{array}$ & $\begin{array}{r}30,5 \\
6\end{array}$ \\
\hline & $\begin{array}{l}\text { Equal } \\
\text { varianc } \\
\text { es not } \\
\text { assume } \\
\text { d }\end{array}$ & & & $\begin{array}{r}39 \\
1\end{array}$ & $\begin{array}{r}10,51 \\
9\end{array}$ & 704 & 4,69 & 12,02 & $\begin{array}{r}21,9 \\
2\end{array}$ & $\begin{array}{r}31,3 \\
2\end{array}$ \\
\hline
\end{tabular}




\section{ANEXO V - ANÁLISE DE ASSOCIAÇÃO ENTRE A IDADE, PESO E ALTURA COM A PRESENÇA DE GRANULOMA.}

\begin{tabular}{||l|l||r||r|r|r||}
\hline \hline & granuloma & $\mathrm{N}$ & Mean & Std. Deviation & Std. Error Mean \\
\hline \hline \multirow{2}{*}{ idade } & presente & 8 & 64,00 & 17,15 & 6,06 \\
\cline { 2 - 6 } & ausente & 42 & 59,07 & 13,51 & 2,09 \\
\hline \hline \multirow{2}{*}{ peso } & presente & 8 & 67,50 & 7,21 & 2,55 \\
\cline { 2 - 6 } & ausente & 42 & 71,62 & 12,65 & 1,95 \\
\hline \hline \multirow{2}{*}{ alt } & presente & 8 & 171,75 & 7,80 & 2,76 \\
\cline { 2 - 6 } & ausente & 42 & 173,36 & 7,60 & 1,17 \\
\hline \hline
\end{tabular}

\begin{tabular}{|c|c|c|c|c|c|c|c|c|c|c|}
\hline & \multicolumn{2}{|c|}{$\begin{array}{l}\text { Levene's Test } \\
\text { for Equality of } \\
\text { Variances }\end{array}$} & \multicolumn{7}{|c|}{ t-test for Equality of Means } \\
\hline & & \multirow[t]{2}{*}{$\mathrm{F}$} & \multirow[t]{2}{*}{ Sig. } & \multirow[t]{2}{*}{$\mathrm{t}$} & \multirow[t]{2}{*}{ df } & \multirow{2}{*}{$\begin{array}{l}\text { Sig. } \\
(2- \\
\text { tailed })\end{array}$} & \multirow[t]{2}{*}{$\begin{array}{c}\text { Mean } \\
\text { Difference }\end{array}$} & \multirow[t]{2}{*}{$\begin{array}{l}\text { Std. Error } \\
\text { Difference }\end{array}$} & \multicolumn{2}{|c|}{$\begin{array}{l}95 \% \text { Confidence } \\
\text { Interval of the } \\
\text { Difference }\end{array}$} \\
\hline & & & & & & & & & Lower & Upper \\
\hline \multirow[b]{2}{*}{ IDADE } & \begin{tabular}{|l} 
Equal \\
variances \\
assumed
\end{tabular} & 1,364 & ,249 & ,906 & 48 & ,369 & 4,93 & 5,44 & $-6,01$ & 15,87 \\
\hline & \begin{tabular}{|l} 
Equal \\
variances \\
not \\
assumed \\
\end{tabular} & & & ,769 & 8,733 & ,462 & 4,93 & 6,41 & $-9,64$ & 19,50 \\
\hline \multirow[b]{2}{*}{ PESO } & $\begin{array}{l}\text { Equal } \\
\text { variances } \\
\text { assumed }\end{array}$ & ,726 & ,398 &,- 889 & 48 & ,379 & $-4,12$ & 4,64 & $-13,44$ & 5,20 \\
\hline & $\begin{array}{l}\text { Equal } \\
\text { variances } \\
\text { not } \\
\text { assumed }\end{array}$ & & & 1,283 & 16,643 & ,217 & $-4,12$ & 3,21 & $-10,91$ & 2,67 \\
\hline \multirow[b]{2}{*}{ ALT } & \begin{tabular}{|l} 
Equal \\
variances \\
assumed
\end{tabular} & ,006 & ,939 &,- 546 & 48 & ,588 & $-1,61$ & 2,94 & $-7,53$ & 4,31 \\
\hline & $\begin{array}{l}\text { Equal } \\
\text { variances } \\
\text { not } \\
\text { assumed }\end{array}$ & & &,- 536 & 9,711 & ,604 & $-1,61$ & 3,00 & $-8,31$ & 5,09 \\
\hline
\end{tabular}




\section{ANEXO W - ANÁLISE DE ASSOCIAÇÃO ENTRE O NÚMERO DE LINFONODOS, ÁREA, EIXOS MAIOR E MENOR COM A PRESENÇA DE GRANULOMA.}

\begin{tabular}{|c|c|c|c|c|c|c|c|c|c|c|}
\hline & \multicolumn{2}{|c|}{$\begin{array}{l}\text { Levene's } \\
\text { Test for } \\
\text { Equality of } \\
\text { Variances }\end{array}$} & \multicolumn{7}{|c|}{ t-test for Equality of Means } \\
\hline & & \multirow[t]{2}{*}{$\mathrm{F}$} & \multirow[t]{2}{*}{ Sig. } & \multirow[t]{2}{*}{$\mathrm{t}$} & \multirow[t]{2}{*}{$d f$} & \multirow[t]{2}{*}{$\begin{array}{l}\text { Sig. } \\
(2- \\
\text { tailed })\end{array}$} & \multirow[t]{2}{*}{$\begin{array}{c}\text { Mean } \\
\text { Difference }\end{array}$} & \multirow[t]{2}{*}{$\begin{array}{l}\text { Std. Error } \\
\text { Difference }\end{array}$} & \multicolumn{2}{|c|}{$\begin{array}{c}95 \% \\
\text { Confidence } \\
\text { Interval of the } \\
\text { Difference } \\
\end{array}$} \\
\hline & & & & & & & & & Lower & Upper \\
\hline \multirow[b]{2}{*}{ N_LINF } & $\begin{array}{l}\text { Equal } \\
\text { variances } \\
\text { assumed }\end{array}$ & ,000 & ,998 & $1,46^{-}$ & 48 & ,150 & $-6,80$ & 4,66 & $-16,16$ & 2,56 \\
\hline & $\begin{array}{l}\text { Equal } \\
\text { variances } \\
\text { not } \\
\text { assumed }\end{array}$ & & & $1,43^{-}$ & 9,68 & ,184 & $-6,80$ & 4,75 & $-17,44$ & 3,83 \\
\hline \multirow[b]{2}{*}{ ÁREA } & $\begin{array}{l}\text { Equal } \\
\text { variances } \\
\text { assumed }\end{array}$ & ,861 & ,358 & ,365 & 48 & ,717 & 4,69 & 12,86 & $-21,17$ & 30,56 \\
\hline & $\begin{array}{l}\text { Equal } \\
\text { variances } \\
\text { not } \\
\text { assumed }\end{array}$ & & & ,391 & 10,51 & ,704 & 4,69 & 12,02 & $-21,92$ & 31,32 \\
\hline \multirow[b]{2}{*}{$\begin{array}{l}\text { eixo } \\
\text { maior }\end{array}$} & $\begin{array}{l}\text { Equal } \\
\text { variances } \\
\text { assumed }\end{array}$ & 1,074 & ,305 & ,841 & 48 & ,404 & ,84 & 1,00 & $-1,17$ & 2,87 \\
\hline & $\begin{array}{l}\text { Equal } \\
\text { variances } \\
\text { not } \\
\text { assumed }\end{array}$ & & & ,90 & 10,61 & ,384 & ,84 & ,93 & $-1,21$ & 2,91 \\
\hline \multirow{2}{*}{$\begin{array}{l}\text { eixo } \\
\text { menor }\end{array}$} & $\begin{array}{l}\text { Equal } \\
\text { variances } \\
\text { assumed }\end{array}$ &, 513 & ,477 & 1,16 & 48 & ,251 & ,65 &, 56 &,- 47 & 1,79 \\
\hline & $\begin{array}{l}\text { Equal } \\
\text { variances } \\
\text { not } \\
\text { assumed }\end{array}$ & & & 1,16 & 9,88 & ,271 & ,65 &, 56 &,- 60 & 1,91 \\
\hline
\end{tabular}


ANEXO X - TAMANHO PADRÃO MÁXIMO DO EIXO MENOR DOS LINFONODOS MEDIASTINAIS POR CADEIA.
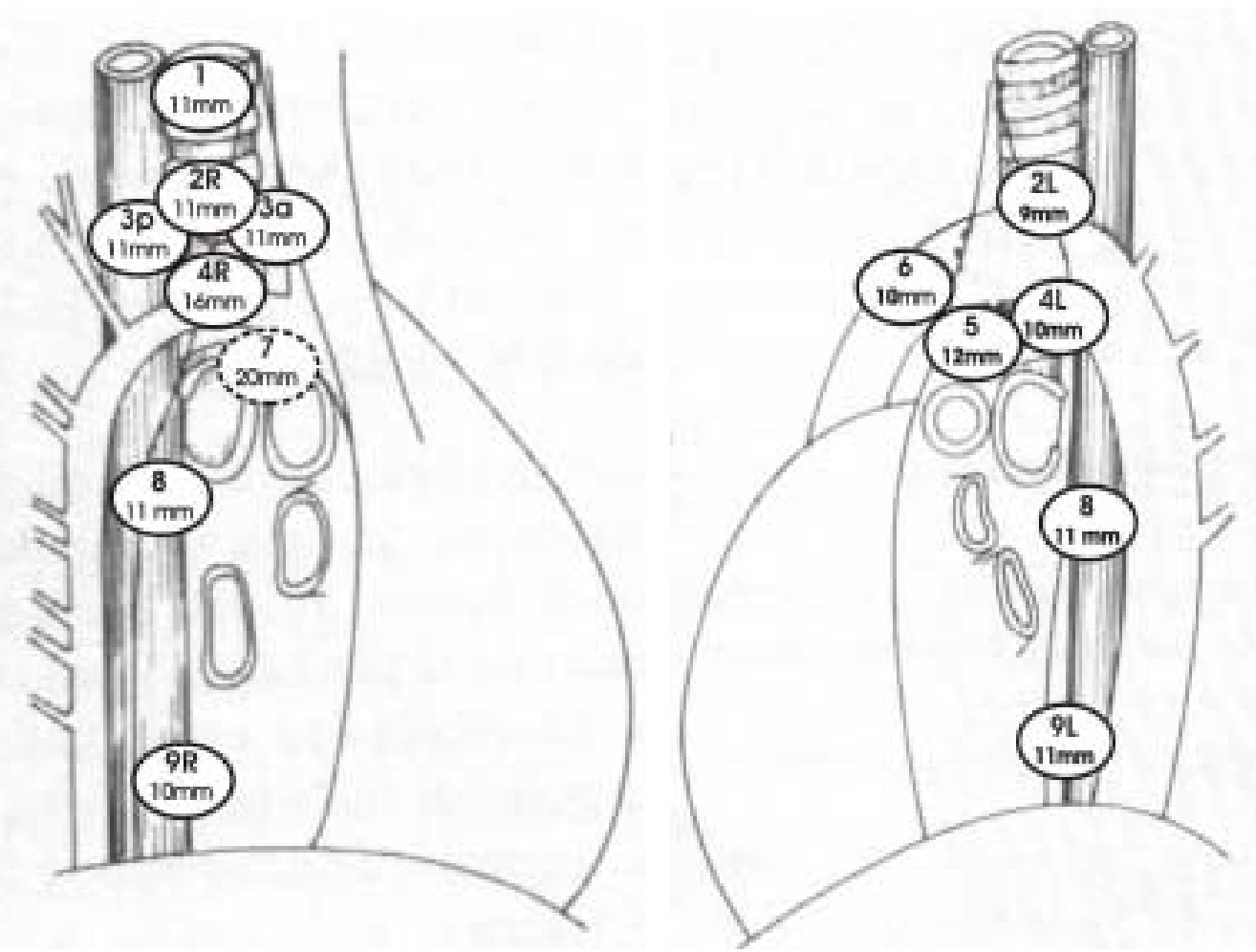
9. REFERÊNCIAS BIBLIOGRÁFICAS 


\section{Referências bibliográficas}

AMERICAN THORACIC SOCIETY — Clinical staging of primary lung cancer: ATS mapping scheme. Am. Ver. Resp. Dis., 127:659-69, 1983.

ARITA, T.; MATSUMOTO, T.; KURAMITSU, T.; KAWAMURA, M.; MATSUNAGA, N.; SUGI, K.; ESATO, K. - Is it possible to differentiate malignant mediastinal nodes from benign nodes by size? Chest, 110:1004-8, 1996.

CAPLAN, I. - Anatomical review of the lymph nodes of the human mediastinum. Surg. Radiol. Anat., 12:9-18, 1990.

CONSELHO NACIONAL DE SAÚDE - Resolução nº 01/88: normas de pesquisa em saúde. Bioética, 3:137-54, 1995.

ERLY, W.K.; BORDERS, R.J.; OUTWATER, E.K.; ZAETTA, J.M.; BORDERS, G.T. - Location, size and distribution of mediastinum lymph nodes enlargement in chronic congestive heart failure. $J$. Comput Assist. Tomogr., 27:485-9, 2003.

FERNANDEZ, A. - Análise comparativa entre a tomografia axial computadorizada e a mediastinoscopia no estadiamento linfático do câncer do pulmão. São Paulo, 1992. 110p. [Tese (Doutorado) Faculdade de Medicina da Universidade de São Paulo]

GENEREUX, G.P. \& HOWIE, J.L. — Normal mediastinal lymph node size and number: CT and anatomic study. A.J.R., 142:1095-100, 1984. 
GLAZER, G.M.; GROSS, B.H.; QUINT, L.E.; FRANCIS, I.R.; BOOKSTEINS, F.L.; ORRINGER, M.B. - Normal mediastinal lymph nodes: normal size according to American Thoracic Society mapping. A.J.R., 144:261-65, 1985.

GUPTA, N.C.; GRAEBER, G.M.; BISHOP, H.A. - Comparative efficacy of positron emission tomography in evaluation of small $(<1 \mathrm{~cm})$, intermediate $(1$ to $3 \mathrm{~cm})$ and large $(>3 \mathrm{~cm})$ lymph node lesions. Chest, 117:773-8, 2000.

HOKSCH, B.; ABLASSMAIER, B.; WALTER, M.; MUELLER, J.M. - The thoracoscopic lymphadenectomy: experiences in a cadaver model. Cardiovasc. Eng., 5.91, 2000.

KIYONO, K.; SONE, S.; SAKAI, F.; IMAI, Y.; WATANABE, T.; IZUNO, I., OGUCHI, M.; KAWAI,T.; SHIGEMATSU, H.; WATANABE, M. — The number and size of normal mediastinal lymph nodes: a postmortem study. A.J.R., 150:771-76, 1988.

LIEN, H.H.; LUND, G. - Computed tomography of mediastinal lymph nodes: anatomic review base on contrast enhanced nodes following foot lymphography. Acta Radiol., 26:641-7, 1985.

McLOUD, T.; BOURGOUIN, P.M.; GEENBERG, R.W.; KOSIUK, J.P.; TEMPLETON, P.A.; SHEPARD, J.O.; MOORE, E.H.; WAIN,J.C.; MATHISEN, D.J.; GRILLO, H.C. - Bronchogenic carcinoma: analysis of staging in the mediastinum with CT by correlative lymph node mapping and sampling. Radiology, 182:319-23, 1992. 
MOUNTAIN, C.F \& DRESLER, C.M. - Regional lymph node classification for lung cancer staging. Chest, 111:1718-23, 1997.

MURAKAMI, G.; SATO, T.; TAKIGUCHI, T. - Topographical anatomy of the bronchomediastinal lymph vessels: their relantionships and formation of the collecting trunks. Arch. Hist. Cytol., 53:219-35, 1990.

MURRAY, J.G.; O'DRISCOLL, M.; CURTIN, J.J. - Mediastinal lymph node size in an Asian population. Br. J. Radiol., 68:348-50, 1995.

NARUKE, T. \& SUEMASU, K. - Surgical treatment for lung cancer with metastasis to mediastinal lymph nodes. J. Thorac. Cardiovasc. Surg., 71:279, 1976.

NARUKE, T.; SUEMASU, K.; ISHIKAWA, S. - Lymph node mapping and curability at various levels of metastasis in resected lung cancer. J. Thorac. Cardiovasc. Surg., 76:832-9, 1978.

NARUKE, T. - Mediastinal lymph node dissection. In: PEARSON, F.G. Thoracic Surgery. 1.ed. New York, Churchill Livingstone, 1993. p.909-17.

NARUKE, T.; TSUCHIYA, R.; KONDO, H.; NAKAYAMA, H.; ASAMURA, H. - Lymph node sampling in lung cancer: how should it be done? Eur. J. Cardiothorac. Surg., 16s:s17-24, 1999.

NOHL, H.C. - An investigation into the lymphatic and vascular spread of carcinoma of the bronchus. Thorax, 11:172-85, 1956.

NOMORI, H.; HIROTOSHI, H.; NARUKE, T.; SUEMASU, K. - What is the advantage of a thoracoscopic lobectomy over a limited thoracotomy 
procedure for lung cancer surgery? Ann. Thorac. Surg., 72:879-84, 2001.

PEREIRA, J.C.N.; Silva, A.G.P.; SOARES, F.; AB'SABER, A.M.; SCHMIDT, A.F.; RODRIGUES, O.R.; GARIPO, A.; CAPELOZZI,M.; CAMPOS, J.R.M.; TAKAGAKI,T.; JATENE, F.B.; MARTINS,S.; CAPELOZZI, V.L. - Nuclear and enviroment morphometric profile in tumor size and nodal metastasis of resected typical pulmonary carcinoid. Pathol. Res. Pract., 200:459-67, 2004.

PRENZEL, K.L.; MÖNIG, S.P.; SINNING, J.M.; BALDUS, S.E.; BROCHHAGEN, H.G.; SCHNEIDER, P.M.; HÖLSCHER, A.H. Lymph node size and metastatic infiltration in non-small cell lung cancer. Chest, 123:463-7, 2003.

RIQUET, M.; HIDDEN, G.; DEBESSE, B. - Lymphonoeuds intertracheobronchiques: afférences et efferences étudiées à partir des segments pulmonaires de 200 sujets adultes. Bull. Ass. Anat., 70:43-8, 1986.

RIQUET, M.; HIDDEN, G.; DEBESSE, B. — Direct lymphatic drainage of lung segments to the mediastinal nodes. J. Thorac. Cardiovasc. Surg., 97:623-32, 1989.

RIQUET, M.; MANAC, D.; DUPONT, P.; DUJON, A.; HIDDEN, G.; DEBESSE, B. - Anatomic basis of lymphatic spread of lung carcinoma to the mediastinum: anatomo-clinical correlations. Sur. Radiol. Anat., 16:229-38, 1994. 
RODRIGUES, O.R.; ANTONANGELO, L.; YAGI, N.; MINAMOTO, H.; SCHMIDT JUNIOR, A.F.; CAPELOZZI, V.L.; GOLDENBERG, S.; SALDIVA, P.H. - Prognostic significance of argyrophilic nucleolar organizer region (AgNOR) in resected non-small cell lung cancer (NSCLC). Jpn. J. Clin. Oncol., 27:298-304, 1997.

RODRIGUES GRANDE, N.; RIBEIRO, J.; SOARES, M.; CARVALHO, E. The lymphatic vessels of the lung: morphological study. Acta Anat., 115:302-9, 1983.

ROSNER, B. - Fundamentals of biostatistics. Boston, PWS Publishers, 2nd ed., 1986. 584p.

ROUVIÈRE, H. - Les vaisseaus lymphatiques des poumons et les ganglions viscéraux intra thoraciques. Ann. Anat. Pathol., 6:113-58, 1929.

TRAPNELL, D.H. - The peripheral lymphatics of the lung. Br. J. Radiol., 36.660-72, 1963. 